Andrews University

Digital Commons @ Andrews University

2014

\title{
A Conflict Resolution Program for the New Life, Warner Robins, Georgia, Seventh-day Adventist Church
}

Everton Alphonso Ennis

Andrews University

Follow this and additional works at: https://digitalcommons.andrews.edu/dmin

Part of the Practical Theology Commons

\section{Recommended Citation}

Ennis, Everton Alphonso, "A Conflict Resolution Program for the New Life, Warner Robins, Georgia,

Seventh-day Adventist Church" (2014). Professional Dissertations DMin. 471.

https://dx.doi.org/10.32597/dmin/471

https://digitalcommons.andrews.edu/dmin/471

This Project Report is brought to you for free and open access by the Graduate Research at Digital Commons @ Andrews University. It has been accepted for inclusion in Professional Dissertations DMin by an authorized administrator of Digital Commons @ Andrews University. For more information, please contact repository@andrews.edu. 


\begin{abstract}
A CONFLICT RESOLUTION PROGRAM FOR THE NEW LIFE, WARNER ROBINS, GEORGIA, SEVENTH-DAY ADVENTIST CHURCH
\end{abstract}

by

Everton Alphonso Ennis

Adviser: James J. North Jr. 


\title{
ABSTRACT OF GRADUATE STUDENT RESEARCH
}

\author{
Project Document
}

Andrews University

Seventh-day Adventist Theological Seminary

\section{Title: A CONFLICT RESOLUTION PROGRAM FOR THE NEW LIFE, WARNER ROBINS, GEORGIA, SEVENTH-DAY ADVENTIST CHURCH}

Name of researcher: Everton Alphonso Ennis

Name and degree of faculty adviser: James J. North Jr., DMin

Date completed: March 2014

\section{Problem}

In December 2008, the membership of the New Life Seventh-day Adventist Church in Warner Robins, Georgia, was listed at 120. In actuality, however, there was only about one half of that number of members and guests attending on a regular basis. Over the next two years the church experienced a further decline in membership attendance. As of December 31,2010, the voted membership stood at 58. Two key identifiable factors were responsible for the reduced membership. First, a necessary membership audit was undertaken. Second, there were additional losses due to damaging congregational conflict. A history of disunity, an offensive culture of irreverence, seven pastors in twenty-three years, and a general lack of regard for the purpose of the church did little to make most people want to stay. It was time to transition this church. 


\section{Method}

A congregational conflict resolution training program consisting of the creation and presentation of a series of seminars and sermons was conducted over the course of four months. After each presentation, a focus group was utilized to discuss the material presented, gather feedback, and serve as an evaluation mechanism to measure the impact upon the thinking of the congregation. Five seminars and sermons on congregational conflict resolution were presented. Topics dealt with the dangers of judging, conflict resolution at work and at home, and the dynamics of congregational conflict. Seminar participants were provided with handouts. Only church members and Sabbath School members, eighteen years of age and older, were invited to be part of the focus groups.

\section{Results}

Change is a slow and tedious process. This conflict resolution training program is about changing a mindset. The main objectives of the seminar series were accomplished: (1) expose the membership to the factors that cause conflict, (2) teach the membership how to avoid preventable conflict, (3) teach the church how to correctly conclude conflict, (4) cultivate a new culture of love and mutual accountability as it pertains to congregational relationships, and (5) create a more harmonious relational context in which community outreach and church membership growth could occur. The focus group research method indicated strong acceptance of the conflict resolution principles among the membership. Those members who participated in the seminars overwhelmingly embraced the instruction presented in the training program and became the nucleus of the renewed church experience. New Life has been transformed from a constantly conflicted, discordant congregation to a much more peaceful, community-focused congregation in 
just under two years since the training program was first implemented. The new emphasis on mutual accountability and making the church a safe place where people can have a positive encounter with God, has greatly assisted in ushering in a new era of peace and harmony at New Life. The congregation is now visibly and consistently involved in the community, offering various outreach ministries such as Bible studies, youth activities, a revamped and highly successful men's fellowship, and life enrichment seminars that speak to the needs of the community. Several new people have started attending on a consistent basis. Several former members have since returned to the church, and have commented on the positive developments in the light atmosphere of the congregational fellowship instead of tension, and the uplifting ambiance of the worship services. The recently voted mission statement expresses the new paradigm: "Our mission is to demonstrate God's love to all, be a blessing to our community, and invite people to walk in newness of life in Christ Jesus."

\section{Conclusions}

This study demonstrates that a dysfunctional church can be transformed, given the proper handling of old and new conflicts. Change is possible. Plateaued or declining churches can live again. The impact of skillful pastoral intervention and congregational education has been shown through this study to hold major implications for the state of the church-at-large. One of the primary outcomes of this research process is the realization that in the Seventh-day Adventist church, there is a serious problem regarding inadequate emphasis on practical training in the area of conflict ministry. This study reveals an important need to better equip pastors and educate congregations in art of congregational conflict resolution training and practice. 
Andrews University

Seventh-day Adventist Theological Seminary

\title{
A CONFLICT RESOLUTION PROGRAM FOR THE NEW LIFE, WARNER ROBINS, GEORGIA, SEVENTH-DAY ADVENTIST CHURCH
}

\author{
A Project Document \\ Presented in Partial Fulfillment \\ of the Requirements for the Degree \\ Doctor of Ministry
}

by

Everton Alphonso Ennis

March 2014 
(C) Copyright by Everton A. Ennis 2014 All Rights Reserved 
A CONFLICT RESOLUTION PROGRAM FOR THE NEW LIFE, WARNER ROBINS, GEORGIA, SEVENTH-DAY ADVENTIST CHURCH

A project document presented in partial fulfillment of the requirements for the degree Doctor of Ministry

by

Evertor A. Ennis

APPROVAL BY THE COMMITTEE:

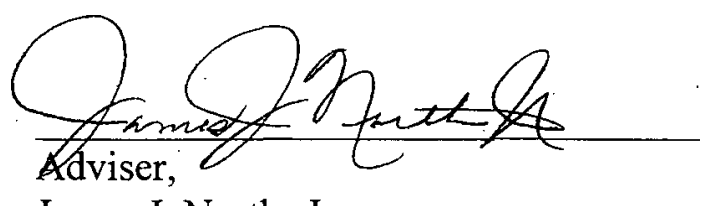

James J. North, Jr.

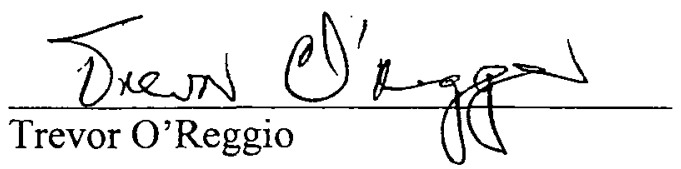

BARON

Boubakar Sanou

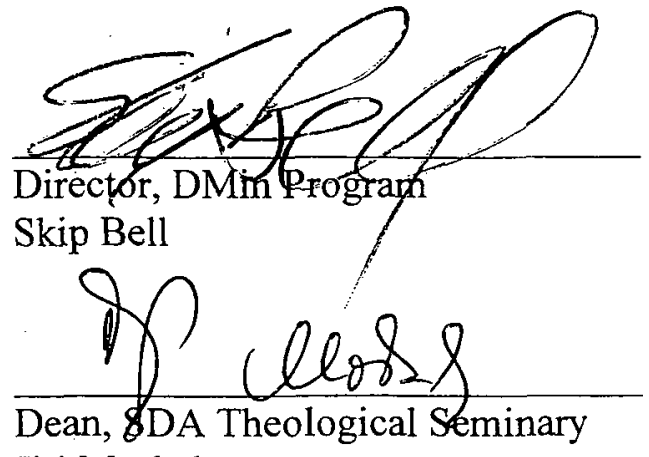

Jeri Moskala

March 31.2014

Date approved 
Dedicated to the Special Women in My Life

First, to my wife Ingrid M. Ennis, who prayed fervently and encouraged me daily throughout this long and difficult journey. She suffered much alongside me through the harsh realities of "the work" and through the many setbacks that assailed me during this obstacle-filled, but rewarding journey. Second, to my mother Delores Beswick-Ennis, who taught me at an early age and encouraged me throughout my entire adult life up until the realization of this dream to never stop learning or reaching for my goals. She instilled a thirst for learning in me that has blessed my life. Then to my "twin" sister Colleen A. Ennis, who I have known almost my entire life, and to whom I am forever grateful for her loving support in getting into college to earn my first degree, making this milestone possible in the end. Lastly, but not least, to the virtuous woman of Scripture, God's remnant Church, without which I would not have become the person I am today, and for which I tirelessly labor in love to always seek her good. 


\section{TABLE OF CONTENTS}

ACKNOWLEDGMENTS ........................................................................ vii

\section{Chapter}

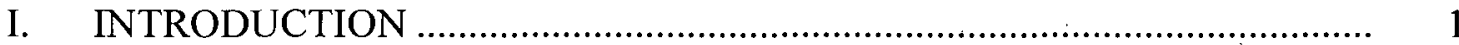

Statement of the Problem ............................................................... 1

Statement of the Task ................................................................. 2

Justification for the Project................................................................. 2

Expectations of the Project................................................................... 3

Definition of Terms ...................................................................... 4

Limitations of the Project ................................................................. 4

Methodology .................................................................................. 5

Outline of the Project ................................................................ 6

II. TOWARD A THEOLOGY OF CONGREGATIONAL CONFLICT AND CHRISTIAN CONFLICT RESOLUTION............................................ 8

Introduction ............................................................................... 8

The Great Controversy Motif in Understanding Conflict...................... 9

Biblical Parallels to Causes of Modern Congregational Conflict............ 13

Rebellion and Opposition to Leadership..................................... 14

Leadership Problems as the Cause of Church Conflict .................... 18

The Problem of Personal Greatness and Pre-eminence .................. 21

Cultural Differences as a Factor in Congregational Conflict............. 22

Theological Disputes as the Catalyst for Conflict ........................... 26

Disregard for Protocol Causes Conflict ....................................... 29

Mishandling of Disagreements and Misunderstandings .................. 32

The Appeal of Jesus for Oneness in Congregational Relationships ........ 35

Conclusion .................................................................................... 36

III. LITERATURE RELATING TO CONFLICT RESOLUTION ....................... 37

Introduction ........................................................................ 37

Characterizations of Conflict ....................................................... 38

Causes of Conflict..................................................................... 41 
Common Christian Conceptions of Conflict.............................................. 48

Consequences of Catastrophic Congregational Conflict ......................... $\quad 50$

Capitalizing on Constructive Changes Created by Conflict ...................... 57

Correctly Concluding Conflict................................................................ 58

Conclusion .................................................................................... 61

IV. IMPLEMENTING THE CLASS ACT SEMNAR SERIES-A PROGRAM FOR CONGREGATIONAL CONFLICT RESOLUTION TRAINING.......... 62

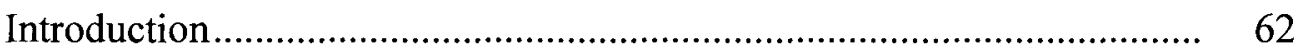

Congregational Conflict Resolution at New Life ............................ 62

Conference Approval .................................................................... 64

Church Board Approval .............................................................. 65

A Comprehensive, Multi-faceted Approach to Conflict Training ............ $\quad 65$

Personal Interviews with Parties to Conflict..................................... 66

Modeling the Principles of Biblical Conflict Resolution.................. 68

Sermon and Seminar Series on Conflict Resolution........................ 69

Utilization of the Focus Group Method of Feedback ...................... $\quad 70$

The CLASS Act Conflict Resolution Seminar Series............................... 73

Conclusion ................................................................................... 73

V. RESEARCH METHODOLOGY, RESULTS AND RECOMMENDATIONS 75

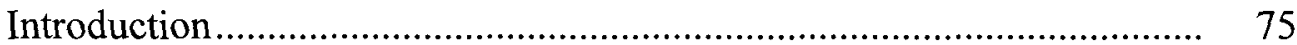

Research Methodology ...................................................................... $\quad 76$

A Qualitative Analysis of the Conflict Resolution Training Program...... $\quad 78$

Analysis of Seminar One ............................................................ $\quad 79$

Analysis of Seminar Two............................................................ 81

Analysis of Seminar Three........................................................... 84

Analysis of Seminar Four .......................................................... $\quad 87$

Analysis of Seminar Five ............................................................... 90

Moderator Evaluation of the Focus Group Research Method .......... 91

Outcomes of the Conflict Resolution Training Program .......................... 93

My Personal Growth in Conflict Resolution Theory and Practice ... 93

My Transformation as a Ministry Professional .............................. 93

Sundry Membership Reactions to the Training Program ................ 96

A Transformed Congregation Emerges Out of Chaos...................... 98

Summary ............................................................................... 100

Conclusions ................................................................................. 100

Recommendations ................................................................................ 101

Appendix

A. CLASS ACT CONFLICT RESOLUTION SEMINAR SERIES .............. 105

Sermon: The Dangers of a Judgmental Spirit ......................................... 106

Seminar One: Resolving Family Conflict............................................... 113

Seminar Two: Navigating the Obstacle Course of Workplace Conflict... 117 
Seminar Three: Welcome the Sabbath............................................ 122

Seminar Four: By This Shall All Men Know ..................................... 128

Seminar Five: Healing the Wounds .............................................. 135

B. SURVEY APPROVAL AND PROMORIONAL DOCUMENTS .......... 140

Church Board Approval Letter ......................................................... 141

Focus Group Interview Protocol .................................................... 142

Doctor of Ministry Committee - Project Approval Letter ..................... 143

IRB Approval Letter ................................................................ 144

Focus Group Volunteer Request - Bulletin Insert.............................. 145

Focus Group Volunteer Request - Poster.......................................... 146

Informed Consent Form ............................................................... 147

CLASS Act Conflict Resolution Seminar Schedule ............................. 149

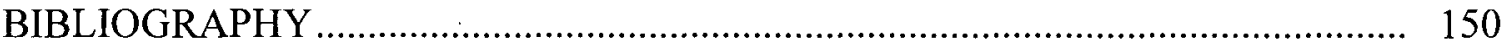

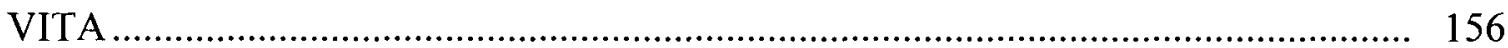




\section{ACKNOWLEDGMENTS}

I am deeply grateful to James J. North Jr., my adviser, friend, encourager-in-chief, and mentor for his diligence in helping me bear up under the burden of this project dissertation, while combating the several bouts of illness my dear wife underwent all throughout the academic process. His prayers and timely words of affirmation must be recorded somewhere in the book of remembrance.

Special thanks to my friend and mentor, my pastor, Lawrence Hamilton, DMin, General Vice-President of South Atlantic Conference of Seventh-day Adventists, and who became my ministerial director when I first began this journey. Were it not for his incessant encouragement to complete this journey as I was beset with obstacle after obstacle, the outcome could have been otherwise.

Thanks to all my colleagues who supported me throughout this endeavor, and especially to those who allowed me to present seminars and workshops on congregational conflict resolution training in their churches. Their confidence in me has been instrumental in helping me develop as a competent conflict resolution consultant.

Finally, special thanks to my New Life church family for being so courageous in allowing me to perfect my craft as a conflict minister in our "laboratory," where we were blessed to witness the mighty move of God in the transformation of the congregation. I am forever indebted to those who served as participants in the various focus groups. 


\section{CHAPTER I}

\section{INTRODUCTION}

\section{Statement of the Problem}

In December 2008 when I was installed as pastor, the membership of the New Life Seventh-day Adventist Church in Warner Robins, Georgia, was listed at $120 .^{1}$ In actuality, however, there was only about one half of that number of members and guests attending on a regular basis. Over the next two years the church experienced a further decline in membership. As at December 31,2010 , the voted membership stood at $58 .^{2}$ Several factors were responsible for the reduced membership. First, there was a necessary membership audit which was undertaken under my leadership. Next, there were some losses due to long-standing unresolved congregational conflicts. One of the first indicators of conflict when I arrived was the fact that even though they had done the church elections two months before I was installed as pastor, and though there were four serving elders, there was no head elder. There was obvious tension among the elder staff.

'South Atlantic Conference of Seventh-day Adventists, 2007-2008 Membership Directory: Warner Robins, Georgia, New Life Seventh-day Adventist Church (Atlanta, GA: South Atlantic Conference of Seventh-day Adventists, 2007), 105.

\footnotetext{
${ }^{2}$ The newly voted membership of 58 was not an indication of actual members who attended at the time of the membership audit. This number represents those who could be accounted for in regular attendance, as well as those who had moved away to other churches but had not transferred their membership. The number also included a few non-attending individuals who were known to not attend any particular church, but a majority in the congregation tended to feel they could be encouraged to return.
} 


\section{Statement of the Task}

The task of this project was to develop a congregational conflict resolution program for implementation in the Warner Robins, Georgia, New Life Seventh-day Adventist Church, in an effort to foster a deeper congregational understanding and appreciation of the biblical pretocols for resolving conflict, the goal being to inspire healthy behavioral change in how conflict is handled. The program was implemented during special training sessions, followed by evaluation and feedback by focus groups.

\section{Justification for the Project}

Improper handling of interpersonal'and congregational conflict can be a major factor in stunted church growth, and therefore deserves the full attention of Christian leaders and congregations.

Like many churches, the Warner Robins New Life Seventh-day Adventist Church has experienced episodes of disruptive congregational conflict over the span of its existence. For example, during an interview with Pastor Dante Tobias, the first pastor assigned to New Life after its launch as a new congregation in 1985, I discovered some unsettling information. Tobias stated that during his pastoral tenure there was much debilitating conflict, to the extent that certain former members would get up and leave when he stood up to preach! $!^{3}$ When I was installed, I became the seventh pastor of the church in twenty-three years. Unresolved conflict and an unsafe worship and fellowship environment can have long-lasting effects that undermine a church's ability to rise to their full ministry and discipleship potential. A carefully structured and intentional focus

${ }^{3}$ Dante Tobias, interview by author, Orangeburg, SC, October 11, 2011. 
on conflict resolution-based discipleship training seemed appropriate and essential to help foster church unity, and promote a passion for soul winning and church growth.

\section{Expectations of This Project}

The aim of this project is to contribute to the discipleship process of the New Life church, contributing to a more healthy worship and fellowship environment where both spiritual and numerical growth can take place. This project is also intended to add to my knowledge of how to navigate the sometimes treacherous trail of crippling congregational conflict. Additionally, discoveries made during this project will provide a potential reservoir of information from which I can create additional training resources.

The New Life church family is expected to be transformed by the instructional process, by being made aware of the causes and practical solutions for conflict within the congregation. In order to accomplish this purpose, I took a comprehensive approach in the examination of contexts of conflict to cover the range of realities for the congregants, namely: Family conflict, workplace conflict, and congregational conflict. I took this path, as it is my view that how people respond to conflict anywhere impacts upon how they respond to conflict everywhere, and that unresolved conflict in any of these contexts may carry over into relationships in the other contexts. Due to the comprehensive nature of the seminars, I expect that many members will be delivered from negative and ineffective responses to conflict. Also, the fruit of the Spirit should be more evident in the members' future dealings with each other because of their heightened sensitivity to matters relating to congregational conflict. 


\section{Definition of Terms}

As defined by The Business Dictionary Online, conflict refers to "friction or opposition resulting from actual or perceived differences or incompatibilities. ${ }^{\circ 4}$ Compare with the working definition I offer in this paper on p. 41.

New Life refers to the Warner Robins, Georgia, New Life Seventh-day Adventist Church.

CLASS Act Seminars refers to my consulting service. ${ }^{5}$ CLASS is an acronym for Church Leadership and Strategic Solutions. The term CLASS Act also had implications for my passion to see God's people (the Church) be a class act for Him. Other terms will be defined on an as needed basis throughout this manuscript as it unfolds.

\section{Limitations of the Project}

This project is limited to creating and implementing a conflict resolution training program at the New Life church. While it is hoped that the training program will produce an environment conducive to spiritual and numerical growth, it is not the purpose of this project to measure, evaluate, or determine if or how these changes do in fact occur. It is also not the purpose of this project to identify all the factors which caused the conflicts at New Life over the years, or to provide specific responses for any particular issue.

The original project called for six seminars to be created and presented over a sixmonth period. However, upon further review of the length of the program and the church

\footnotetext{
${ }^{4}$ The Business Dictionary, s.v. "Conflict," http://www.business dictionary.com/definition/conflict .html (accessed February 28, 2012).

${ }^{5}$ CLASS Act Seminars is the name of my consulting service, and is a registered Limited Liability Company (LLC). CLASS is an acronym for Church Leadership and Strategic Solutions. The seminar series mentioned above was developed as a result of this project. CLASS Act Seminars was not compensated as part of this study at New Life Seventh-day Adventist Church.
} 
calendar, the series was reduced to five seminars over a three-month period, from the end of November 2011 to the end of February 2012.

\section{Methodology}

The aim of this project is to furnish a congregational conflict resolution training program for the New Life Church through the creation and presentation of a series of seminars and sermons. After each presentation, a focus group was utilized to gather feedback and serve as an evaluation mechanism to measure the impact upon the thinking of the congregation. Of the five seminars and sermons presented, four were done during the regular divine service period on Sabbath. One seminar was presented during a Wednesday night service. On the Sabbaths of the seminars and focus group sessions, I provided lunch for all group participants and their household members who desired to remain after church. There was great fellowship, as well as lively and self-revealing discussion concerning the seminar material.

I had previously secured voted permission of both the church and the conference executive committee to conduct the research in the church. I kept a journal of the various responses to the lead-off and follow-up questions to the focus group, along with the names of attendees, dates, and time of the focus group sessions. Afterward, I typed these notes in my computer for compilation and evaluation during the portion of this document where it is called for. Respondents were assured that they would not be identified in any way for the responses they provided.

A review of relevant literature was engaged in the production of the seminars. Appropriate citations were given for referenced materials. Each seminar was done as a PowerPoint presentation, and a handout copy was given to every worshipper above the 
age of eighteen, regardless of whether or not they would participate in the focus group session that followed. The PowerPoint handouts were done with three slides per page and included lines beside each slide for worshippers and focus group participants to write their own notes as they listened.

In addition to providing handouts, each presentation was shown on the projector screen. In at least two seminar instances, supplemental reading material was given out to limit the length of the presentation. The focus group sessions tended to maintain a core group of individuals, and several persons were in fact part of each session. Altogether, there were fifteen focus group participants, with a mean attendance of eight per session. The focus group sessions lasted between an hour-and-a-half to two hours.

\section{Outline of the Project}

1. Chapter one outlines the purpose of the project, giving insight as per the task, the justification, the limitation, and the methodology by which the project will be implemented.

2. Chapter two establishes a theological foundation for conflict resolution, with focus on two primary themes, namely: God's will for love and harmony among His people, and the correlation between these factors and church growth. Within this context, a systematic biblical teaching on the principles of healthy congregational conflict resolution is developed.

3. Chapter three discusses my engagement with the theories of contributors in the field of conflict resolution, primarily, but not limited to congregational conflict. Literature relevant to the project is reviewed and cited. This included books, articles, online sources, and dissertations on conflict resolution. 
4. Chapter four describes the CLASS Act Seminars which were developed for this project, and records important features of their implementation.

5. Chapter five focuses on the evaluative interactions with the focus groups which were utilized during this project to gather qualitative evaluation of the training program. The received data is organized, analyzed, interpreted, and reported as part of this document. Chapter five also conveys my conclusions and recommendations arising from the project process. The chapter describes how the project process has impacted me, in transforming my own understanding of, and response to conflict.

Congregational conflict resolution training at New Life is a necessary part of the process of transitioning the church from the effects of damaging conflict to harmonious fellowship and membership growth. 


\section{CHAPTER II}

\section{TOWARD A THEOLOGY OF CONGREGATIONAL CONFLICT \\ AND CHRISTIAN CONFLICT RESOLUTION}

\section{Introduction}

Ever since my baptism into the body of Christ in 1987, I have been concerned about the amount and level of conflict and resulting dysfunction in a great many local congregations. I do understand and accept that conflict is inevitable, and is a reality in all aspects of life, as is evident in all relationships and throughout history. Pastors, it appears, tend to receive the brunt of the consequences of strife in troubled congregations: With such widespread evidence of troubled churches, there is sufficient cause for seeking a theological understanding of interpersonal and congregational relationships and conflict, as well as a solid theological foundation for the need of congregational harmony as it relates to church growth.

Pastors and other church leaders would greatly benefit from such a study, as their efforts to advance the mission of the church hinge, in part, on their ability to transition conflict-ridden congregations to becoming healthy, safe, growing communities, where both the members as well as seekers can grow together in grace. The Scriptures provide ample principles of love and ethics in human relations for the development of a theological understanding of this nature. 
It is a fundamental principle that our beliefs affect how we behave. Our worldview is also determined by our belief system. It is therefore essential that in our churches, there is a healthy, biblically based understanding of what constitutes acceptable and unacceptable responses to conflict. Not only is this true, but it is equally important that as Christians, we know and apply God's will concerning how to avoid preventable and unnecessary conflicts.

It goes without saying that a conflict-free existence in a sin-filled world is impossible. However, as God's people, Christians are obliged to know and practice responsible conflict management and conflict resolution as taught by His Word. A sound theological understanding may greatly assist in this preferable lifestyle of harmony, peace, and love in all the churches of God, resulting in the advancement of the gospel.

The purpose of the theological reflection in this chapter is to survey particular biblical directives and principles with a view to setting forth a biblical foundation for conflict resolution, keeping in mind the spiritual cosmic reality of the Great Controversy between Christ and Satan for the souls of human beings. I will also conduct an exploration of key concepts relative to the duties of the offended, the offender, and the observer in conflict and dispute situations.

\section{The Great Controversy Motif in Understanding Conflict}

Conflict is portrayed throughout Scripture in various ways. These include interpersonal conflict (Saul and David, or Paul and Barnabas), international conflict (Israel and their enemies), and the cosmic conflict (Great Controversy) between God and Satan. Conflict is represented as a breakdown in love and harmony or as an intense difference of opinion, resulting in strife or separation in a relationship. There are several biblical words 
that depict conflict. For example, strife, from the Hebrew ryb (בר) in Gen 13:7; contention, from the Hebrew myrbh (מְריבָה), which indicates a quarrel ${ }^{2}$ in Gen 13:8. ${ }^{3}$ Also, in the New Testament, we find the Greek word philoneikia ( $($ iroveikía) which indicates a quarrel or dispute in Luke 22:24. ${ }^{4}$ In Rom 13:13 and 1 Cor 3:3 we find the word eris ("̌pls), which depicts altercation, strife, and discord or contentious disposition. ${ }^{5}$ Van Yperen reveals that "the word conflict is assumed everywhere and stated almost nowhere in Scripture." He cites Hab 1:3 and Gal 5:17 as the only places in each Testament, based on the New International Version, where the word actually appears. ${ }^{6}$

All human conflict should be understood in the context of the great cosmic controversy between good and evil. The Bible depicts a spiritual war in heaven, the result of Lucifer's disloyal movement against God, his Creator (Rev 12:7-12). The conflict is represented as the manifestation of a rebellious spirit against the authority of God, with Lucifer desiring both the position and the authority of God as his own (Isa 14:12-15 and Ezek 28:11-19).

\footnotetext{
${ }^{1}$ F. Brown, S. Driver and C. Briggs, The Brown-Driver-Briggs Hebrew and English Lexicon (1906; repr., Peabody, MA: Hendrickson Publishers, 1999), 936.

${ }^{2}$ Ibid., 937.

${ }^{3}$ Unless otherwise indicated, all Bible references in this paper will be taken from the New King James Version (NKJV). Where texts are used in quotations, the quoted version of the text is preserved.

${ }^{4}$ Wesley J. Perschbacher, ed., The New Analytical Greek Lexicon (1990; repr., Peabody, MA: Hendrickson Publishers, 1999), 429.

${ }^{5}$ Ibid., 172.

${ }^{6} \mathrm{Jim}$ Van Yperen, Making Peace: A Guide to Overcoming Church Conflict (Chicago, IL: Moody Publishers, 2002), 94, 95.
} 
On this subject, White writes:

The Father wrought by His Son in the creation of all heavenly beings. "By Him were all things created ... whether they be thrones, or dominions, or principalities, or powers: all things were created by Him, and for Him." Colossians 1:16. Angels are God's ministers, radiant with the light ever flowing from His presence and speeding on rapid wing to execute His will. But the Son, the anointed of God, the "express image of His person," "the brightness of His glory," "upholding all things by the word of His power," holds supremacy over them all. Hebrews 1:3. "A glorious high throne from the beginning," was the place of His sanctuary (Jeremiah 17:12); "a scepter of righteousness," the scepter of His kingdom. Hebrews 1:8. "Honor and majesty are before Him: strength and beauty are in His sanctuary." Psalm 96:6. Mercy and truth go before His face. Psalm 89:14. ${ }^{7}$

She further states:

So long as all created beings acknowledged the allegiance of love, there was perfect harmony throughout the universe of God. It was the joy of the heavenly host to fulfill the purpose of their Creator. They delighted in reflecting His glory and showing forth His praise. And while love to God was supreme, love for one another was confiding and unselfish. There was no note of discord to mar the celestial harmonies. But a change came over this happy state. There was one who perverted the freedom that God had granted to His creatures. Sin originated with him who, next to Christ, had been most honored of God and was highest in power and glory among the inhabitants of heaven. Lucifer, "son of the morning," was first of the covering cherubs, holy and undefiled. He stood in the presence of the great Creator, and the ceaseless beams of glory enshrouding the eternal God rested upon him. "Thus saith the Lord God; Thou sealest up the sum, full of wisdom, and perfect in beauty. Thou hast been in Eden the garden of God; every precious stone was thy covering. . . . Thou art the anointed cherub that covereth; and I have set thee so: thou wast upon the holy mountain of God; thou hast walked up and down in the midst of the stones of fire. Thou wast perfect in thy ways from the day that thou wast created, till iniquity was found in thee." Ezekiel 28:12-15. ${ }^{8}$

Sinful, selfish desire is identified as the root cause of sin and rebellion. Satan's

desire for the pre-eminence got the better of him. White states:

Little by little Lucifer came to indulge the desire for self-exaltation. The Scripture says, "Thine heart was lifted up because of thy beauty, thou hast corrupted thy wisdom by reason of thy brightness." Ezekiel 28:17. "Thou hast said in thine heart .. . I will exalt my throne above the stars of God. . . I will be like the Most High."

${ }^{7}$ Ellen G. White, Patriarchs and Prophets (1890; repr., Nampa, ID: Pacific Press, 1958), 34.

${ }^{8}$ White, Patriarchs and Prophets, 35. 
Isaiah $14: 13,14$. Though all his glory was from God, this mighty angel came to regard it as pertaining to himself. Not content with his position, though honored above the heavenly host, he ventured to covet homage due alone to the Creator. Instead of seeking to make God supreme in the affections and allegiance of all created beings, it was his endeavor to secure their service and loyalty to himself. And coveting the glory with which the infinite Father had invested His Son, this prince of angels aspired to power that was the prerogative of Christ alone. ${ }^{9}$

The spirit of pride and rebellion originated with Lucifer in the heavenly courts. Having lost the spiritual conflict, he was cast down to the earth as Scripture indicates (Rev 12:10-13). Now the avowed enemy of God, this former highly exalted being set his sights on destroying humanity. Using the same cunning with which he distorted God's character and manipulated the angels, Satan launched his destructive plan to cause conflict and chaos among the inhabitants of this planet. While only two people occupied the earth, Satan artfully sowed the seeds of perpetual rebellion and conflict in the hearts of humankind. It may be noted in Gen 3:8-10, that one of humanity's first reactions to their fall in Eden was to "hide" (חָָָָ chaba - to withdraw, hide) from God. ${ }^{10}$ This hiding or withdrawal is indicative of a broken relationship. Humanity now finds themselves in conflict with God and His righteous principles. The great controversy which began in heaven has now come to earth, and all humanity is involved, not as spectators, but as participants. Humanity's separation from the Creator mimics Lucifer's separation from Him. Both are the result of disloyalty. The result is the same- broken relationships and a loss of harmony.

At the end of Genesis 1, the Creator God had declared everything in the created world to be very good. Humankind had been created. The provisions for their habitation

\footnotetext{
${ }^{9}$ White, Patriarchs and Prophets, 35.

${ }^{10} \mathrm{~F}$. Brown, S. Driver and C. Briggs, The Brown-Driver-Briggs Hebrew and English Lexicon, 285.
} 
of the earth were perfect. Perfect order had been established. Now the fall of humanity (Genesis 3) caused a distortion of what God had intended. From open communion with God to withdrawal from God, humanity had fallen into a state of "not so good", which is effectively a reversal of Gen 1:31.

The great controversy between God and Satan therefore becomes the foundation, the source of all conflict. The great controversy motif is instinctively evident in every conflict situation, as it is a contrary and destructive reality to the harmony and peace that the Creator had planned for humankind and the universe. Wars and strife between nations and individuals are mere microcosms of the cosmic controversy which started in heaven and was introduced to our planet by the fallen angel Lucifer. Against this backdrop, I make the following arguments: (1) conflict is universal and is inevitable as long as sin exists; (2) wherever there is conflict, it should be recognized that Satan is at work to divide and destroy; and (3) humankind in general, and Christians in particular, have a responsibility to learn how to prevent and resolve conflict, as far as is possible.

Scripture is clear that all conflict will one day end ( $\operatorname{Rev} 21: 1-5)$ because Satan and all sinners will be destroyed (see John 8:28, 29 and Rev 20:5, 6). Until that time comes, Christian congregations that love and worship the Creator God have many biblical examples from which to extract important lessons on the causes of, and resolution of conflict. These principles may be studied for the purpose of understanding and resolving congregational conflict. I will now explore some of these cases.

\section{Biblical Parallels to Causes of Modern Congregational Conflict}

The various types of conflict situations I have observed in the Bible may be grouped under certain general headings, or classifications of counsels and admonitions 
that may be of benefit to church congregations. Here, I offer my reflections on these groupings, though these categories and classifications do not necessarily indicate an exhaustive list of possible headings. For the purpose of this document, I will limit my focus to those here mentioned. This reflection on parallels between biblical examples of conflict and modern congregational conflict may well provide the impetus for further research and study for a future work.

I have chosen to categorize my observations as follows: (1) rebellion and opposition to leadership, (2) leadership problems as the cause of church conflict, (3) the problem of personal greatness and pre-eminence, (4) cultural bias as a factor in congregational conflict, (5) theological disputes as the catalyst for conflict, (6) disregard for protocol causes conflict, and (7) mishandling of disagreements and misunderstandings.

\section{Rebellion and Opposition to Leadership}

Perhaps one of the clearest examples of rebellion against one of God's appointed spiritual leaders is the people's treatment of Moses in the story of the Exodus. As recorded in various books of the Bible (Exodus, Leviticus, Numbers, and Deuteronomy), Moses was severely and constantly criticized, even abused, for just about everything he did as their leader. His instructions were almost always second guessed. There was open disagreement with him on almost every major directive he gave. God Himself regarded the behavior of the people as rebellion. What concerns me is that Moses' leadership was visibly affirmed by the LORD on several occasions, beginning with the plagues in Egypt, then confirmed by the Red Sea crossing, and the many miracles which were done in the wilderness. At a glance, I failed to understand how the people could have missed the fact 
that Moses was God's man doing God's bidding. However, upon closer examination, there is a clear pattern of decided resistance among the Children of Israel. On every occasion that I have surveyed, God regards their actions as rebellion against Himself.

In Num. 14, God's view of the people's actions and attitudes comes into sharp focus. The text indicates that they complained and murmured against Moses. Verses 5-9 serve to demonstrate the spiritual reality of the matter. Joshua and Caleb, two of the spies who surveyed Canaan, cautioned the faithless and faultfinding throng against rebelling against the Lord. The text indicates that these two men understood that Moses was not acting on his own accord. To them, Moses was the Lord's appointed leader, through whom He was directing Israel concerning what to do and where to go. It was the Lord who set Moses over them to carry out God's purpose of giving them the land of Canaan. They saw Moses' leadership and God's leadership as one and the same. Ellen White commented concerning this scripture passage that those who opposed Joshua and Caleb's urging to go up and inherit the land had not only set themselves against Joshua and Caleb, but also against Moses and God Himself. She held that in the tumult and confusion that followed, it was Satan who was in control of the people. ${ }^{11}$ In this same chapter ${ }^{12}$ of Patriarchs and Prophets, White uses the terms "rebels" and "rebellion" several times to describe the behavior of the people toward the leadership of Moses and the authority of God. The apostle Paul later asserted that the story of the Israelites' pilgrimage from Egypt to Canaan was preserved because "these things happened to them as examples, and they were written for our admonition, upon whom the ends of the ages

\footnotetext{
${ }^{11}$ White, Patriarchs and Prophets, 389.

${ }^{12}$ White, "The Twelve Spies," in Patriarchs and Prophets, 387-394.
} 
have come" (1 Cor 10:1-12). This text is one of my reasons for surveying the biblical parallels to the causes of today's congregational conflicts.

The Exodus story provides several examples of consequences resulting from rebellion against God's appointed leaders. These consequences included: snake bites (Num 21:6), rebels swallowed alive by the earth (16:32), rebels consumed by fire (v. 35), complainers dying with flesh between their teeth (11:33), extended wanderings in the wilderness by four decades (chap. 14), the plague (11:31-34), leprosy brought upon Miriam (12:4-15), fighting men lost in battle because of stubborn delay in taking the land of Canaan (14:39-45), and the most serious consequence of all, which is the judgment of death upon all the pilgrims above the age of twenty who left Egypt to go to Canaan. This is not an exhaustive list of consequences arising from the many occasions of rebellion and faithlessness.

Today, resistance and rebellion against God's appointed leaders in the congregational setting are similarly damaging. There are many books on the Christian literature market that address this issue. The problem is widespread. Many congregations have plateaued or declined or have been completely destroyed because of congregational conflict and its stagnating and destructive effect. The Exodus experiences show how a relatively small faction within the congregation can quickly and negatively influence the entire congregation, or enough people in the congregation against their pastors and other leaders. This activity leads to open rebellion that can cripple the church.

Scripture recognizes that there was a "mixed multitude" within the congregation of the Children of Israel during their wilderness sojourn. Of these, White writes:

The mixed multitude that came up with the Israelites from Egypt were a source of continual temptation and trouble. They professed to have renounced idolatry, and to 
worship the true God; but their early education and training had molded their habits and characters, and they were more or less corrupted with idolatry and with irreverence for God. They were oftenest the ones to stir up strife, and were the first to complain, and they leavened the camp with their idolatrous practices and their murmurings against God. ${ }^{13}$

The mixed multitude was without excuse, however, concerning their arrogance, faithlessness and rebellious actions. Though they were not Israelites, they were quite aware, as were the Israelites, that it was Jehovah who was leading them on their journey. There was constant, reliable, visible physical evidence of this fact. The Egyptians were idolaters who worshipped images in order to "see" their gods. Their religion was by sight, not by faith. Their confidence rested entirely in what they could see. The Children of Israel had apparently accepted this way of worship as well, as part of their sojourn in Egypt. No wonder then, that God would provide visible, physical evidence of His leading: "God Himself directed the Israelites in all their travels. The place of their encampment was indicated by the descent of the pillar of cloud; and so long as they were to remain in camp, the cloud rested over the tabernacle." 14

There is an important principle to note here. In situations where the members of the church complain and rebel, it is often viewed as merely a movement against, or dissatisfaction with the pastor. The pastor is the leader the people see. However, what the story of the Exodus shows, is that Moses was not the one directing the journeys of Israel; God Himself was their leader. He was the One directing the very path they were taking. Moses was merely carrying out the mandate of God as shown to him. This is an important theological insight that is often missed or misunderstood by church members.

\footnotetext{
${ }^{13}$ White, Patriarchs and Prophets, 408.

${ }^{14}$ White, Patriarchs and Prophets, 376.
} 
Complaining, revolting, and refusing to cooperate with church leaders is a more serious spiritual matter than most realize.

God appears in the Exodus narrative and takes strong exception to the attitudes and behaviors of the people that in any way hinder the leadership of His servants whom He chooses to carry out His purpose. The lesson here may be summed up like this: God leads His people through the leaders of His own choosing. These leaders are to be obedient to Him, faithfully carrying out His mandate. Meanwhile, the congregation is to be respectful and positively responsive in their cooperation with the servants of God.

\section{Leadership Problems as the Cause of Church Conflict}

Moses is described in Scripture as the meekest man alive. "Now the man Moses was very humble, more than all men who were on the face of the earth" (Num 12:3). With such an unimpeachable endorsement, how could Moses have experienced so much congregational conflict in his ministry as the spiritual leader of Israel? It seems logical that church members would respond positively to a leader who, by all accounts, was almost perfect, and had been shown to be in direct contact with God. What may be clearly understood from this reality is that the character of the leader will not exempt him or her from conflict. No amount of humility that Moses possessed prevented the people from attacking him and constantly complaining about him. It does not matter who the leader is, or what is their leadership style, "conflict is inevitable for leaders, and it exists at the root of some of their best ideas and at the core of many of their worst failures." ${ }^{\prime 15} \mathrm{In}$

\footnotetext{
${ }^{15}$ Craig E. Runde and Tim A. Flanagan, Becoming a Conflict Competent Leader: How You and Your Organization can Manage Conflict Effectively (San Francisco, CA: John Wiley \& Sons, 2007), 1.
} 
fact, trouble at times may mean that the spiritual leader is fulfilling God's will. ${ }^{16}$ This view may not receive the acceptance by some, but that fact makes it no less true.

There are those times however, though not in the majority of cases, when the damaging congregational conflict is the leader's fault. Suffice it to say, and it is generally understood, that as human beings, pastors do have strengths, weaknesses, limitations, and flaws as do all other human beings. That said, there are some specific types of personal baggage that will almost always trigger conflict. Susek identifies two of these types of baggage as (1) destructive family backgrounds and (2) un-resolved psycho-social needs. ${ }^{17}$ Reflecting on these two concepts, I agree with the writer that the spiritual leader's needs are best met by God Himself. Attempts by a pastor to extract personal sympathy or any other form of emotional support for the satisfaction or fulfillment of personal psychological needs from the congregation may trigger unnecessary conflicts as the members begin to question their leader's credibility and emotional stability. Selfknowledge and clearly defined accountability measures would be advisable for any pastor, seeing that there are so many occasions for compromised behavior as a result of emotional imbalance.

Christian leaders cannot be too careful in the matter of sorting out their own feelings and psycho-social issues. Failure to do so can lead to terrible consequences for the pastor and for the congregation as a whole. This is probably truer in the area of pastoral counseling of parishioners than any other situation, where "many pastors fail to

\footnotetext{
${ }^{16}$ Ron Susek, Firestorm: Preventing and Overcoming Church Conflict (Grand Rapids, MI: Baker Books, 1999), 71.

${ }^{17}$ Ibid., 81-89.
} 
recognize their own inner signals." ${ }^{18}$ Unhealthy dependencies between pastor and congregant may form in cases where the pastor is not emotionally and psycho-socially well.

King Saul appears to have had a psychological problem (1 Sam 16:14-22). The king is described in the text as a man with a distressed spirit. Ellen White indicates that this disturbed state of mind was brought on by an evil spirit, and that David was brought in "to soothe the mind of the troubled monarch till the evil spirit should depart from him. ${ }^{\prime 19}$ With this psychological imbalance, it is understandable that he would behave in the manner that he did, especially in response to the people's favoring of David. The youngster had not done anything to offend the king; however, the king became violent toward him. As the leader, Saul should have provided inspiration and moral support to those who served under him, but the king was psychologically distressed. David was brought in to minister to this particular need. The king became dependent upon David's music to calm his maniacal emotions. He apparently failed to depend on the Lord to be his helper. Leaders who are emotionally or psycho-socially unbalanced, risk escalating conflict, and may contribute to "resentment, alienation, and eventually resistance from those on the losing side. ${ }^{20}$

Saul's irritated nerves got the better of him, and in his insecurity and jealousy, he tried on occasions to kill David. His personal insecurities led him to pursue and persecute David, a subordinate. Saul's actions were often irrational. This narrative demonstrates

\footnotetext{
${ }^{18}$ James J. North Jr., "The Minister as a Counselor," in The Adventist Minister, ed. C. Raymond Holmes and Douglas Kilcher (Berrien Springs, MI: Andrews University Press, 1991), 92.

${ }^{19}$ White, Patriarchs and Prophets, 643.

${ }^{20}$ Runde and Flanagan, Becoming a Conflict Competent Leader, 35.
} 
that emotional instability in leaders can trigger conflict with church members because of how leaders relate to their intra-personal issues. The Christian leader needs to be emotionally secure in Christ. It is only the leader's personal relationship and complete dependence upon Jesus and His grace that will enable him or her to lead with integrity, and maintain a focus of helping the people, rather than seeking help from the people.

The Problem of Personal Greatness and Pre-eminence

There was conflict among Jesus' twelve disciples. They had misunderstood the nature of Christ's kingdom. ${ }^{21}$ The prophets and rabbis had for many years taught the restoration of their nation. With this view of a literal restoration of the kingdom to Israel, accompanied by an intense longing for deliverance from the Romans, the disciples were motivated to secure positions of honor for themselves. They argued about who should be the greatest among them (Mark 9:34; Luke 9:46). Jesus responded by likening greatness to servant-hood and humility. The desire for pre-eminence has often been a trigger for conflict, both in the world and in the church. Among the closest followers of Christ, selfish desires, jealousy, and ambition invariably led to strife.

It was during the heart-searching preparation for the baptism of the Holy Spirit that the disciples realized their error. They were changed. "No longer were they ignorant and uncultured. No longer were they a collection of independent units or discordant, conflicting elements. No longer were their hopes set on worldly greatness."22

\footnotetext{
${ }^{211 " C h r i s t ' s ~ K i n g d o m, " ~ S D A ~ B i b l e ~ C o m m e n t a r y, ~ e d . ~ F r a n c i s ~ D . ~ N i c h o l ~(1956 ; ~ r e p r ., ~ W a s h i n g t o n, ~}$ DC: Review and Herald, 1980), 6:122.

${ }^{22}$ Ellen G. White, The Acts of the Apostles (Nampa, ID: Pacific Press, 1911), 45.
} 
The quest for personal greatness and self-exaltation did not originate on earth, but in heaven with Lucifer. In Eden, the serpent enticed the woman with the promise that "you will be like God" (Gen 3:5). This statement inspired what would become mankind's all consuming passion - to be great, superior, exalted above their fellow human beings. Humility was compromised, degraded, and devalued as a result.

As seen earlier in the narrative of the Exodus, Korah, Dathan, and Abiram sought to exalt themselves in competition against Moses, God's chosen leader. They became the cause of divisive conflict as a result. These men brought terrible consequences upon themselves and upon those who followed their evil example. Lucifer too, had indulged self-exaltation, even though he was already more highly exalted than all created beings. His quest to obtain God's glory caused disharmony in the perfect atmosphere of heaven. ${ }^{23}$

\section{Cultural Differences as a Factor in Congregational Conflict}

Cultural differences have probably been a challenge for human relationships since the very early history of humanity. ${ }^{24}$ With the introduction of different languages at Babel (Gen 11), and the accompanying scattering of people to other parts of the earth, cultures probably began emerging in a more structured manner. Just as individuals are different, people groups also have unique qualities and norms that identify them by a systematic way of thinking and doing. It is my observation that religion appears to have been a predominant differentiator between peoples of the Bible times. The Hebrew people were

\footnotetext{
${ }^{23}$ White, Patriarchs and Prophets, 36.
}

\footnotetext{
${ }^{24}$ For purposes of this paper, I have defined culture as: A norm by which people identify with, and demonstrate that they belong to a particular group, based upon ethnicity, language, race, age, vocation, or other identifiable group classification. These norms may be expressed through language, music, religious beliefs and practices, social traditions, etc.
} 
distinct from other peoples, not only because they worshiped Jehovah while most worshiped heathen gods, but also because they were regarded as a "special" people who came into existence because of God's covenant with Abraham (Gen 12-18).

The existence and reality of cultures is further complicated by their sub-cultures. A sub-culture is defined as "a group having social, economic, ethnic, or other traits distinctive enough to distinguish it from others within the same culture or society." ${ }^{25}$ The existence of cultures and sub-cultures additionally brings into focus the necessity of understanding and appreciating cultural diversity, both in society and in the church. The embracing of diversity is a Christian value. This opens up at least two important conversations: (1) How to achieve and preserve unity in the context of such diversity, and (2) that the nature of cultural diversity makes uniformity impractical.

It would be a mistake to assume that the natural challenges brought about by cultural diversity would somehow be eliminated by the fact that the congregation is the body of Christ. This indicates a rather simplistic view or what cultural diversity is and does. On this point, Hohnberger offers that:

Unity never comes as a result of membership in a church, never as the result of joining a ministry or institution, and never as the result of agreeing to certain truths. Unity comes only as a result of different people from different backgrounds and, yes, even with different biases joining themselves to Jesus Christ. Unity is experienced only to the degree to which we are united to Jesus. ${ }^{26}$

I agree with Hohnberger that church membership alone, or even the acceptance of doctrines, cannot take the place of personal conversion and transformation in order that naturally carnal minded people can "dwell together in unity" (Ps 133:1). Menjares holds

\footnotetext{
${ }^{25}$ Dictionary.com, s.v. "Sub-culture," http://dictionary.reference.com/ browse/sub-culture?s=t (accessed May 8, 2012).

${ }^{26} \mathrm{Jim}$ Hohnberger, with Tim and Julie Canuteson, It's About People: How to Treat Others Especially Those We Disagree With, the Way Jesus Treats Us (Nampa, ID: Pacific Press, 2003), 88.
} 
that "the overwhelming testimony of scripture is that the church is to be a multi-cultural, multi-national, and multilingual gathering of believers. ${ }^{27}$ Oosterwal opines that communication is impacted by cultural differences, that the varying values in people's basic assumptions are shaped by their cultural background; and that these assumptions shape their perceptions of reality and their views of right and wrong. ${ }^{28}$ Jesus is concerned about the unity of the Church. He prayed that his followers would be one (John 17:17).

Much space is noticeably dedicated in the Bible to outlining God's will for human relationships. So is giving divine instruction concerning what to do when relationships go wrong. Cultural differences are common causes of interpersonal conflict and church fights. These differences show up in various aspects and times of congregational life, such as: worship and music preference; the why, how, and when to implement changes; and the degree of involvement of members in the decision-making process of the church.

Sometimes cultural differences manifest themselves along the lines of gender. One notable example of this is the current debate in the Seventh-day Adventist Church over the question of women in ministry in general, and their ordination to the ministry in particular. I hold that there is no biblical ground for excluding women from the gospel ministry, with ordination, and access to all the associated rights, responsibilities, and privileges of full-time clergy. I see the debate strictly as a cultural one, based upon the patriarchal norms of the Jewish people and some cultures today. In some congregations,

\footnotetext{
${ }^{27}$ Pete C. Menjares, "Is There a Biblical Basis for Encouraging Diversity?" 26 April 2010, http://unityinchristmagazine.com/theology/is-there-a-biblical-basis-for-encouraging-diversity (accessed May 8, 2012).

${ }^{28}$ Gottfried Oosterwal, "Leaders and Cross-Cultural Communication: Communicating Across Cultural Boundaries," in Embracing Diversity: How to Understand and Reach People of all Cultures, ed. Leslie N. Pollard (Hagerstown, MD: Review and Herald, 2000), 22.
} 
women are not allowed to be elders, based upon the perception that it would be wrong, or even worse, a sin to allow women to serve as spiritual leaders (see Joel 2:28, 29).

Another sensitive way in which culture impacts the church is the almost constant debate about music in worship. This debate tends to center on the question of what is considered to be appropriate church music. Significant differences exist in this dialog between the old and the young, between races, and between ethnic groups. In my experience and observation, the responses to this question are culture based, seeing that the Bible does not specifically address what worship music should look and sound like.

Seeing that there is so much opportunity for conflict, I am of the view that a proper theology of worship is essential for harmony among the congregation and for the moving of the Spirit to be effectual. Segler puts it this way, "Worship should be regulated and determined by doctrine. ${ }^{29}$ In this, I agree with him. Many conflicts have crippled untold numbers of churches over the question of worship, and music in worship. The strongest viewpoints in my own experiences have not been Bible based, but rather the expression of the opinions and traditions of the strongest or noisiest people in the church.

In some churches, certain instruments are forbidden, for example, the drum. I have yet to hear a Bible text appropriately quoted and faithfully exegeted in support of such a position. Doctrinal instruction may go a long way in helping congregations to properly understand the difference between personal preferences, traditions, and right versus wrong. Proper instruction would also teach tolerance and acceptance of other cultures, and an appreciation of their norms of worship. Dudley Weeks argues for caution

\footnotetext{
${ }^{29}$ Franklin M. Segler, rev. by Randall Bradley, Understanding, Preparing for, and Practicing Christian Worship (Nashville: Broadman \& Holman Publishers, 1996), 47.
} 
in how people manage their perceptions, because "conflict usually involves a struggle between absolutes, such as right and wrong and good and evil." 30

\section{Theological Disputes as the Catalyst for Conflict}

When I arrived as the new pastor at New Life, only a few people attended the adult Sabbath School. It did not take long for me to learn why. For years, the adult Sabbath School class had developed a reputation for being a place of heated arguments, leaving those who ventured to attend shaking their heads in bewilderment. A certain member had made it his weekly duty to create conflict, arguing vehemently with the class teacher, regardless of the scheduled subject. I soon observed that the particular member did not bring a copy of the Sabbath School Lesson Guide to Sabbath School. In fact, the individual rarely ever carried or opened a Bible. It became my view that the member had a psychological need to create conflict, as every week, like clock-work, his incredulous statements would derail the class discussions. Most times, his outlandish statements would have nothing to do with the subject for that day's study. The problem was chronic.

The worst part in dealing with this member was that after several one-to-one and group meetings which I had with him, nothing changed. Not only that, but I discovered that at least three pastors besides me had previously talked with him about this behavior. To add to my frustration, he was also serving as an elder of the church. That was not acceptable to me as a minister of the gospel. I removed him from the speaking roster, instructed that he must not be assigned to teach the Sabbath School class, and then directed the nominating committee later that year that he should not be considered for any 1992), 9.

${ }^{30}$ Dudley Weeks, The Eight Essential Steps to Conflict Resolution (New York: Penguin Putnam, 
office in the church. The nominating committee was happy for the leadership I showed on the issue. For years, they had felt paralyzed by fear of conflict, powerless to take action in the case of someone who so flagrantly violated the harmony and peace of the church. Unfortunately, these occurrences are not rare in our congregations.

Theological harmony is not optional in the church. Paul advocated that there be "one faith" (Eph 4:5). The brother in the above example eventually stopped attending New Life. He was of the view that he had a right to his opinions, and even had the right to preach those views to the members and visitors of the church. Even though the false teachings of this member were a constant cause of disgruntlement, when I took action to remove him from positions of influence in the church, there were some who came to his defense, urging that I was denying him the right to his opinions. I had made it clear that the decision to discontinue his speaking privileges was for the sake of harmony and to preserve the doctrinal purity of the church. His supporters began to vehemently attack my character and credibility, and questioned my authority to "sit him down."

While at Miletus, Paul sent for the elders from Ephesus. He charged them to remain faithful to the word of God, and warned them that after his departure, false teachers would seek to come in among them and devour the congregations with spurious doctrines (see Acts 20:1-32). The great apostle, in his second letter to Timothy, urged him to be faithful to the word, and to preach nothing else (2 Tim 3:10-4:5). Paul refers to these disputes as "vain babblings" because they profit nothing (2 Tim 2:16). 
Ellen White encouraged the continuous, prayerful study of the Scriptures, and that the student should in humility accept advancing light. She also cautioned against error:

If a brother is teaching error, those who are in responsible positions ought to know it; and if he is teaching truth, they ought to take their stand at his side. We should all know what is being taught among us; for if it is truth, we need to know it. The Sabbath school teacher needs to know it, and every Sabbath school scholar ought to understand it. We are all under obligation to God to understand what He sends us. He has given directions by which we may test every doctrine- "To the law and to the testimony: if they speak not according to this word, it is because there is no light in them." But if it is according to this test, do not be so full of prejudice that you cannot acknowledge a point simply because it does not agree with your ideas. ${ }^{31}$

Keeping in mind that worship is at the heart of the great controversy, there can be no tolerance of error being taught to the members of the church. It was by twisting the Word of God that the serpent was able to deceive the woman in Eden (Gen 3:1-6).

Doctrines are important. Doctrinal correctness is even more important. People live by their beliefs, so it is critical that only truth be presented and accepted, as this will affect the life. When a doctrinal dispute erupted in the early church, the apostles, being led of the Holy Spirit, wisely decided to meet in Jerusalem to pray together, and settle the matter collectively and lovingly (Acts 15:1-29). They did not engage in theological oneupmanship. They realized the necessity of moving in concert with one another to prevent causing division in the body. Doctrinal unity promotes congregational unity.

The apocalypse emphasizes that terrible judgments of God will be poured out upon those who reject His word, and live outside of His revealed and written will. In the apocalyptic narrative, the Lord also stressed the importance of what John the writer was shown to be "the everlasting gospel" (Rev 14:6, 7). The word "everlasting" (from the

\footnotetext{
${ }^{31}$ Ellen G. White, Testimonies to Ministers and Gospel Workers (1923; repr., Mountain View, CA: Pacific Press, 1962), 110.
} 
Greek $\alpha i \omega$ vios) is used only here in Scripture in connection with the gospel. There is only one gospel, and it will continue as long as time exists. ${ }^{32}$

\section{Disregard for Protocol Causes Conflict}

The matter of protocol in handling the affairs of the church is an important subject. I have seen many conflicts occur as a result of disregard for established protocol. God is a God of order (1 Cor 14:33) and requires system and order in the church.

Without organization and intelligent procedures for handling the things of the gospel, utter chaos would reign. It must be recognized that the Bible does not provide specific procedures for doing most church functions of administration and ministry today. What it provides are mostly broad principles that must be developed and applied to the contemporary context. This is a good thing, seeing that as times change, the method of doing many things in life also change. Doctrines are developed from the unchanging Word of God, but unlike doctrines, the methods of delivering the doctrinal message of the Bible are subject to constant review and updating.

McSwain and Treadwell make a good argument when they talk about the importance of how a church is organized, with respect to the impact the structure will have on the potential of the church to fall into conflict. This is mainly due to the ease with which the structure allows effective communication to take place.

Some structures contribute more to competition between departments or ministries than to communication. In addition, an emphasis on structure that is not

\footnotetext{
32“"Everlasting Gospel," SDA Bible Commentary, 7:827.
} 
balanced by adequate and clearly thought out and agreed-upon processes is prone to

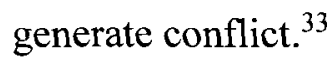

One common example of McSwain and Treadwell's assertion is the working relationship between the pastor and elders of the church. I have found from years of observation that unless a written ministry description is agreed to and distributed to each elder, there will be more frequent incidents of conflict. Even though the Bible lets the church know about the office of elder, in general, and even though the SDA Elders Handbook provides more information about specific duties, the fact is that neither source of information speaks specifically to an elder concerning his or her specific ministry in the local church. In my pastorate, for example, I assign the elders to specific ministry functions based on two factors: (1) the spiritual gifts of the elder and (2) the specific needs of the church for that year, based on our ministry vision and plans.

On a few occasions over the course of my ministry, elders have departed from or disregarded the agreed-upon protocol, and sure enough, major conflict either occurred or came close to happening. In another case, a ministry leader violated the clearly articulated protocol of not asking anyone to be a guest speaker at the church, for any reason, until and unless I had approved such a move. On three occasions within two months prior to the breach, I had re-iterated the protocol in the board meetings. Nonetheless, the member decided to defy my authority, disregard the established protocol, and invited someone to speak for divine service on a certain Sabbath, without my prior knowledge or approval.

\footnotetext{
${ }^{33}$ Larry McSwain and William Treadwell Jr., Conflict Ministry in the Church (Hagerstown, MD: Review and Herald Graphics, 1997), 25-26.
} 
As if that was not bad enough, the member then sent an e-mail to the entire congregation announcing that such and such a person would be the guest speaker for that ministry's special day. I found out about it at the same time and I the same way as did all the members of the church-through the e-mail.

A conflict ensued with that member as I informed the intended "speaker" that he was not authorized to speak in the church that I was responsible for. The intended speaker was also a pastor, and should have seen to it that protocol was followed. He knew better than to accept a speaking invitation from a lay member of a church where a pastor has been assigned by the governing conference. This was an unnecessary conflict that the church was caused to endure by a reckless and disrespectful member. There were some family members of hers who sided with her, based on their view that I should not have cancelled the "speaker," in spite of her blatant disregard for my responsibility to the congregation to protect them from situations like this, which could result in dangerous people gaining access to the pulpit and could potentially teach erroneous doctrines.

Such was the case with Moses and the blatant disregard for God's protocol regarding the offering of sacrifices on the altar. In the story (see Lev 9:22-10:7), Nadab and Abihu, Moses' own nephews; two of the sons of Aaron, foolishly offered unauthorized fire before the Lord, thinking that God would accept their folly. Instead, God sent a fire from above and consumed them before all Israel for their presumptuous sin. Bible parallels of the disregard for protocol, such as told in this narrative, show God's serious insistence concerning order and decency among His people: Those who have the privilege of leading out in any aspect of God's work must take these admonitions seriously. Other examples of the importance of following protocol in holy 
things include the transporting of the Ark of the Covenant on a cart, and God's subsequent immediate, decisive judgment upon Uzzah (2 Sam 6:1-13) who dared to violate God's well-known rule of respect for the things of God.

\section{Mishandling of Disagreements and Misunderstandings}

A theology of conflict must necessarily include the appropriately sweeping biblical principle which states that "whether therefore you eat or drink, or whatever you do, do all to the glory of God" (1 Cor 10:31). While personal disagreements are normal and even healthy, this text admonishes us to glorify God in all things, which would include how to handle disputes and disagreements. Lucifer sought to diminish God's glory and envied His power. The consequences of Satan's covetousness serve as important lessons for God's people. The apostle says, "But you are a chosen generation, a royal priesthood, a holy nation, His own special people, that you may proclaim the praises of Him who called you out of darkness into His marvelous light" (1 Pet 2:9, 10). It should be noted here that the admonition is to do the opposite of what Lucifer did in heaven. God's glory is why He is worshipped.

Whatever humankind does, whether in eating or drinking, or whatever we do, has a bearing on the glory that is due to God. God should be glorified even when His people have disagreements. Unfortunately, in too many cases of disagreement; He is not glorified. Disagreements are mishandled and deteriorate into fighting or in-fighting among the people of God. This in-fighting causes a state of damaging conflict to prevail in the church. Ricki Lee Brooks advances the view that "the answer then for differences is not fighting. Neither is it to cover them or hide them. Rather, differences should be 
mutually worked out until a sound resolution is found." 34 This mishandling is often characterized by accusing and counter-accusing, as well as the increased circulation of negative information about opposing parties. The object of glorifying God must therefore be included in how we relate to conflict.

The apostle Paul appears to have had special cause to plead with the members of the church at Ephesus concerning their interpersonal relationships, and dealing with misunderstandings and conflict appropriately. His plea serves as biblical recognition that church members will sometimes be angry because of relational breakdowns; however, the following text admonishes persons in disputes and conflict to deal with their differences and misunderstandings in a manner that honors God. Paul makes this case well:

Therefore, putting away lying, "Let each one of you speak truth with his neighbor," for we are members of one another. "Be angry, and do not sin": do not let the sun go down on your wrath, nor give place to the devil. Let him who stole steal no longer, but rather let him labor, working with his hands what is good, that he may have something to give him who has need. Let no corrupt word proceed out of your mouth, but what is good for necessary edification, that it may impart grace to the hearers. And do not grieve the Holy Spirit of God, by whom you were sealed for the day of redemption. Let all bitterness, wrath, anger, clamor, and evil speaking be put away from you, with all malice. And be kind to one another, tenderhearted, forgiving one another, even as God in Christ forgave you (Eph 4:25-32).

In the expression of anger during conflict or disputes, people sometimes sin. Sin may be expressed by being untruthful; hence the text admonishes conflicted parties to speak the truth. Conflicted persons may become resentful as a result of anger; therefore the text calls for speaking not only the truth, but doing so in love. There is also the danger of the offender being unrepentant or the offended being unforgiving. Paul cautions readers to avoid prolonging their anger toward others. Prolonged anger easily becomes

\footnotetext{
${ }^{34}$ Ricki Lee Brooks, Let's Stop the Fighting: A Biblical Approach for Working Out Our Differences (Silverdale, WA: Sound Communication, 2012), 36-37.
} 
wrath. Paul urges the speedy resolution of disputes. His use of the expression "do not let the sun go down" is perhaps more of an exhortation to quickly settle differences, rather than a concern for the time of day that settlement is achieved. Surely, anger arising from serious difference or dispute can occur after the sun has already gone down.

In the text, the terms "be angry" and "sin not" are in the imperative mood. They are commands. This appears inconsistent at first glance; therefore, a closer examination of the text is warranted. A commentary on the text offers that various suggestions have been made in an attempt to avoid the implication of a command to be angry, none of them satisfactory. The simplest solution seems to be to regard the anger here spoken of as a righteous indignation. A Christian who is not aroused to the point of indignation by manifest wrongs and injustices may be insensitive to some things that ought to concern him. Righteous indignation has a most important function in stimulating men in the battle against evil. Jesus was not angered by any personal affront, but by hypocritical challenges to God and injustices done to others. ... Justifiable anger is directed against the wrong act without animosity toward the wrongdoer. To be able to achieve the two is a supremely great Christian achievement. ... A warning is issued lest justifiable anger lead to feelings of personal resentment, vindictiveness, and loss of control. ${ }^{35}$

This is a plausible explanation of the text, given the imperative mood of the elements involved. It is apparent that Paul was by no means advocating interpersonal animosity or the bitterness which typically characterizes congregational conflict. In fact, one may infer from the text that it is desirable for Christians to be righteously vexed about damaging conflict or other threats that negatively affect the church.

Jesus clearly expressed how His followers should address issues and conflicts with one another (Matt 18:15; Luke 17:3,4). The text indicates Christ's will, in that interpersonal disputes and conflict should be settled in the one-to-one forum where conversation, confession, and conclusion of the difference or hurt best occurs. A broader

\footnotetext{
35"Be angry" and "Sin not," SDA Bible Commentary, 6:1027.
} 
view of the responsibility of both the offender and the offended in conflict is discussed later.

\section{The Appeal of Jesus for Oneness in Congregational Relationships}

Jesus was passionate about the unity of the church when He was on earth. He is just as passionate about the unity of the church today while He intercedes for His people in the heavenly courts. He declared that by showing love to one another, the church would establish and maintain its authenticity as His true followers (John 13:34, 35). Jesus later prayed for His followers to be one, so the world would believe in Him. ${ }^{36}$ Sande argues that unity is an essential part of Christian witness that essentially makes Jesus look good in the eyes of unbelievers when they see His peace operating in the hearts of His followers. A peaceful church is a powerful witness. ${ }^{37}$

Through His servants, Jesus makes many appeals to His followers to live in harmonious relationship with one another. This is a recurring theme throughout the New Testament. On the contrary, I have read several works in which the writers argue that conflict is necessary. Some have proposed that some conflict is good for the church. I will examine some of these positions later in this paper, but suffice it to say that based upon what I have read and studied in the teachings of Scripture, I must stoutly disagree with those learned writers.

Conflict is a direct consequence of sin. Disharmony and stress are major manifestations of conflict. That being true, one can reason that it would not be God's will

${ }^{36}$ Brooks, Let's Stop the Fighting, 13-14.

${ }^{37}$ Ken Sande, The Peace Maker: A Biblical Guide to Resolving Personal Conflict (Grand Rapids, MI: Baker Books, 2004), 47-50. 
for there to be conflict in the church. It is my view that disagreements and even misunderstandings are inevitable, but I do not accept the view that these are the same as conflict. Misunderstanding and disagreement, if handled properly, need not become conflict. It appears somewhat inconsistent to me that some conflict would be necessary in a congregation, while Scripture teaches plainly that God is not the author of confusion and division. It is probably more accurate to say that because of the condition of the human heart, there will be conflict in the church. I hold that disagreements are inevitable, but conflict is a choice. Jesus prayed that His followers would be united and loving, and that the unity and peace in the church would be the most powerful witness to unbelievers.

\section{Conclusion}

A biblical understanding of what causes and constitutes conflict, as well as a biblical understanding of how God wants His people to resolve conflict is essential to the peace and prosperity of the Church. Theologically speaking, the majority of conflicts in churches are caused by too much emphasis on self. The biblical commands and instruction on how to address conflict are in some ways uncomfortable for all human beings, but are also not optional if God's will is to be done, especially among those who are Christians. Biblical living is the call of the Church. Godly relationships rightly represent Christ. 


\section{CHAPTER III}

\section{LITERATURE RELATING TO CONFLICT RESOLUTION}

\section{Introduction}

I came to this study with some pre-conceptions that have been challenged by several writers, and some pre-conceptions that have likewise been substantiated by others. The literature on conflict resolution in churches is vast. There are many perspectives on the various facets of cause, consequence, and conclusion of conflict throughout the field of conflict resolution study. For the purpose of this literature review, I surveyed authors, spanning up to ten years, while seeking to keep my main focus on the body of literature published within last five years. However, I found that the more contemporary writers all seem to give homage to a few contributors to the field who go back perhaps thirty to forty years. These are considered to be "fathers" of the conflict ministry field of study. I will signify these whenever they are first referenced here.

Upon reading from the enormously diverse perspectives of peers in this field, I settled on six basic themes that may form the basis of a coherent conversation on the process of conflict ministry in the local church. ${ }^{1}$ These six themes are by no means exhaustive, but are intended here to serve as a basic platform for a wider conversation.

\footnotetext{
I "Conflict ministry is the multiple actions of a person seeking to apply the Christian principles of forgiveness, love, and reconciliation to conflict in such a way that Christian growth results for the persons involved. It is a constellation of steps one takes in the face of conflict. Its ultimate objective is reconciliation in Jesus Christ for all of the parties to the conflict (McSwain and Treadwell Jr., 19.).
} 
For the most part, the many works appear to contain these basic components to which I have limited this literature review: (1) characterizations of conflict, (2) causes of conflict, (3) common Christian conceptions of conflict, (4) consequences of catastrophic congregational conflict, (5) capitalizing on constructive changes created by conflict, and (6) correctly concluding conflict.

\section{Characterizations of Conflict}

There are many characterizations or definitions of conflict in the literature that speaks to the field of conflict ministry. What appears consistent in the literature is that there is no certain or conclusive agreement concerning what conflict is. In other words, there are conflicting views of what constitutes conflict. Some of these characterizations of conflict include: Bullard, who holds that "simply defined, conflict is the struggle of two objects seeking to occupy the same space at the same time." ${ }^{\prime 2}$ Poirier argues that rather than being intrusions into ministry, conflicts are instead "assignments from Godthe very means by which he causes us to see our poverty and the riches of his wisdom, power, justice, and mercy." 3 Stagner refers to conflict as "a situation in which two or more human beings desire goals which they perceive as being attainable by one or the other but not by both." ${ }^{\prime 4}$ Speed B. Leas reasoned that the inability of getting a definitive grasp on what constitutes conflict may be found in the fact that "we use one word2008), 10 .

${ }^{2}$ George W. Bullard Jr., Every Congregation Needs a Little Conflict (St. Louis, MO: Chalice Press,

${ }^{3}$ Alfred Poirier, The Peace Making Pastor: A Biblical Guide to Resolving Church Conflict (Grand Rapids, MI: Baker Books, 2006), 14.

${ }^{4}$ Ross Stagner, comp., "The Dimensions of Human Conflict" (Detroit, MI: Wayne State University Press, 1967), 136, quoted in McSwain and Treadwell, Conflict Ministry in the Church, 17. 
conflict-to describe many different experiences and situations, but each of the experiences so named are not all the same."

I happen to agree with Leas, in that the term conflict is probably too loosely used. It is my view that some normal disagreements are unnecessarily referred to as conflict, and that some major conflicts are minimized and referred to as normal or. even healthy conflict. Clearly then, there may be an opportunity here for more intentional work to seek an industry-wide consensus on what constitutes conflict. I view this as an important factor in seeking to develop more consistent approaches to conflict resolution. Currently, the literature in the field of conflict resolution appears to be struggling with of one of the main problems with conflict-the lack of consensus on a working definition of conflict.

Other contributors' characterizations of conflict include: Sande, who views conflict as "a difference in opinion or purpose that frustrates someone's goals or desires. $"$ Van Yperen holds that "church conflict is always theological, never merely inter-personal ... is always about leadership, character, and community." Mayer makes a good point, when he posits that "conflict emerges and is experienced along cognitive (perceptive), emotional (feeling), and behavioral (action) dimensions." ${ }^{\prime 8}$ This characterization appears more complete than the usual focus on behavior only, rendering the issues rather limited. This limitation would undoubtedly also limit the range of

\footnotetext{
${ }^{5}$ Speed B. Leas, introduction to Conflict Management in Congregations, edited by David B. Lott (Herndon, VA: The Alban Institute, 2001), 4.

${ }^{6}$ Sande, The Peace Maker, 29.

${ }^{7}$ Van Yperen, Making Peace, 24.

${ }^{8}$ Bernard Mayer, The Dynamics of Conflict: A Guide to Engagement and Intervention (San Francisco: Jossey-Bass, 2012), 4.
} 
optional approaches utilized, in order to intervene successfully. Ramsbotham, Woodhouse, and Miall view conflict as "the pursuit of incompatible goals by different groups." This is an example of over-simplification, from my perspective. I have seen how this view in and of itself has sparked conflict. This rather loose characterization does not take into account the right of people to freely express differing viewpoints, without being accused of harm to others. It seems to me that incompatible goals, in and of themselves, should not be seen as conflict. However, poor handling of those differences can become conflicted.

This, again, is an area where more work could be done in the conflict ministry field to come to consensus on the meaning of conflict. Perhaps a good illustration of this concern can be seen in what Lederach points out in his work on conflict transformation. On a visit to Central America in the 1980 s, he found that the term "conflict resolution" was viewed with suspicion by the natives, who during those times of socio-political unrest across the region, perceived the term as an attempt to stifle genuine disagreement and necessary advocacy. They felt that the goal or emphasis of conflict resolution was one way to deny needed changes, in other words, to muzzle them. This caused Lederach to realize that people's perceptions of terminologies, and the meanings attached to them, may be a source of conditions that can indeed escalate conflict. ${ }^{10}$

Certainly, more could be said about the many characterizations or definitions of conflict, but suffice it to say that I have presented a good sampling here of the

\footnotetext{
${ }^{9}$ Oliver Ramsbotham, Tom Woodhouse, and Hugh Miall, Contemporary Conflict Resolution (Malden, MA: Polity Press, 2011), 30.

${ }^{10}$ John Paul Lederach, The Little Book of Conflict Transformation (Intercourse, PA: Good Books, 2003), 3.
} 
complexities involved in agreeing to what congregations are wrestling with-conflict that must first be defined, then acknowledged, and then properly concluded. It is only fitting that having come to the realization that there are many variations of the definition of conflict in the field of conflict resolution theory and practice; I should establish a working definition that would be congruent with this project document. For the purpose of this paper, I offer that conflict is a state of tension or alienation between two or more parties, resulting from malice (desire or action to inflict harm, injury or suffering upon another) or the mishandling of a disagreement. I will now turn attention to what various conflict resolution theorists and experts deem to be the causes of congregational conflict.

\section{Causes of Conflict}

Greenfield argues the case of clergy killers and pathological antagonists as being responsible for the abuse of ministers in many local churches. These are usually people who have some form of personality disorder, or are simply just evil. ${ }^{11}$ This work is perhaps the most self-effacing description of a pastor's journey in ministry that I have ever encountered. To be sure, not all conflict falls into the category of the worst kind of intentional destruction that Greenfield sets forth, but personality disorders are a realistic contributor to conflict in every context of life, and are sometimes not factored into congregational conflict. This may be due to naiveté on the part of church leaders and members, or even due to a typical negative moralizing of necessary action as being "unChristian" for the church to do. There are psychologically challenged people in every aspect of life, including church life, who abuse others. In their work on the effects of

\footnotetext{
${ }^{11}$ Guy Greenfield, The Wounded Minister: Healing From and Preventing Personal Attacks (Grand Rapids, MI: Baker Book House, 2001), 25.
} 
personality disorders in the workplace, Cavaiola and Lavender examine the typical issues caused by individuals who are affected by the various disorders, such as: narcissism, histrionic personality, antisocial personality, borderline personality disorder, obsessive compulsive personality, dependent personality disorder, passive aggressive personality, avoidant personality, schizophrenia, and paranoid personality. I will not go into an examination of these respective disorders, as such scientific analysis is outside the scope of this paper. However, suffice it to say that the astute church leader would benefit greatly from a working knowledge of these issues in order to understand how people respond and react to stress, and be better able to manage conflict or potential conflict situations that may arise. Cavaiola and Lavender define personality disorders as follows:

Personality disorders are long-standing disturbances in personality that usually begin in late adolescence and continue throughout adulthood. They reveal themselves when an individual engages in repetitive patterns of nonproductive interactions with others, which is a manifestation of the impaired aspects of their personality. Personality disorders cause a person to consistently act in disturbing patterns of behavior in both occupational and social relationships ... an individual can have traits of several different types of personality disorders; there really is no one "pure" type. Also, personality-disordered people can have different intensities or severity of their disorder. $^{12}$

Most certainly, whatever affects the workplace, also affects the church. My purpose for including this aspect of the conflict process is not to cast undue negative aspersions upon people affected by these disorders, but rather to heighten awareness of an aspect of conflicted churches that is often overlooked. The conflict minister would be wise to keep this perspective in mind, while recognizing God's power to help those affected by these negative behavior patterns. I would also urge church leaders not to fall

\footnotetext{
${ }^{12}$ Alan A. Cavaiola and Neil J. Lavender, Toxic Coworkers: How to Deal with Dysfunctional People on the Job; Working with Narcissists, Borderlines, Sociopaths, Schizoids, and Others (Oakland, CA: New Harbinger Publications, 2000), 4.
} 
into the temptation of judging people, or pronouncing clinical diagnoses upon others when it is not in the realm of their legal authority or professional expertise to do so. Haugk produced a classic work on one aspect of what Cavaiola and Lavender so ably treated in their work cited above. He deals with the damaging effects of antagonists in the church from the perspective of personality disorders. Again, while the aim of this manuscript is not an exhaustive treatment of the social or psychological science background of my topic, I am of the view that at the minimum, church leaders would greatly benefit from at least a basic working knowledge of personality disorder issues as they relate to conflicts in the church. Haugk states that "antagonists are individuals who, on the basis of nonsubstantive evidence, go out of their way to make insatiable demands, usually attacking the person or performance of others. These attacks are selfish in nature, tearing down rather than building up, and are frequently directed against those in a leadership capacity." 13

Haugk also shows:

Antagonists frequently evidence at least several of five personality characteristics: negative self-concept, narcissism, aggression, rigidity, and authoritarianism. Although these same personality traits occur in "normal" individuals as well, two factors distinguish these characteristics as they appear in antagonists: first, antagonists usually display at least several of them; second, antagonists exhibit them in extreme forms. ${ }^{14}$

Pneuman identifies nine causes of church conflict. These are: (1) differences in beliefs and values; (2) structural ambiguity; (3) congregants' conflicts with the pastor's role and responsibilities; (4) an outdated congregational structure that no longer fits the

\footnotetext{
${ }^{13}$ Kenneth C. Haugk, Antagonists in the Church: How to Identify and Deal with Destructive Conflict (Minneapolis, MN: Augsburg Publishing House, 1988), 59.

${ }^{14}$ Ibid., 60-61.
} 
congregation's size; (5) conflicting clergy and lay leadership styles, in particular, differences between consultative versus authoritarian styles of leadership; (6) the new pastor making changes too quickly; (7) clogged communication channels as conflict escalates; (8) general mismanagement of conflict by church members; and (9) disaffected members hold back participation and pledges. ${ }^{15}$

While Pneuman makes a compelling case for the causes of conflict, there is yet one of his causes that I suggest needs modifying. The sixth cause he gives is not without debate, as it is common knowledge that there will be some church members who will oppose change, no matter how or when it is implemented. I concur that changes that are done too quickly may be a trigger for conflict. However, for some people, change at any time and for any reason is deemed a threat, once they have come to regard that which is being changed as a sacred symbol. In my own pastorates, I have found that no amount of tactful and timely communication, no amount of intentional and careful implementation, will prevent some people from claiming that the change was too sudden, unnecessary, or that they were unaware of the pending change. They will accuse the change agent, usually their pastor, of being inconsiderate, simply because they feel as if they are "losing" something personal in the process.

Sande and Johnson posit that "conflict happens when you are at odds with another person over what you think, want, or do." ${ }^{16}$ Sometimes, Pneuman's sixth cause of conflict is the very essence of what Sande and Johnson claim. They (Sande and Johnson)

\footnotetext{
${ }^{15}$ Roy W. Pneuman, "Nine Common Sources of Conflict in Congregations," in Conflict Management in Congregations, ed. David B. Lott (Herndon, VA: The Alban Institute, 2001), 45-53.

${ }^{16} \mathrm{Ken}$ Sande and Kevin Johnson, Resolving Everyday Conflict (Grand Rapids, MI: Baker Books, 2011), 14.
} 
further explain that other factors also contribute to the start of conflict: God-given diversity; simple misunderstandings; sinful attitudes and desires; and sinful human nature. ${ }^{17}$

Poirier, in his discourse on the heart of conflict, addresses such causes similar to those espoused by Sande and Johnson. Elaborating on Jas 4:1-5:6, he discusses various kinds of desires as primary causes of conflict, and the inter-personal damage they produce in relationships. However, Poirier adds that "the real problem is not simply that we have broken relationship with others. We have broken relationship with God. Our sinful conflicts reveal and reflect our broken relationship with God."18

Van Yperen deals with the root causes of conflict in a most pointed and enlightening manner. He cites cultural issues such as the Western pre-occupation with individual needs, the chronic self-help mentality, the "what's in it for me?" mindset, and consumerism as major problems that undermine the Christo-centric appeal of the gospel. He further shows that structural issues contribute to conflict. By structure, he means the system of the organizational (denomination or local church) structure, and with reference to how these systems impact the decision-making process. Often, the "way" things are done operate as a catalyst for conflict. In this regard, Van Yperen asserts that not all conflict is personal, as indeed, much conflict can be shown to be systemic in nature. This viewpoint therefore represents the need to accurately get to the source of conflict, rather than merely treating the symptoms with well-intentioned remedies that may not speak in a relevant and successful manner to the actual underlying issues.

\footnotetext{
${ }^{17}$ Ibid., 16-19.

${ }^{18}$ Poirier, The Peace Making Pastor, 50-59.
} 
Spiritual issues, such as putting oneself first, failing to confess or repent of sins while claiming to be forgiven, and of failing to be holy through transformation within the context of Christian community, all significantly contribute to the potential for church conflict. The renewed heart is critical for the church to be what God ordained it to be. Van Yperen makes the bold claim that "all church conflict is theological." This speaks to his view that the church has become a theologically faulty, autonomous entity, rather than an entity which operates on the basis of spiritual integrity. In this, he posits the thoughtprovoking view that integrity, from the word "integer" which means whole or complete or something undivided, is the calling of the church; not autonomy, which means self-ruling and independent. ${ }^{19}$

Of particular concern to me is the problem of autonomy. Out of this mindset, flow most of the ills of congregational dysfunction here-to-fore described. I have witnessed first-hand the damaging consequences of autonomous attitudes that inspire some members to develop the belief that "this is our church!" Clearly, this is a cause of serious conflict in many places, given that pastors are then rendered incapable of moving the church forward, if in fact, those with an autonomous viewpoint do not see eye-to-eye with the pastor's direction. The correct theological reality is that the church is God's church, and that all the members together (the integer, the undivided whole) make up the body of Christ, the church. The church belongs to no one but God alone, and is not the property of humans. This theologically bankrupt mindset is a primary source of major church conflict in many places and results in power struggles between laity and clergy.

\footnotetext{
${ }^{19}$ Van Yperen, Making Peace, 27-46.
} 
The "this is our church" attitude also obviously fails to take into account the fact that the pastor is also a member of the community of believers. In his contribution to an attempt to better equip the Adventist pastor, Staples answers the question "What is the church?" He gives vital insight into the pastor's role as a member of the church community—one who works to build the community. ${ }^{20}$ Obviously, a faith community or local church that sees their pastor as not belonging to the community, as they would view an outsider, will not be quick to trust or follow their pastor. A biblical understanding of what and who constitutes the church, and what is God's purpose for the church is vital in insuring healthy attitudes and better capability for avoiding preventable conflicts.

A pastor who is viewed as an outsider will be treated like an intruder whenever he or she tries to lead. While it is true that taking time to know the members will alleviate some of the potential distance between pastor and congregation, the simple fact is that there will always be a perhaps small, but significantly influential group who will never readily relinquish their hold on a church. They are driven by the need to hold onto power. The pastors who come to serve will be seen as a threat to their power in "their church." So much more could be said about the causes of church conflict. The main idea however, in this review of contributors to the field of conflict ministry, is to establish that conflict is perhaps not as simple or simplistic as sometimes perceived. Many Christians are weary of conceding the fact of conflict's presence among them, simply because it feels out of place for Christians to be at odds. At the same time though, this denial may provide the context for more conflict, as minor issues are left unresolved, opportunities

\footnotetext{
${ }^{20}$ Russell L. Staples, "The Minister as a Member of the Community," in The Adventist Minister, ed. C. Raymond Holmes and Douglas Kilcher (Berrien Springs, MI: Andrews University Press, 1991), 4552.
} 
for learning how to resolve minor conflict are lost, and minor issues grow into damaging conflict that leads to dysfunction in the church. Of note too, is the reality that there is great complexity surrounding how conflict starts and develops. Nevertheless, the power of the Cross rightly understood and applied to the life of those who have been transformed by the gospel of Christ, is the power behind the ministry of reconciliation.

\section{Common Christian Conceptions of Conflict}

Goertzen, in referencing several studies that indicate the severe lack of conflict management knowledge and expertise, states that "such statistics, alarming as they are, indicate the need for conflict management, but also simply reflect the obvious; the Church in general and Christians in particular are not immune to conflict." ${ }^{21}$ Not only is the church not immune to conflict, but the church is often guilty of accommodating people who cause conflict. Haugk argues that "for too long, congregations have been places where antagonists can operate with success."22 This reality exists because (1) many Christians are instinctively repulsed by the word "conflict" and therefore fail to acknowledge its existence among them; and (2) many Christians are instinctively repulsed by the suggestion of any form of church discipline. At the same time, however, the conflict continues to grow, and even though most members will not personally seek to help to find constructive ways to resolve the matter, they will most often blame church leadership for the fallout that results from inaction.

\footnotetext{
${ }^{21}$ Leroy W. Goertzen, Understanding, Managing \& Redeeming Church Conflict (Lexington, KY: Corban University, 2012), 9-10.

${ }^{22}$ Haugk, Antagonists in the Church, 39.
} 
While most writers accept conflict as present and dominant in churches, the majority of church members appear wary of coming to the same conclusion. It is not uncommon for church members to say that there is "confusion" in the church, but fail to acknowledge the confusion as "conflict," or as the result of conflict. It seems difficult for many to say the word. The reason could be either the lack of a clear definition of what constitutes conflict, or it could be the result of their theological or cultural background.

Perhaps one of the most frustrating realities for church leaders is the challenge of knowing that conflict is working like leaven throughout the congregation, but many members are unwilling or unable to constructively participate in the resolution process, due either to fear, or crippling misconceptions about conflict. Bixby observes that "we may never be able to rid ourselves of conflict altogether, but we can contain it and limit its power." ${ }^{23}$ This sentiment, taken against the backdrop of the many and varied types of problems inherent in church structures, shows the need for intentional education of congregations on conflict ministry and the ministry of reconciliation. Goertzen speaks to the inevitability of church conflict, reasoning that there are theological, sociological, and psychological reasons why this is so. ${ }^{24}$

A young pastor recently said that a more senior minister gave him some "good advice," that "if you love on the people, you won't have any problems with them." Not only was I shocked, I was dismayed. While I am certain that our senior colleague meant well, his advice speaks to one of the conceptions (in this case, misconceptions) people,

\footnotetext{
${ }^{23}$ Douglas J. Bixby, Challenging the Church Monster: From Conflict to Community (Eugene, OR: Wipf and Stock Publishers, 2007), 17.

${ }^{24}$ Goertzen, Understanding, Managing \& Redeeming, 23-40.
} 
even some church leaders, have about conflict. Moses, Nehemiah, and Jesus all dearly loved the people whom they served, but that fact certainly did not exempt them from being attacked, ill-treated, slandered, and hated. Jesus was eventually killed by the very ones he came to save, heal, and forgive. De Ville aptly makes this point in his work. ${ }^{25}$

The general conception of conflict as a negative, bad or un-Christlike reality to be denied or avoided is extremely unhealthy for the church. This is not to say conflict should be welcome. One typical conception of conflict among church members is that all conflict is evil. This may be partly due to the church's emphasis on peace, harmony and love. Conflict, by its very nature, appears to be inconsistent with these Christian ideals.

\section{Consequences of Catastrophic Congregational Conflict}

There are many kinds of damaging results that can accrue from improperly handled conflict in a local church. It is generally understood that the membership experiences severe stress during times of congregational conflict. Congregational stress in times of severe conflict situations often results in fight, flight, or freeze responses by the membership. Where isolated individuals are at odds, they are directly affected, but the church is not necessarily exempt from feeling the consequences of their personal fallout. The church's witness and influence in the community may also be negatively impacted, as knowledge of the internal problems becomes public. One aspect of consequences arising from conflict that is sometimes overlooked, is the impact conflict has on pastors and their families.

${ }^{25}$ Jard De Ville, The Pastor's Handbook of Interpersonal Relationships: Keys to Successful Leadership (Silver Spring, MD: Review and Herald Graphics, 1995), 129-133. 
Bolton writes:

I detest conflict because at best it is disruptive, and at worst it is destructive. Once it erupts, conflict is difficult to control. Destructive controversy has a tendency to expand. Often it becomes detached from its initial causes and may continue after these have become irrelevant or have long been forgotten. Conflict frequently escalates until it consumes all the things and people it touches. ${ }^{26}$

What Bolton here describes is typically what causes the human psyche to activate protective mechanisms to primarily seek an escape from conflict or stress triggered by the threat of conflict. The fear of conflict and its consequences triggers an involuntary physiological reaction commonly known as fight or flight. These commonly recognized adrenaline inspired auto responses serve as a means of survival or escape from perceived threat or danger.

Ursiny concurs with the established view that the fight-flight response is the result of a fear of harm. He explains the role and place of the two responses as follows:

Human beings have a built in fight-or-flight instinct, and many times the wiser person will take the flight option. It is smart to avoid a dangerous area of a city that you have never been to before. It shows wisdom to get out of a physically abusive relationship. ... However, sometimes we have a flight response in reaction to a false perception of harm. In our minds we can exaggerate the emotional harm someone can cause us in a relationship. The more we exaggerate the harm, the more likely it is that we will avoid the conflict. This explains why some people are better able to face conflict with general acquaintances than with loved ones. The more we love and respect someone, the more vulnerable we feel to being emotionally hurt by his or her reaction. On the other hand, facing conflict [fight] is most important to do with those with whom we want intimate relationships. Therefore, we often need to risk getting hurt feelings in order to bring the relationship to a deeper level. ${ }^{27}$

${ }^{26}$ Robert Bolton, People Skills: How to Assert Yourself, Listen to Others, and Resolve Conflict (New York: Simon \& Schuster, 1979), 206-207.

${ }^{27}$ Timothy Ursiny, The Coward's Guide to Conflict: Empowering Solutions for Those Who Would Rather Run Than Fight (Naperville, IL: Sourcebooks, 2003), 27-28. 
The concept of fight-flight was theorized and popularized by physiologist Dr. Walter Bradford Cannon when he published The Wisdom of the Body in $1932 .{ }^{28}$ In recent years, another dimension has been added to the flight-fight concept. It is the freeze effect or freeze response. Neuro-scientists have recently been recognizing and giving more attention to this fear or stress response of the brain. A common illustration of this response is the "deer in the headlight" phenomenon. It is regarded as a response of hopelessness or giving up. Barth explains it this way: "Sometimes our brain, in its frozen state, leads us to a sense of helplessness, hopelessness and/or apathy. 'I can't do anything about it, it's too big for me, might as well just accept it', are all reactions to that frozen brain." 29

This might be a developing conversation to watch in the scientific community, as it somewhat revolutionizes the previously held views about stress responses in the brain. Again, this project document is not primarily concerned with scientific research, per-se, except to the extent that established facts may be able to answer and clarify some of the questions which impact this project.

I decided to explore the outer edges of the flight-fight-freeze concept because of the value it appears to present in understanding some of the consequences of catastrophic church conflict. I proffer that the congregation as a whole reacts in much the same way to catastrophic conflict as do individuals. It is well established in the literature that members June 3, 2013).

28" Walter Bradford Cannon," http://en.wikipedia.org/wiki/Walter_Bradford_Cannon (accessed

${ }^{29}$ F. Dianne Barth, "Off the Couch: Thoughts about the Therapeutic Process, and the Dynamics of Client-therapist Interactions," http://www.psychologytoday.com/blog/the-couch/201210/managinganxiety-in-the-face-real-danger (accessed June 3, 2013). 
either flee or fight during major conflict situations. I will therefore limit any further attention of fight-flight-freeze to the freeze aspect of this stress response.

Congregations sometimes freeze, when a significant portion of the members who have not fled get to the place of perceived hopelessness regarding any recovery from the prevailing conflict. This sense of lethargy and apathy takes over the mood of the congregation and the result is stagnation, which I will refer to as "the comatose state," during which period, if the church is not resuscitated through specialized intervention, may eventually result in death. My analysis of the literature, supported by my personal observations of conflicted churches, is that sometimes the actual issue which sparked the conflict in the first place, is not what brings about comatose or death. It is instead the freezing of the members as a result of despair due to any combination of reasons with respect to their inability or unwillingness to effectively deal with conflict. They lose hope. They neither fight nor flee. They merely exist, and continue to go through the motions of church attendance, with no particular missional or relational purpose in mind.

Another aspect of consequences that might accrue from catastrophic church conflict is the diminished witness and influence of the church in the community. It is no secret that church fights tend to become public knowledge. The evening news has carried stories of local church fights in many towns and cities. People have posted videos of embarrassing church quarrels and physical altercations on popular social sites such as YouTube and Facebook. Newspaper columnists have expressed alarm and even made fun of distasteful behavior by members of local churches in their cities. Given the reality of instant news and the plethora of amateur pseudo-journalists who are armed with mobile phones and video cameras, and not a great deal of regard for the privacy of anyone, 
church conflicts have and will continue to undermine the effectiveness of the church in this generation.

As disgruntled and hurt members flee conflicted churches, they take with them and spread the stories of horror, sometimes with a dose of exaggeration for good measure. To make matters worse, those who leave tend not to tell the whole truth about what happened. They certainly do not tell how they contributed to the conflict. Most church members are ill-equipped or unwilling to properly handle conflict, opting instead to fight, flee, or freeze. Runde and Flanagan identify and describe the five levels of intensity related to conflict situations: level 1 (differences), level 2 (misunderstandings), level 3 (disagreements), level 4 (discord), and level 5 (polarization). It is from level 3-5 that conflict begins to get ugly. These writers note that level 3 (disagreements) "are basically differences with an attitude. ${ }^{30}$ Shawchuck says that destructive conflict is cyclical in nature, generating patterns of conduct in persons and organizations that soon become predictable to the skillful observer. ${ }^{31}$ The reality of cyclical conflict is a good reason for churches to become educated in conflict ministry. Barthel and Edling argue, "For the sake of Christ's reputation in the world, God calls on his people to do all they can to bring a definite end to conflict." ${ }^{\prime 32}$

The cost of congregational conflict to pastors and their families is unimaginable and incalculable. According to Pastoral Care Inc., the number one reason pastors leave

${ }^{30}$ Runde and Flanagan, Becoming a Conflict Competent Leader, 65-80.

${ }^{31}$ Norman Shawchuck, How to Manage Conflict in the Church, vol. 2 of Conflict Interventions \& Resources, 5th ed. (Fargo, ND: Spiritual Growth Resources, 2003), 5.

${ }^{32}$ Tara Klena Barthel and David V. Edling, Redeeming Church Conflicts: Turning Crisis into Compassion and Care (Grand Rapids, MI: Baker Books, 2012), 239. 
the ministry, is that "church people are not willing to go the same direction and goal of the pastor. Pastors believe God wants them to go in one direction but the people are not willing to follow or change. ${ }^{.33}$ In this same survey, the research team found that

$75 \%$ report significant stress-related crisis at least once in their ministry. $90 \%$ of pastors said the ministry was completely different than what they thought it would be like before they entered the ministry. $40 \%$ report serious conflict with a parishioner at least once a month. $50 \%$ of pastors feel so discouraged that they would leave the ministry if they could, but have no other way of making a living. $50 \%$ of the ministers starting out will not last 5 years.

1 out of every 10 ministers will actually retire as a minister in some form. $80 \%$ of pastors' spouses wish their spouse would choose a different profession. Over 1,700 pastors left the ministry every month last year.

Over 1,300 pastors were terminated by the local church each month, many without cause. $^{34}$

The statistics above paint a gloomy picture of the realities of pastoral ministry in America today. Pastors and their families, who give so much at great personal sacrifice, are often abused by those to whom they minister. Susek counseled that "leadership today is potentially lethal to a career. Taking biblically correct action does not guarantee a biblically correct response from the board and/or congregation." ${ }^{\prime 35}$ Susek continues by illustrating how deep-rooted and unsolved conflict in churches often resulted in the congregation being "focused on superficial problems instead" and abusing their pastors, seeing they seem able to find unity in that particular activity. ${ }^{36}$ A quarter of a century ago, Haugk wrote that "recent literature in the area of conflict resolution has begun to

\footnotetext{
33"'Statistics in the Ministry," Pastoral Care Inc., http://www.pastoralcareinc.com/statistics (accessed June 3, 2013). (This reflects 2012 statistics provided by The Fuller Institute, George Barna, and Pastoral Care Inc.)

34"Statistics in the Ministry."

${ }^{35}$ Susek, Firestorm, 142.

${ }^{36}$ Ibid., 143.
} 
recognize that there are individuals who initiate and thrive on unhealthy conflict, persons who have no desire whatsoever to see conflict resolved." ${ }^{37}$ Unfortunately for the pastor, antagonists concentrate their mischief on church leaders, the authority figure in the church. The statistics show that there is a real human toll being paid in broken lives of abused clergy and their families. Pastors' children leave the church in alarming numbers. No longer do the sons of the prophets flock to the schools of the prophets, for they have seen too much. Ministry leads change. Change breeds trouble.

Nelson and Appel wrote that "leaders need to realize that not all of the conflict that the improvement plan can manifest is created by the change itself." 38 This came against the backdrop of the assumption that the conflicts normally surrounding transitions initiated by pastors is always because of something that the pastor did wrong in the change process. The writers show here that oftentimes "people are prone to transfer their anger and frustrations onto moving objects. They attach their baggage to current affairs, even though they may be totally unrelated. ${ }^{339}$

Catastrophic conflict has serious as well as long-term consequences for churches, communities, and also for clergy and their families. Fight-flight-freeze has impacted many churches, leaving a terrible trail of wounded church members. Communities have been denied their right to see the faithful witness of Christ exemplified by the loving, united relationships among professed Christians. Many pastors and their families have

\footnotetext{
${ }^{37}$ Haugk, Antagonists in the Church, 32.

${ }^{38}$ Alan Nelson and Gene Appel, How to Change Your Church Without Killing It (Nashville: Word Publishing, 2000), 231.

${ }^{39}$ Nelson and Appel, How to Change Your Church, 231.
} 
been badly and even permanently damaged by cruel abusers and ill-formed organizational structures that weakened or ruined their ministry.

There is no wonder then, that so many pastors are forced out of the ministry every year, largely because of church members' resistance to the changes they propose. All human beings struggle with change, and all must wrestle with the complex emotions surrounding transitions. From appearances, it appears that most people react to change in negative ways. Unfortunately, in the church, anger and frustration are normally directed against the visible agent and advocate of change- the pastor. The aftermath is often devastating. The human and professional cost in terms of dignity, family well-being, health, and even continuation in ministry is often calamitously ruinous.

Bolton asserts that "conflict is a dangerous opportunity. On an emotional level at least, many of us are more aware of its perils than of its possibilities." ${ }^{.40}$

\section{Capitalizing on Constructive Changes Created by Conflict}

While the general results of major conflict are negative, some good can come out of conflicted situations. At first, and in the heat of emotional battle, positive lessons may not appear possible, but Strauch offers that

it is helpful to keep in mind that there is nothing wrong with Christians disagreeing with one another or passionately defending our beliefs. This is how we learn, how we sharpen and correct our thinking, and how we help others improve. The Holy Spirit often uses the emotional upheaval that accompanies disagreements and conflict to get our attention and drive us to make necessary changes in our families, churches, and personal lives. Conflict can help us to discover our character weaknesses, correct mistaken theological ideas, sharpen our beliefs, refine our plans, grow in wisdom and

${ }^{40}$ Bolton, People Skills, 207. 
life experience, learn to trust God during difficult times, and deepen our prayer lives. ${ }^{41}$

Runde and Flanagan contend,

The most effective leaders are extraordinarily competent at handling conflict ... they respond to conflict constructively. In doing so, they not only keep potentially damaging situations under control, they discover options, solutions, and possibilities previously unseen or unknown. They learn to embrace conflict not as an organizational enemy but as an opportunity for growth and a source of creative energy. ${ }^{42}$

Nelson and Appel agree with the plausibility of positive outcomes from conflict, urging that "how you handle anger and disagreements as a church family is a huge lesson on life and spiritual growth." ${ }^{\prime 3}$ These points made by these various writers are all good principles to keep in mind and to practice. So often, conflict in the church only reaps the negative results. With a more enlightened approach to conflict situations, church leaders and members should be able to seize upon the potential for good that conflict presents.

\section{Correctly Concluding Conflict}

Even though many writers promoted the idea of conflict resolution, it is well to be cautioned that all conflict will not be resolved. McSwain and Treadwell talk of "concluding conflict" 44 in recognition of this reality. Some conflicts will be concluded by one of the conflicted parties leaving the church, or both agreeing to end open hostilities, even though agreement on the issue is never reached and hard feelings may continue to

\footnotetext{
${ }^{4 !}$ Alexander Strauch, If You Bite and Devour One Another: Biblical Principles for Handling Conflict (Littleton, CO: Lewis and Roth Publishers, 2011), 3.

${ }^{42}$ Runde and Flanagan, Becoming a Conflict Competent Leader, 115.

${ }^{43}$ Nelson and Appel, How to Change Your Church, 239.

${ }^{44} \mathrm{McSw}$ ain and Treadwell, Conflict Ministry in the Church, 32-33.
} 
be privately harbored. In order to get the best outcome, Poirier's challenge that "Christian conflict theory must be theologically rooted and ecclesiastically integrated, ${ }^{, 45}$ is critical if conflict is to be correctly or biblically concluded. I hold the view that conflict is prolonged and becomes damaging to the church due to the general lack of willingness on the part of most Christians to obey the biblical protocol for resolving conflict.

One of the most critical aspects of conflict resolution is the responsibility of the offending party, both to the offended and to God. Of this responsibility, Poirier writes, "If we are ever to witness true reconciliation, the peacemaking process must begin with confession. ${ }^{" 46}$ Poirier continues by stressing that in addition to confessing sins to God, the offending parties also confess to one another regarding sinful words, attitudes, and actions. In this exhortation, he specifically shows how a confession should be done, using the "Seven A's of Confession" which include: (1) address everyone involved; (2) avoid if, but, and maybe; (3) admit specifically; (4) accept the consequences; (5) alter your behavior; (6) ask forgiveness; and (7) allow time for the offended party to forgive. ${ }^{47}$ On the last note, Poirier further states,

Assuming the person we are counseling has made a good confession of sin, it remains incumbent upon us as peacemaking pastors to help the one confessing a sin to distinguish the difference between God's immediate response to a confession made and the various reasons why the one who has been offended may be slow to respond. ${ }^{48}$

\footnotetext{
${ }^{45}$ Poirier, The Peace Making Pastor, 13.

${ }^{46}$ Ibid., 113.

${ }^{47}$ Ibid., 118-131.

${ }^{48}$ Ibid., 129.
} 
Poirier additionally explains, "If I confess my sin to a brother, I cannot and should not be the one who demands he forgive me. Before God, it is my responsibility to confess my sin, while it is his responsibility to forgive." ${ }^{49}$ I have seen many make this very mistake, resulting in worsened conflict when the offender has "confessed" their sin against the offended, and then started a campaign of demanding forgiveness. This is usually done by telling others or by telling the offended party how unforgiving they are. It is a guilt trip designed to pacify the guilty conscience of an offender who has not truly confessed or repented. This is an attempt to control the emotions of the hurt party, and it results in greater emotional harm and anger, further alienating the offended person.

Even though Matt 18:15-20 is clearly the will of God as articulated by Jesus, it is also true that people find it hard to come to a solution to their particular conflict or challenge. This is "because we are fallen people who do not always think alike, and sometimes we do not know how to come to resolution." 50

As we reflect on and rejoice in the gospel of Christ ... we can let go of our illusion of self-righteousness, honestly examine ourselves, and find freedom from guilt and sin by admitting our wrongs ... repair any harm we have caused to others and to be reconciled to those we have offended." 51

It takes mutual commitment, in addition to cooperation with all parties to conflict and faithful obedience to the word of God, for true resolution to be achieved among feuding parties. One party cannot successfully conclude conflict. The centrality of the

\footnotetext{
${ }^{49}$ Poirier, The Peace Making Pastor, 130.

${ }^{50}$ Chris Brauns, Unpacking Forgiveness: Biblical Answers for Complex Questions and Deep Wounds (Wheaton, IL: Crossway, 2008), 180.

${ }^{51}$ Sande, The Peace Maker, 117.
} 
Cross is a power for transforming the human heart from a heart of stone to a heart of flesh so that reconciliation is made possible.

\section{Conclusion}

The literature on church conflict resolution is vast. This is a testament to the high levels of incidences and intensity of problems in the church. Often, it is assumed by church members that inaction or lack of confrontation will make the issues go away. What I have learned from interfacing with such a wide cross-section of contributors to the field of conflict ministry is that conflict is as real in the church as it is in secular society. Conflict hurts churches, but Christians can learn valuable lessons from the conflict process. 


\section{CHAPTER IV}

\section{IMPLEMENTING THE CLASS ACT SEMINAR SERIES-A PROGRAM FOR CONGREGATIONAL CONFLICT RESOLUTION TRAINING}

\section{Introduction}

In this chapter, I explain the method and procedure of the conflict resolution training series that I presented and implemented at New Life. There are several alternative approaches to conflict resolution training for congregations that have been espoused by various contributors to this field of study. I therefore do not hold the view that my approach is either exclusive or exhaustive. However, it is my belief that the comprehensive approach that I have taken to dealing with the ever-present challenge of congregational conflict is one that opens up a broader view of underlying factors that must be addressed in congregational conflict resolution.

The concept of my intervention and training program was approved by the Executive Committee of the South Atlantic Conference of Seventh-day Adventists and the Board of the New Life Church. I then utilized sermons and seminars to teach and guide the church toward a better understanding of, and acting according to God's plan.

\section{Congregational Conflict Resolution at New Life}

The situation at New Life when I arrived was quite a challenge. I was the seventh pastor in twenty-three years of the church's existence on the day I was installed. Upon my arrival, and shortly thereafter when I had gotten an opportunity to talk with members 
and colleagues familiar with the church, I discovered that New Life had been a troubled church for many years. According to one pastor, "that church was born out of conflict."

I started keeping a ministry journal when I was transferred to Warner Robins. As I looked back over some of what I wrote in my journal two years into my tenure at New Life, this popped out at me:

The New Life Church has been a challenge [for me] from day one. It reminds me of Philadelphia, only several times more difficult. At Philadelphia, while there were issues and very difficult times, I never felt hated by any member. Here, it is different. Outright hatred has been manifested in what some of the people have been willing to do and say in their cause to make life as hard and unpleasant for me as they can, hoping perhaps, that I'will give up and leave. That's one thing they forgot to tell the people when I was assigned here-I don't quit! If I did, so many wonderful things perhaps would not have been accomplished in other places. God taught me well in North Carolina. Those lessons I am determined to contextualize and use here, to His honor and glory, and to the breaking of Satan's long standing stranglehold on the work in this part of the vineyard. ${ }^{1}$

New Life has been a handful for every pastor assigned to this district. Another fact to note is the history of people leaving New Life soon after they start attending, heading off to worship at other area churches. For example, when I arrived as the new pastor in December 2008 and inquired into the small attendance in such a large city, I was informed by several elders and other members that more than thirty people who were at that time living in Warner Robins, actually attended the Bethany church in Macon. ${ }^{2}$

As a result of close observation during my first two years, as well as talking with members and guests who stopped attending, I concluded that people were turned off from

\footnotetext{
${ }^{\prime}$ Everton A. Ennis, New Life Ministry Development Journal: Personal Ministry Notes and Reflection on My Tenure in Warner Robins, GA, journal entry on February 25, 2011, pp. 1, 2. Note: Philadelphia is the name of one of the churches I pastored in North Carolina before coming to Warner Robins. It was a conflicted church, but God transformed that congregation into a united, soul winning church.
}

${ }^{2}$ People would historically leave New Life to attend the Bethany church in Macon, which is the largest city in middle Georgia, and is approximately thirty minutes north of Warner Robins. 
New Life due to: (1) the much-vaunted lack of respect for pastors by certain dominant members, (2) the wanton irreverence displayed by some of the youth during the worship services, notably the children of said dominant members, (3) the spiritual coldness of the church, brought on by long-term conflict, and (4) weekly arguments over unscheduled theological issues that tended to derail the adult Sabbath School class discussions.

I also chronicled the complaints of several members and visitors who reported being invited to Sabbath dinner by certain of the dominant members, only to be subjected to uncomfortable, negative, scandalous conversations about me and other supportive members of the church. Several individuals stopped attending New Life because of these negative and divisive experiences. It became clear to me that it was necessary to embark upon a systematic program of teaching the congregation how to properly handle conflict.

\section{Conference Approval}

Before I could proceed with my plan to make New Life the project context for a training program in congregational conflict resolution, permission was needed from the South Atlantic Conference of Seventh-day Adventists. This was to insure that (1) the conference, as the governing authority under which my ministry as a pastor falls, as well as the body that is legally and denominationally responsible for the safeguard of all the churches in the conference territory, was both aware and in support of my plans; (2) the legal and ethical requirements of Andrews University may be met, as it pertains to institutional consent to conduct research; and (3) the New Life church would be assured that my plans were part of a larger conversation, with implications for improved congregational relationships beyond the New Life church family.

On April 26, 2011, the conference executive committee approved my request to 
do my research and focus my project at the New Life church. This action paved the way for me to formally request the approval of the church board.

\section{Church Board Approval}

The church board met on April 27, 2011 to decide upon my request to conduct the training program at New Life. The approval letter from the conference was presented. The board voted to approve the training program, and authorized my request to solicit for volunteers to participate in the focus group process to gather relevant feedback. A copy of the approval letter from the board can be found in Appendix B.

\section{A Comprehensive, Multi-faceted Approach to Conflict Training}

One of the important realizations I came to during my survey of literature on conflict resolution is the connection between conflicts in various arenas of a person's life. The conflicts which erupt at church are probably not due solely to things that happen at church. Workplace conflict may indeed be connected to conflict at home. Church conflict may be connected to the residual effects of workplace conflict or family conflict.

Given these realizations, I endeavored in my conflict resolution training program to address the conflicts that occur in these various settings, with the intent of showing how individuals can carry the hurt and emotions from one setting to another, thereby causing conflict to occur wherever they are. A comprehensive, multi-faceted approach was therefore developed as part of the training program. This included teaching the congregation the following: how to resolve family conflicts; how to navigate workplace conflict; how welcoming the Sabbath properly can contribute to conflict resolution at home and prevent conflicts at church; the power of loving relationships as a factor in discipleship and church growth; and how to heal from the wounds of conflict, as well as 
how to heal the wounds of others who hurt. These themes were presented in the form of six seminars and sermons from November 30, 2011 to February 25, 2012.

The presentations will be described later in this project manuscript. However, I will first describe the various approaches that I employed in dealing with the conflicted New Life church, both prior to and during the seminar series.

\section{Personal Interviews with Parties to Conflict}

One of the main recurring behaviors that I observed during my first year at New Life was the high incidence of members who came to me to complain about other members, in particular, about some hurt or disagreement they personally experienced as a result of conflict with the other person, or the expression of consternation or disgust they felt toward the other person because of some attitude or behavior displayed by the other person, be it personal or non-personal with the individual who complained to me. Several individuals would do this more than once concerning either a specific person, or concerning more than one person for whom they felt a measure of disdain and disgust.

In each of these informal interviews, I would inquire whether the one complaining to me had gone privately and in a Christ-like manner to the alleged offending party to seek resolution of the matters described. The overwhelming majority of plaintiffs admitted that they had not gone to the accused on a one-to-one basis. These conversations were somewhat uncomfortable on my part, partly because New Life was not my first pastorate, and I was well aware of the possible fallout of someone going away from a conversation with me to tell others that as pastor, I had agreed with their representation of the problem.

It was not uncommon that the very individuals who would seek to communicate 
their concerns about conflict events which occurred before I was installed as pastor would be seen happily talking with the people they had spoken to me about just moments earlier. In some cases, I observed people who had privately complained to me about one another, happily interacting with the party they had complained to me about. All of this gave me cause to wonder about the sincerity quotient of the church.

One of the first series of interviews I conducted upon my arrival as the new pastor was with the elders. There were four elders of the church, but no head elder. The church election was conducted that September and October before I arrived in December 2008. It appeared strange to me that there was no head elder, so I inquired of the group of elders at our first meeting as to the reason there was no head elder. There was silence in the room. Later that evening, I called the elders individually to inquire again. Three of the four elders told me about the divisive theological views of the fourth elder, and how my pastoral predecessors had met with him to express their concerns and the concerns of the congregation, but to no avail. He had defiantly insisted on pushing his own opinions in the Sabbath School, habitually taking issue with the Sabbath School lesson, and was determined to preach un-Adventist doctrines. The elders who spoke with me individually had told the previous pastor of their decision to not serve as elders again, if the defiant brother was re-elected. The disagreeable brother was not re-elected during the regular election process. The three elders consented to serve again. However, the offending brother was unexpectedly elected at the final business meeting conducted by the outgoing pastor, having been nominated from the floor by his supporters, without the benefit of the nominating committee or the church board recommending his name. Understandably, this unsanctioned procedure angered the other serving elders. 
As pastor, I saw that I could oftentimes get more information from members by having personal interviews with them, as they were quite unwilling to address their concerns in the presence of their fellow members, especially those they had issues with. Whenever members complained to me about one another, I dutifully asked them if they had gone to their brother or sister, in a Christ-like manner, to seek one-to-one resolution of the issue. The answer was almost always "no."

\section{Modeling the Principles of Biblical Conflict Resolution}

In addition to being the preacher and other important things to the members, my role includes modeling how to conflict biblically. New Life had had six pastors in their first twenty-three years, prior to my installation. At the time of completing the writing of this manuscript (October 2013), I would have been the pastor for just under five years (December 2013). My two immediate predecessors were transferred in just under four years each. It appears that New Life has not been as forcefully challenged and held accountable in the area of biblical conflict resolution as over the past five years.

A majority of the members appeared to be unfamiliar and uncomfortable with the level of accountability I brought to bear upon the church. I had insisted that all members and I must take personal responsibility for our attitudes, actions, and words, especially in the meetings of the church, where I had observed that most breakdowns in respect tended to occur. It was disheartening to realize that there was a long-standing culture of hurting one another, with hardly any apologies for wrongs done. On several occasions, I personally met with individuals in an effort to address and settle problems that were publicly evident, most times with no success in securing their cooperation in handling their issues in a more productive manner. On at least three occasions, a certain member 
circulated slanderous emails about me in an effort to misrepresent my leadership of the church. On several occasions, I met with another member to discuss his habit of arguing with the Sabbath School teacher, debating against just about every lesson almost every Sabbath, including arguing against doctrines that were not part of the week's lesson.

By the same token, I publicly and regularly invited members to come to me about any issues they were having regarding me as a person or as the leader of the church. I urged them to also go to one another in a Christ-like manner to address their concerns. These pleas were hardly ever honored. People preferred to complain to someone else about the person they were upset with, rather than speak directly with the individual.

Some members resisted my emphasis on personal responsibility for their behavior, and refused to submit to the Bible's admonitions regarding congregational unity, or to the order and discipline of the church. In several cases, the church board was called upon to send letters of notice to cease and desist from certain unbecoming actions on the part of members who appeared to feel entitled to behave in un-Christlike ways toward church leadership and other members. The more antagonistic members gradually departed for other area and far-away churches when it became clear with the passing of time that I was unflinching in my resolve to transition New Life from a plateaued, relationally dysfunctional congregation to being a healthy, missional church.

\section{Sermon and Seminar Series on Conflict Resolution}

I implemented the training program in November of 2011. Sermons and seminars were used to present the material to the church. While I was presenting, the members followed along with the handout of the material which I supplied. They were able to make notes in the space provided. The handouts were the exact copy of my PowerPoint 
presentation of each seminar. Members who were not a part of the focus group were also given the handouts, in order that they would also benefit from following along while I presented. Members were allowed to keep their hand-outs.

\section{Utilization of the Focus Group Method of Feedback}

As approved by the church board, I advertised with fliers on the church bulletin board and in the church bulletin for volunteers over the age of eighteen to assist me with my research using the focus group method. A copy of the solicitation flier may be found in Appendix B. I also sent emails and text messages to the members of the congregation to solicit their participation and help. Several people signed up to assist me. A copy of the solicitation email may be found in Appendix B. There was no monetary compensation for their help. On some occasions, I provided dinner after the Sabbath service for the focus group volunteers. We ate together and discussed their feedback. On the other Sabbaths, we had potluck dinner after worship. It was not necessary for me to provide a meal.

More details of the results and outcomes of the seminars and the focus groups are recorded in chapter 5 of this project document. The old adage that says "the same sun that melts butter, also hardens clay" is one that applies to just about any exposition of the Word of God. People are naturally resistant to change, especially personal character change, unless they are being led by the Holy Spirit. While the exposure to biblical protocols for conflict resolution was transformative for most of the members, there were those who were clearly more carnally hardened by what they heard. Some saw the series on conflict resolution as an attempt to stifle freedom of expression, or to show them up.

Some members who were known to be openly antagonistic toward my leadership chose to be absent whenever the conflict resolution sermons and seminars were being 
presented. Those who took this leave of absence were noticeably the primary sources of conflict in the church. This view is confirmed by the fact that since several of the key antagonists have removed themselves from New Life the long-standing atmosphere of tension, rude conduct, open rebellion, and drama no longer characterize the church. Also noticeable, was the fact that the members who consistently attended the seminars grew in their boldness to effectively engage the conflict resolution process. As a direct result of this increased boldness, the church board became more vigilant in holding persons accountable for unruly and divisive conduct. Those who remained at New Life now accept that it is their collective responsibility to make the church a safe place where people can have an encounter with God, instead of being a place where worshipers are constantly subjected to disruptive, divisive, and un-Christlike conduct by unruly people.

One example of this is when the church board voted a "Letter of Notice to Cease and Desist," and distributed the letter among the congregation in order to curtail the divisive activities of a certain woman and her family who had made a project of disseminating slanderous, personal attacks against me via emails to the members of the church. She also circulated these emails among members of other congregations and visitors to the church. This particular family was previously thought to be untouchable, and one of the "leading" families at New Life.

When I arrived as pastor, I quickly observed that this woman, the matriarch of the family, ran everybody scared. This included most of the men of the church. She soon tried to usurp my pastoral authority and openly and covertly expressed contempt for me. Twice she refused my request to meet so we could resolve issues affecting our personal and working relationship. Her defiance was supported by her husband, who added fuel to 
the fire by insulting me when I met with him in an effort to solicit his assistance in resolving the increasingly damaging conflict between his wife and me. The congregation had begun to suffer from the obvious tension between us. Members started taking sides. The church quickly became polarized between those who wanted to do the right thing and give deference to the duly assigned pastor of the church, and those who felt compelled to remain loyal to a long-standing and strong-willed member, even though she was clearly insubordinate and had a history of negative behavior at New Life. Through my principled stance, and the effect of a sermon series on church unity, more members began to realize that New Life was God's church and not the personal domain of any individual or family.

The church board demanded an end of hostilities toward the leadership of the church, specifically the transmitting of divisive and slanderous emails about the pastor. The letter stated that failure of any member to yield to the admonition of the church board with immediate effect would be cause to initiate disciplinary action. This letter came as a shock to some who thought they could continue to get away with attempts to control the church, and with open rebellion against pastors, as they had done for so long. Several of the guilty individuals almost immediately stopped attending church at New Life. Since the church board voted and distributed the letter, there has not been another attack email send out in an attempt to undermine my leadership or discredit me, up to and including the time of completion of this project manuscript.

It is important to note that the idea for this letter was not originated, instigated, or initiated by me, the pastor. For the church board at New Life to take the initiative for such a letter was a major development, given the once perceived "indispensable" status of the individuals concerned. The perpetrators of this assault against me and the members 
who stood with me never believed the church would ever take a stand against their disruptive behavior. My emphasis on congregational conflict resolution and unity paid off by helping to settle the church in terms of focusing on building meaningful relationships and looking beyond the congregation to ministering to the people in our community.

\section{The CLASS Act Conflict Resolution Seminar Series}

The training seminars were presented over the course of three months, from November 2011 to February 2012. Prior to that, on October 15, 2011, I preached a sermon entitled "The Dangers of Judging" as a precursor to the conflict resolution series. The five conflict resolution seminars were presented on November 30, 2011; December 31, 2011; January 14, 2012; January 28, 2012; and February 25, 2012. The various seminars are outlined in Appendix A of this project document.

\section{Conclusion}

The development and presentation of the conflict resolution seminar series was quite helpful to me as a pastor. The process opened up several aspects of conflict ministry that I had not previously thought of or engaged. For example, the focus on workplace conflict as a factor in how people behave at church became quite fascinating. In my survey of conflict literature, I did not observe any contributor making a study of this aspect of conflict ministry. This is certainly an area that I may well delve into in a deeper manner at some time in the future as part of my consulting service of ministering to churches dealing with damaging conflict.

In addition to the benefits of the training program to the New Life congregation, I personally benefited in that I learned more about my own conflict responses. The literature review and the writing of the training series challenged me to examine my own 
involvement in past conflicts, and I was certainly able to see where I could perhaps have done some things differently. Doing things differently does not necessarily guarantee that the eventual outcomes in any or all of my prior conflict experiences would have been different, but at the least, I have been able to see where my own processing and handling of conflict can and has grown exponentially.

Chapter 5 of this document will examine more closely how the conflict resolution training program has benefited New Life. I will record the outcomes of the seminar series from the perspective of the focus groups, and also register my evaluation of their feedback. 


\section{CHAPTER V}

\section{RESEARCH METHODOLOGY, RESULTS AND RECOMMENDATIONS}

\section{Introduction}

My task in this chapter is to synthesize, analyze, and present the responses of members who were involved in the qualitative research process aimed at answering the question of how the seminars presented in the training process have enlightened their knowledge and understanding of conflict, and how their responses to conflict situations have or will be affected as a result. As the research process unfolded, the responses led me to believe that New Life, a conflicted and stagnated congregation for many years, could overcome this state of stagnation through consistent, skillful conflict ministry.

A vital transformative factor was that as pastor, I would undergo specialized training in the rudiments of congregational conflict resolution. I believed that by practicing the principles and acquired skills, then imparting them to the church, the congregation would benefit by experiencing a transition from conflict to peace, and the membership would begin to increase in an environment which was much more suitable for numerical growth. 


\section{Research Methodology}

Cooper and Schindler explain that "Qualitative research is designed to tell the researcher how (process) and why (meaning) things happen as they do." Also, that "Qualitative research aims to achieve an in-depth understanding of a situation..."1

A focus group is a group of people (typically 6 to 10 participants), led by a trained moderator, who meet for 90 minutes to 2 hours. The facilitator or moderator uses group dynamics principles to focus or guide the group in an exchange of ideas, feelings, and experiences on a specific topic... The basic output of the session is a list of ideas and behavioral observations, with recommendations by the moderator. These ideas and observations are often used for later quantitative testing. ${ }^{2}$

There were no survey questionnaires or direct post-seminar engagement of the entire congregation after the presentations, since I made exclusive use of focus groups to acquire feedback. Participation was restricted to members eighteen years old and above, who volunteered to serve on a focus group. I arbitrarily used this age restriction because of the rigorous Institutional Review Board protocols that applied to research involving minors (those under the age of eighteen). It was not within the scope of this paper to necessarily seek data concerning the effect of the project implementation upon minors.

The focus groups were comprised of both men and women, ranging in age from twenty-four to sixty-five. There was also a mixture of cultures: mostly AfricanAmericans, as well as a Haitian and Jamaicans. This mixture of age and cultural diversity provided a cross-section of perspectives that more accurately mirrored the make-up of the congregation. The racial makeup of the membership at New Life is Black, with the exception of one member, a Caucasian female in her late sixties. She did participate in

\footnotetext{
'Donald R. Cooper and Pamela S. Schindler, Business Research Methods, $11^{\text {th }}$ ed. (New York, NY: McGraw-Hill Irwin, 2011), 160.

${ }^{2}$ Ibid., 147.
} 
one group session, but was absent for most of the seminars, and was unable to sit through the other focus group sessions due to a severe, years-long health problem. I did not in any way cause or influence the final make-up of the focus groups. Those who comprised the focus groups all freely volunteered.

The focus groups were also academically and socio-economically diverse. There were retired persons as well as gainfully employed persons. Some were stay-at-home moms, some nurses, there was one physical therapist, a barber, one in active military service, one was in sales, and there was at least one computer technician, as well as persons of other vocations. One member was unemployed at the time we held the sessions. Most focus group members were holders of at least a first degree. Approximately one half of the group was married. Those who were not married had never been married. There were no divorcees at the time of the group sessions.

Focus group sessions were always held on the same day that the seminars were presented. Most times, I provided lunch so we could eat as a group, or if the seminar happened to fall on the same day as the church potluck I did not need to provide lunch. Even though the Informed Consent Form states that "my responses will be recorded electronically, as well as in hand written or typed notes for later transcription and organization," I did not in fact do any electronic recordings of the sessions. I determined that I would probably get more feedback from the heart than if a recording device was sitting on the table. No focus group participant was paid by either cash or kind for their services. Their participation was entirely voluntary. Focus group sessions had no less than seven participants. There were as many as ten participants on some occasions. 
No part of any statement by any focus group member has been attributed to any specific person, either in this document, or in any other publication or media. In fact, my notes from the group discussions do not have any name attached or ascribed to any particular focus group contributor. Total confidentiality has been observed throughout and since the focus group process. All of the notes which were taken by me during the sessions have been carefully preserved and secured in my home. No person other than me has ever seen or read the responses. No statement in my notes has been linked to any person via any personal identifier, including: name, nickname, initials, phone number, social security number, control number, email address, etcetera.

\section{A Qualitative Analysis of the Conflict Resolution Training Program}

In this section, I will report the sentiments of the focus groups in order to demonstrate how the program was received by the church members who attended the implementation process, with corresponding data to show how the group members indicated that their behaviors were and would be impacted as a result. The full outline of all seminars can be found in appendix A. It should be noted that the focus group members did not all participate in every group session, thus the analysis represents the views of a balanced cross-section of the congregation. I have included the start-off questions for each session below, followed by a report of the various ideas and observations generated in the discussions among group members.

After the evaluation of each seminar is presented, I will compile a summary analysis of the sessions, focusing on primary aspects of the sessions such as: (a) seminar presentation and group information, (b) group dynamics and discussion, and (c) my analysis and recommendations arising from the group interview session. 


\section{Analysis of Seminar One}

The group was asked to share what they learned from the presentation entitled "Resolving Family Conflict." Some indicated that the presentation confirmed much of what they had been taught before. One participant asked about the necessity of, and a timeline for cooling down by going for a walk after an argument, or to remove oneself from the scene when an argument is imminent. The group discussed this for a few minutes, concluding that the presentation could have mentioned that walking away was an option when deemed appropriate or necessary. The concern however, was about how this "cooling down" was done, and to insure that it was not used as an escape from dealing with issues. I had not included this in the presentation, since my primary objective was to show participants how to engage and conclude conflict in an active and positive manner, instead of practicing passive withdrawal.

Group members agreed that family relationships also affected relationships at church. The various human relationships are not exclusive or compartmentalized, but are part of one continuous social fabric. All relationships impact upon other relationships in some way, whether consciously or unconsciously, intentionally or unintentionally. Group members were appreciative of the emphasis on family members practicing the "common courtesies" of saying "thank you," "please," "I'm sorry," etc., and treating family members like important people, because they in fact, are. This point generated quite an amount of discussion and seemed to have hit a common nerve.

My explanation on not letting the sun go down on our wrath was enlightening to most group members. They had not heretofore thought of it the way I explained it. My explanation was simply, in that "the sun going down" was not a literal effort to beat the 
clock to resolve conflict, per se, but rather an exhortation to resolve conflict quickly. The context of Paul's statement was an exhortation on forgiveness and being reconciled. I had explained in the presentation that many arguments and conflicts tend to occur after the sun had already gone down! Most people see all family members in the late evening or at night, and it is when people are together that conflict mostly occurs. In that sense, the sun has no relevance to solving the problem. The group was satisfied with the explanation.

The follow-up question sought to uncover what part of the presentation group members strongly agreed or disagreed with, and why. Everyone strongly agreed that conflict is inevitable, but should be concluded appropriately and quickly. Members also agreed with the emphasis on making the effort to prevent avoidable conflict. This was deemed to be just as important as resolving conflict. There was no area of strong disagreement on the content of this seminar. There was however, a recommendation that more extra-biblical source material be used in the presentations, for the benefit of families who do not read or believe in the Bible.

The next question centered on group members' views on how they saw the presentation benefitting our members at home and at church. The consensus was that the presentation contributed to a better understanding of the causes and techniques for handling conflict. While the seminar did not address specific types of conflict, it provided a good foundation for application to various scenarios. One group member opined that "if we start implementing in our homes what we learned in the seminar, and start practicing the common courtesies, it would change the atmosphere in our homes and change how we relate to one another as members of the church." Group consensus indicated that the seminar challenged them to be more pro-active in preventing and resolving conflict. 
When asked if there were any ideas concerning information that I did not present in the seminar, but which they believed would add to the instruction for resolving conflict in the home, one respondent shared the view that outside help or professional counseling for the family members should be included in the seminar as an option. This was a valuable observation, since some families may not be able to resolve the conflict on their own. In fact, I have since added this emphasis to the seminar. Another respondent suggested that the roles of the various family members (husband, wife, and children) in matters of family conflict could be listed in the seminar. The group accepted that this would probably not be very practical as a part of a seminar presentation, but would probably work better in a family counseling session, seeing that every conflict situation is unique, in terms of who is involved, what was involved, and etcetera.

Members of the group appeared to be seriously concerned about family conflict. Their comments suggested that they were willing to make the necessary personal changes highlighted in the seminar. I also observed that most of the group appeared willing to help make a difference in resolving church conflict, but feelings of inadequacy and the fear that their involvement might cause conflict to spiral more out of control, often caused them to be reluctant to intervene.

\section{Analysis of Seminar Two}

This group was quite involved in the discussion, eagerly sharing what they had learned from the day's presentation, entitled "Navigating the Obstacle Course of Workplace Conflict: Exploring Principles That Also Work for Transforming Congregational Conflict." Members became aware of their conflict style. One respondent acknowledged that her conflict handling technique is avoidance, but that she was able to 
see from the information shared in the presentation that avoidance does not solve the problem or build the relationship. There was a healthy discussion among the group about the five common responses (conquest, avoidance, bargaining, band-aid, and role player) to conflict. Real life cases were also discussed.

One group member shared that she now understands that conflict, while not preferred, is not to be feared, and that a negative view of conflict tends to trigger her own negative reactions when conflict occurs or is perceived. All agreed that disagreements don't have to become damaging conflicts. Some group members were impressed by the perspective that the conflict should not be used to define the entire relationship, understanding that conflict will regularly punctuate all relationships. The relationship could become better as a result of properly engaging the conflict resolution partnership process. Additionally, respondents strongly agreed that: (a) disagreement does not have to be expressed in a disrespectful manner, (b) the five common approaches to handling conflict are ineffective, and (c) conflict is inevitable, but we need to learn how to prevent damaging conflict.

In terms of the presentation benefitting our members at home and at church, respondents expressed the opinion that all the seminar materials presented could be arranged in a manual or workbook to be used by members of the congregation. I was able to share with them that that is my plan. The members felt that the techniques I shared would help to transform the congregation and our homes. The material presented about transforming our views of conflict was viewed as informative and eye-opening. The members agreed that the seminar should help to alleviate the intense and natural fears of facing conflict. 
Some portions of the presentation were especially challenging to members and caused them to have a stronger desire to resolve conflict biblically. For example, much discussion centered on the idea of viewing the person one is in conflict with as a partner to develop a relationship. The idea that our perceptions about people, events, and information are often misperceptions, and that these misconceptions often contribute to attitudes which cause conflict appeared to have resonated with several members. Other members found it challenging to accept a fearless and comfortable view of conflict. A few group members acknowledged that even though the information presented is true, it was still a challenge to simply accept even normal differences. This view showed that some interpret any difference as a threat. On this point, there was much discussion about the factors that could contribute to why people may fear contradiction and confrontation.

Suggestions were made by the group concerning what they felt would add to the effectiveness of the presentation to help people in conflict at home: (a) tell participants that sometimes conflict resolution efforts do not succeed, and that it is alright to move on after one has done what he or she was supposed to do to resolve the matter, (b) acknowledge that one party cannot determine or be responsible for the actions and decisions of the other party, and (c) use more real life cases to illustrate the points brought out in the presentation.

This session, comprised of 8 group members, was clearly more energetic than the first, though the first session was by no means sedate. The topic for this session caused the lights and whistles to come on in the room, as it appears that most, if not all respondents had experienced some form of workplace conflict. I concluded that this session was also livelier due to the fact that the first session was perhaps more personal, 
dealing with family conflict, and understandably, individuals would be concerned about not wanting to betray any personal issues or experiences regarding family problems. The fact that the respondents collectively suggested creating a manual or workbook containing the seminars for further use by the congregation was a good indication that they were appreciative of the material presented, and that they believed the congregation would benefit from what was being taught.

It appears that the path I have taken to address congregational conflict resolution training by including material on how to deal with scenarios at home with the family and at work has paid good dividends. When I started this program, I theorized that the problems evident in the congregation were not exclusive to congregational relationships, but were part of a larger scheme of interpersonal issues experienced in non-church relationships. The level of animated, agreeable discussions in this session gave credence to my theory. For the group members, it was somewhat a new idea for them to look at conflict as opportunity instead of a sure termination of relationships. Perhaps it will take some time before a widespread re-thinking of conflict is evident in the congregation, but I am hopeful that the seminar sowed some good seed that will produce wonderful fruit over time. The key is for me to periodically reiterate these principles through sermons and other seminar presentations in order to foster continued interest and commitment to these necessary paradigm changes.

Analysis of Seminar Three

The focus group was excited to delve into deep discussion about the material presented in "Welcome the Sabbath: An Examination of How Shifting from an Occupational Mindset before Corporate Sabbath Worship Can Promote Healthy 
Congregational Relationships." Even for me as the presenter and researcher, this topic was rather new and different. Prior to developing this seminar, I was unaware of some of the comments made by Ellen White with regard to the connection between Sabbath keeping and family relationships. Consensus by the group members included, (a) the Sabbath is God's answer to man's weariness, (b) the Sabbath reminds us of where we came from, and (c) a serious attitude adjustment is needed in how Sabbath is observed, as switching from secular to sacred thinking is essential to true Sabbath-keeping.

Some members expressed gratitude for the reminder to welcome the Sabbath before the sun sets, with one stating that "we tend to miss out on the sweetness of the Sabbath by not making the transition." Others agreed that the need to get ready for the Sabbath was a refreshing reminder. The question of how this presentation would benefit our members at home and at church, elicited sentiments such as: (a) "I'm thankful that the benefits of welcoming the Sabbath were explained", (b) "the segment on "lawful to do good on the Sabbath' was particularly helpful and clarified several work-related issues", and (c) "if the principles are implemented at home, Sabbath services at church will improve in every way."

Group members were asked to state how their understanding of God's will for welcoming the Sabbath had been impacted. Some reported needing the reminder of what they already knew, but were not faithful in practicing. One member stated, "I now understand the reasons for welcoming the Sabbath, and realize that it's not just a useless ritual." Some parts of the presentation were positively challenging to members, who reported the kindling of a stronger desire to welcome the Sabbath according to God's will. The realization that Sabbath rest includes and requires resolution of conflicts and 
restoration of relationships in the home and among brethren at church came as a shock to nearly all group members.

There were suggestions to include information that I did not present in the seminar. For example, a member suggested that I provide a list of "essential" workers such as the police, fire, ambulance, etc., and explain how they should relate to the Sabbath. Another member opined that I could include guidelines for sexual intimacy on the Sabbath, as this is a point of conflict in some Adventist homes. Needless to say, the focus group session became rather engaging and entertaining at this point.

There were nine (9) focus group members for this session. I found that most members of the group already had a good grasp on what the Sabbath is and what it represents in terms of recognizing God as Creator. The portion of discussion that captured the group's attention was my introduction of statements by Ellen White that indicated a relationship between true Sabbath observance and family and congregational conflict resolution. Respondents were obviously surprised by this revelation. Two other discussions that took considerable time, hence indicating interest, were the matters of working on the Sabbath and sexual activity on the Sabbath. I must say that the latter probably consumed the most time overall. Of course, I declined to compile a list of what could be taken to be "exempted" persons who might have to do servile work during Sabbath hours. Such a list could conceivably be construed as me making or creating a new precedence to officially endorse members' vocational activities, over which I have no control. The group gracefully accepted my explanation that such a move would probably not be wise, and in any event, was outside of my portfolio as pastor. 
I found that the question of the Sabbath, and in particular, the observance of the Sabbath as it relates to family and congregational relationships, is one that needs more thorough treatment in pastoral instruction and sermonizing. I was curious as to what the reaction of the group members would be to the revelation that conflict resolution is intricately tied to Sabbath keeping. It was during my research that I discovered the statements by Ellen White, and was rather surprised by them myself. I had not heard, and still have not heard another person show a link between the two, outside of this seminar. This is certainly information that needs to be reiterated in the church on a regular basis in order to encourage spiritual growth in families and throughout the congregation.

\section{Analysis of Seminar Four}

The fourth seminar was entitled, "By This Shall All Men Know: The Power of Loving Relationships as a Factor in Discipleship and Church Growth." A key point which appealed to the group was that healthy congregational relationships cannot be built in a few hours at church, most of which are not times of close interpersonal interaction. It takes quality time, spent together, to develop authentic, loving relationships. The members had a lively discussion on what constitutes biblical fellowship, and its necessity for loving relationships to develop. Loving relationships are necessary and required by God in order for church members to effectively witness for Him. Several members felt that many congregational relationships are not authentic, hence sometimes; very few positive relationships are witnessed by non-members. It was agreed that the lack of overwhelmingly loving relationships in the church hinders the witness of the church.

This presentation raised a needed awareness of the damaging effects of gossip in the church. One member declared that, "it's better to take certain things to God on your 
knees instead of sharing them with others." Another opined that, "this lesson should help us in terms of more peace at home and at church." The seminar material touched on some deep issues that were, at the time, part of the problem at New Life. Upon reflecting on the lesson, some members expressed the view that "this seminar is a call to a more meaningful prayer life." On the question of what aspect of the presentation challenged them the most, group members were almost unanimous in their agreement that "as Christians, all members have a responsibility to insure that we do not get caught up in gossip," especially since the destructive impact of gossip on personal and congregational relationships was demonstrated in the seminar material.

Several statements by Ellen White were included in the seminar, treating the subject of the destructive power of the tongue. Considerable time was spent discussing White's gossip comments. When the group was asked if there was anything that they felt could add to the effectiveness of the seminar, one of the members suggested conducting a congregational prayer clinic, specifically to pray for the taming of tongue in the church. Another suggested that in sermons on conflict, more encouragement could be given to members to personally take a stand against gossip and gossipers in the church.

This focus group session was a buzz of discussion. This was truly a hot topic among the group. At least two responders openly acknowledged their own need to be reformed in the area of talking too much. It was a rather self-effacing session. There was a sense of personal and corporate responsibility in the meeting, either as members owned up to their part in some of the problems which have plagued the church, or that others did not feel they intervened as they should to stop other members who had gossiped in their presence. The fact that a group member called for congregational prayer to address and 
pray about taming the tongues in the church was powerful. There was group acknowledgement that gossip had played a major role in the strife that had engulfed the church, and that destructive gossip had been left unchecked for a long time. Group members openly expressed their desire for more loving and trusting relationships at New Life. They wanted to be part of the change that was obviously needed. The seminar's emphasis on love appeared to be timely, and was dominant throughout the discussion.

My personal view when I arrived at New Life as pastor was that there was an uneasy phoniness and shallowness to some of the congregational relationships that I saw. In fact, I viewed these thinly veiled pretentions as mere political alliances, rather than godly relationships. This was evidenced by (a) the fact that very soon after I arrived, various members began coming to me with their grouses about the way things had been going in the church, as well as to complain about their personal issues with specific individuals whom they named, and (b) not long afterward, those very individuals could be seen cozying up to the people they complained to me about.

My first question on every occasion on which I was approached by a complaining member was, "have you personally gone to the brother (or sister) in a Christ-like manner to share how you're feeling and why?" That question was met with an affirmative reply on only two occasions that I can recall. All others said "no." As an experienced pastor, I knew not to get involved in gossip. In my experience, most church members will not follow Matthew 18, but would instead try to use the pastor to do the work of reconciliation for them, or; they will gossip about the person they have the problem with. This session confirmed that New Life had been a hot bed of conflict, waiting to explode, and it did explode when I started dealing with deep-seated problems within the 
congregation. At the same time however, this session was a productive forum, given that this group of members were able to begin exploring some of the historic issues which had contributed to the arrested development of the Warner Robins church. I viewed this session as a turning point in my ministry at New Life because I felt that I was able to identify and now guide an emerging core group of people who could go on to help make the necessary changes that would further the recovery and development of the church. Several of these individuals were not previously known as people who would take an active stand or get involved in change. The implementation of the seminar series created an awareness that helped to transform their consciousness and sense of duty to take more personal responsibility for the well-being of the church.

\section{Analysis of Seminar Five}

The seminar on "Healing the Wounds: The Role and Responsibility of the Offended, Offenders and Observers in Conflict Resolution" was undoubtedly the most powerful and engaging presentation in the training series. Focus group members reflected on the seminar's assertion that the observer's role in conflict is perhaps more predominantly mentioned in Scripture than the role of offender and the offended. The concept of "bystander apathy" was also introduced, and was new to most of the group.

Discussion centered on how members typically related in conflict as the offended, the offender, and the observer. Members affirmed that they have a better understanding of the roles. Several acknowledged that they have been practicing bystander apathy, and attested to the fact that fear of the consequences of getting involved is the cause.

Members gave their feedback on the observer's role in conflict, based on the material presented in the seminar. For one member, "this question makes me think about 
what Jesus would do, and also what does the law require or allow me to do" (such as the Good Samaritan Law). Moderator's word of caution: Observers should seek to insure that they know and understand the facts on all sides of a matter before drawing conclusions. It is truly the observer who makes judgment about the matter under consideration, for example in a court of law as jurors.

Session five of the focus group series brought the curtains down on the project implementation process. Group members were very talkative, and several expressed their appreciation at being invited to participate. Bystander apathy was, by far, the most popular theme of the final session. While all were familiar with the generally known hesitation at getting involved in the issues between others, most were not familiar with the fact that the phenomenon was an area of study for social scientists for years, and that the phenomenon had a name. Bystander apathy was viewed by the group as a major contributing factor in the various conflict scenarios at church, on the job, and in homes.

Another area of concern centered on what to do about verbally and emotionally abusive people in churches and in the workplace. The discussion on this point tended toward the congregational context, and what should be done when those who would be approached, as was taught in the seminar series, refuse to apologize or desist from undesirable behavior that causes hurt and conflict. The consensus was to hold one another accountable for words, conduct and attitudes that undermine Christian harmony.

\section{Moderator Evaluation of the Focus Group Research Method}

The focus group research method was productive as a generator of valuable data in my quest to understand how the CLASS Act Seminar Series impacted the membership of the New Life Church. I remain truly appreciative of, and thankful to all the volunteers 
who sacrificed so many hours to volunteer during the research process, making themselves vulnerable in sharing from the heart. The average attendance for the five sessions was eight (8) volunteers. It is commendable that at no time did any member speak or behave inappropriately, or cause other group members to feel uncomfortable in any way though there were difficult subjects that were wrestled with at times. That was a great benefit to the important work that was done.

By far, the presentation on the role of the observer in conflict scenarios consumed most of the discussion time in the five focus group sessions. I had anticipated that it might generate some considerable conversation, as I had been convinced by many years of personal observation that most people were reluctant to get involved in matters where they perceived that they were not "directly" involved, even though the matter, in fact, affected them too. A common example of bystander apathy, or the "it's not my fight" mentality, is those times when abusive members openly attack the pastor in church board meetings. It is rare for other members to either say or do anything to correct or hold the offender accountable.

Some focus group members were church board members as well. Their courage to do the right thing in the face of the wrong conduct by others was improved considerably as a result of the conflict resolution training program, but especially by their involvement with the focus groups. In fact, one focus group volunteer took a firm stand just months later in a board meeting, by moving to address the matter of the individual who had persisted in urging his false theological teachings upon the church. The individual had been disruptive in church services, and had been infiltrating the church-sponsored small group meetings, in spite of the many pastoral admonitions he had received. 


\section{Outcomes of the Conflict Resolution Training Program}

The implementation of the conflict resolution training program at New Life generated several important outcomes. Some outcomes were observable among the congregation, while other outcomes were gleaned from the qualitative research feedback of focus group sessions. The following sections represent my conclusion of the outcomes which both the congregation and I have experienced.

My Personal Growth in Conflict Resolution Theory and Practice

The implementation of the CLASS Act Seminars on congregational conflict resolution training and the literature review process of this document have been personally beneficial to me. This is equally important to me as the professional growth I have experienced as a result of my study. My exposure to a wide panorama of views espoused by renowned contributors to the field of conflict resolution theory has significantly broadened my understanding and knowledge of the conflict resolution process.

What started out as a quest for knowledge has not only yielded knowledge but also significant personal transformation of my views, understanding and response to conflict situations. As a result of my study in this field, I have a much better understanding of myself, in terms of how and why I react and respond to conflict the way I do. I now have a deeper appreciation for why human beings may react in the ways we all do to information, needs, circumstances, and our own inner conflicts.

\section{My Transformation as a Ministry Professional}

In the past, there were times when I had been quite frustrated with members who appeared to have no regard for the unity and peace of the church, and who habitually 
caused conflict by their poor attitudes and unsettling conduct. This was especially true of those who were antagonistic toward me and toward the other pastors who served the congregations before me. I now appreciate that the conflict process is very complex, and that there are many possible factors that could contribute to how a person acts or express his or her disagreements and concerns. This enlightened understanding has helped me to be more intentional about how I mentally process and manage conflict and potential conflict situations. I am better equipped now with a more deliberate conflict style of patiently viewing every situation from various perspectives, regardless of the other person's behavior, since my initial view of the person's action may not in fact be correct.

This newly upgraded appreciation of the complexity of the conflict process is empowering. Since the implementation of the CLASS Act Seminar series on conflict resolution at New Life, I have had the sheer pleasure of observing the wonderful change that has come over the congregation. My ministry has been positively impacted, both within the local church as well as in the larger sphere of service. Requests for me to speak on congregational conflict resolution in local churches have been pouring in. I also have a request from one local conference (at the time of this writing) to be the main presenter at their conference-wide elders retreat.

In every conflict, there is need for me to search my own heart to prayerfully see if the problem lies with me in any way. The fact is that I am not perfect. My own willingness to submit to the correcting influence of the Holy Spirit, and to persons who may have a word from the Lord for me regarding the my ministry direction and leadership, is vital not only to my own walk with God, but is also vital to preventing conflict which could be caused by my leadership. 
Learning to view conflict situations from the perspective of the person who may be angry with me, even though their approach may be inappropriate and their assumptions incorrect, has tempered my own reactions and responses through my improved ability to more quickly process their concerns and conduct through the principles I have learned. I am a better person, a better husband, and a better leader of God's people because of the project process.

I no longer view conflict as an impediment to, or distraction from my ministry. Being of a Type A personality, with achieving goals as a main driving force in my life, I have struggled much in the past with the desire during various conflicted phases of my ministry to "move past all this chaos and confusion in the church, so I can get back to doing ministry (accomplishing goals)." I now view my ministry differently, coming to realize that most of the people under the purview of my pastoral leadership are dealing with conflict of one kind or another in their lives on any given day and at any given time. I now fully embrace the reality that conflict ministry is ministry of the highest order.

I have embraced the realization that God has called me to the ministry of reconciliation. The goals to be achieved by a minister of the gospel must of necessity include helping people to be at peace with God, at peace within themselves, and at peace with their brothers and sisters in Christ Jesus. The apostle Paul wrote:

Therefore, from now on, we regard no one according to the flesh. Even though we have known Christ according to the flesh, yet now we know Him thus no longer. Therefore, if anyone is in Christ, he is a new creation; old things have passed away; behold, all things have become new. Now all things are of God, who has reconciled us to Himself through Jesus Christ, and has given us the ministry of reconciliation, that is, that God was in Christ reconciling the world to Himself, not imputing their trespasses to them, and has committed to us the word of reconciliation. Now then, we are ambassadors for Christ, as though God were pleading through us: we implore you on Christ's behalf, be reconciled to God. For He made Him who knew no sin to be sin 
for us, that we might become the righteousness of God in Him (2 Cor 5:16-21, italics added).

The vision of the doctor of ministry program of "changing the people who change the world" has been realized in my life. I am grateful for having done this particular emphasis for my doctoral degree. Not only will I and New Life greatly benefit from what I have learned and from how my approach to conflict has been transformed, but through my CLASS Act Seminars consulting service, many more churches will be blessed as well. The implementation of the training program had mixed outcomes for the congregation, in both acceptance and rejection by members.

\section{Sundry Membership Reactions to the Training Program}

The subject of biblical conflict resolution is one of the most challenging for the carnal heart to accept. In order to adhere to the biblical protocol for preventing and resolving conflict, great humility is required. Humility is not a natural human virtue. One of the primary causes of conflict, according to James 4:1, is the selfish desires of men's hearts. Given this reality, it is understandable that selfishness prevents both the offended and the offender in conflict from arriving at resolution according to God's will. Selfishness also prevents observers of conflict from getting involved with a view to facilitating resolution. Those who are offenders, as shown in Seminar 5 (see appendix A), have a tendency to resist their responsibility to make amends for their wrongdoing.

In the case of New Life, the conflict resolution training series tended to not find a positive reception among some of the members who were engaged in open rebellion against me during that period of time. As was stated earlier, "the same sun that melts butter, also hardens clay", and such was the outcome of the seminars. The rebelling members were the clay in this regard. In one sense, the outcome in terms of the rebelling 
members was not positive, but in another sense the outcome was in fact positive. In the latter sense, almost all those who were engaged in open rebellion, which included smear campaigns via slanderous emails and resentment-filled potlucks in their homes, departed New Life.

However, it must be noted that of those who departed because of anger or conflict (six families, totaling twenty-three persons; a number which represents parents and minor children or teenagers), the majority of them (four families, totaling seventeen persons; a number which represents seven parents and minor children or teenagers) had already left prior to the implementation of the training program. It should also be noted that of the four families that left prior to the seminar series, three families are related. In fact, of those three families, two of the wives and one husband are siblings. One can clearly see therefore, the factional nature of their conduct in the church and their subsequent departure.

A smaller number (two families, totaling six persons; a number which represents three parents and five minor children or teenagers) left because of anger or conflict since the training program was completed. The church has a long history of people leaving in anger, and without seeking to resolve their issues in a biblical manner. This could suggest that the training program was probably a factor in helping to stem the tide of ill-advised departures, in that the membership was exposed to systematic, biblical instruction about how to resolve conflict.

As is most often the case in a typical church, the majority of the members at New Life were not actively involved in the perpetuation of congregational conflict. However, most members were aware of the unruly behavior of those who fought my leadership and 
who had also been unkind to my predecessors, but observers had failed to take a principled stand against the wrong-doers. It was only during and after the seminar series was presented that most members either came to recognize their collective responsibility for church unity, or grew found the courage to take the stand they had been afraid to take for years against those who held the church hostage. This group of members accepted the teachings presented in the training program and became an empowered congregation. In the old adage, these members would be the "butter" that the sun melted. It was this acceptance of biblical responsibility which led to the church board actions mentioned in the previous chapter.

\section{A Transformed New Life Church Emerges Out of Chaos}

One and a half years after the final conflict resolution seminar was presented, the transformation of the church is now clearly evident. While not perfect, New Life is no longer a conflicted, dysfunctional congregation. No one refers to the church as "our church" in a possessive way anymore, and the members now refer to the congregation as a church family instead of a family church. Attitudes have generally improved among the membership. At the time of writing this chapter in July 2013, I was able to lead the members into the community to conduct a Community Needs Survey in order to know how to minister to the people of Warner Robins. Most able-bodied members are now engaged in the missional work of the church. As at July 31, 2013, fifty people in the community were enrolled in Bible studies, which the members delivered in person on Sabbaths in preparation for the fall evangelism campaign.

New Life is a more spiritual congregation today because of the transition process. The church is no longer dysfunctional. There is no longer an element that asserts 
theological extremism and excessively opinionated dogma upon the congregation. There are no factions seeking to control the church. The church is also no longer dependent upon audio or other equipment owned by any member. This has eliminated the tendency of angry or controlling elements that would extort the church in order to get their way.

There is more prayer, more laughter, more fellowship, and a fresh new excitement about evangelistic outreach at New Life. Members who previously stayed in the background are now involved in the leadership and functioning of the church. There is currently a smaller membership, but tension no longer dampens the atmosphere. The new emphasis is on being a place where people can have an encounter with God. A few former members have started attending again.

Since the church has transitioned, new core values have been adopted: "A praying congregation; a worshiping congregation; a loving congregation; a fellowshipping congregation; a witnessing congregation." ${ }^{33}$ There is now a customized church bulletin cover which sports the core values. Mission is the focus at New Life, not individuals.

A new mission statement has also been voted: "Our mission is to demonstrate God's love to all, be a blessing to our community, and invite people to walk in newness of life in Christ Jesus." " These values have been ingrained into the minds, ministry, and marketing of the church. All that is now done at New Life is done within this new construct. With the renewed emphasis on outreach, my expectation is that the membership will now grow numerically like it has the potential to grow in a city the size of Warner Robins. The mission statement is also permanently highlighted in the bulletin.

\footnotetext{
${ }^{3}$ Voted on June 2, 2012.

${ }^{4}$ Voted on November 11, 2012.
} 


\section{Summary}

Change is mostly a slow and tedious process. This conflict resolution training program is about change. I trust God to move upon the hearts of all who heard the seminar presentations, and especially those who so graciously volunteered their time to participate in the focus groups and give the feedback recorded here. I consider the seminar series to be a great success, given the kinds of feedback and the level of acceptance evidenced in the focus groups. It is my belief that it takes only one person to be the change that is needed in any situation. In this case, there is more than one.

The case for conflict resolution training in churches has been reinforced in my mind as a result of this project. Overall, the prospects for New Life look great. More church members and churches can surely benefit from this program. The focus group members' openness demonstrate that there are people in the church who desire to be in God's will in their homes, on their jobs, and in their congregational relationships.

As an instructor in the area of conflict resolution, as a conflict minister who no longer views church conflict as a detraction from my ministry, as a human being, and as a husband, I have grown in significant ways in my knowledge, understanding, and practice of this essential field of study. I hope to make a noteworthy and kingdom building contribution to this emerging field of conflict ministry, to the honor and glory of God.

\section{Conclusions}

I have, in the course of this project document, come to these conclusions:

1. Conflict is inevitable and also potentially destructive if not addressed and concluded correctly. 
2. Church members and pastors do not have the natural desire or ability to remedy conflict or potential conflict.

3. Conflict does not have to automatically mean the end of relationships.

4. Conflicted churches can recover and become healthy again, given skilled leadership is provided.

5. More pastors would benefit greatly, and so would the congregations they lead, if they were properly trained in the art of conflict ministry.

6. Church conflict is too often blamed on the pastor.

7. Conflict ministry is probably not for everyone, and it requires a very broad back to take the blows that will come as change is initiated in the congregation.

8. Many Seventh-day Adventist leaders do not appear to have the level of appreciation for the complexities of congregational conflict that would promote a change from the typical reaction of moving the pastor when there are several calls from members about conflict.

\section{Recommendations}

Having experienced both personal and professional growth in knowledge, understanding, and response to conflict, I deem it a privilege to have gone on this remarkable academic journey of learning how to deal more effectively with this everpresent reality that has destroyed many homes, lives, and congregations. There is no question that this has been a most rewarding learning opportunity for me. I have acquired much knowledge, enough to know that there is yet so much more for me to learn. Indeed, my scholarly appetite has been aroused to a new level of inquiry. 
The personal and pastoral benefits which have already resulted in significant changes in my life and at New Life are profound. This reality affords me the humbling privilege of making the following recommendations about congregational conflict resolution training:

1. That local conferences make congregational conflict resolution training for pastors a priority, recognizing the need to move away from the traditional and highly unproductive tendency of moving pastors when there is major conflict in the churches, seeing that churches do not improve as a result.

2. That the North American Division require conference ministerial directors to undergo specialized training in the area of congregational conflict resolution training, in order to better serve and support the pastors in their fields. This is a critical need, one that would serve as an important step in the move away from merely resorting to moving the pastor whenever church members write or call the conference office to complain about their pastor.

3. That a study be done to seek to know what percentage of church conflict is actually caused by the pastor, versus the percentage of conflicts that were embedded in the church history and culture before the current pastors were installed and the amount which occurred during the pastors' tenures. This study could perhaps be done on a sampling basis across many conferences in the North American Division. Such a study could potentially yield data that may suggest the need for a radically different approach than that which is mostly utilized in perhaps a majority of conferences, where it is the pastor and his or her family who always seem to pay the price for church conflicts. 
4. That congregational conflict resolution training be provided at church officers' conventions, elders retreats, and other similar occasions in an effort to curb the apparent rapid deterioration of our churches due to conflict, and to provide support that pastors need by more members becoming aware of the real cost of mishandling church conflict.

5. That a profile on every church be compiled and kept on record at every conference office. This would be based upon the observations of pastors who have served the congregations, as well as conference office personnel who have interacted with the congregations over the years, especially in the area of conflict. This profile could greatly assist conference leaders in decision making when the time comes to send a new pastor, or when the decision must be made to take a stand by insisting that a pastor will not be moved based on the outcry of the people, given the conflicted history of the church.

6. That each year during camp meetings, conference leaders highlight the importance of church unity and the need for mutual respect between churches and pastors. In order for this to succeed, conference leadership would need to commit to not making adverse decisions about their pastors, based on one-sided representations of conflict issues in the churches.

7. That further serious study should be given to the question of how to deal effectively with congregational conflict in the Seventh-day Adventist Church. This is a critical need, given the fact that throughout the course of my research, it was quite noticeable that only a handful of individuals have written or done serious scholarly work in this field within the Adventist Church. Seventh-day Adventist pastors have not written much on this menace of a problem within our ranks. Sunday pastors have all but cornered 
the literature market in the field of conflict ministry. The Sunday denominations are the ones with the notable institutes on church conflict, institutes such as The Alban Institute, Peace Maker Institute, and etcetera. There needs to be an urgent awakening among God's Remnant people concerning this issue of congregational conflict, seeing that it has grave consequences for the accomplishment of our mission. In the words of Jesus Himself, "By this shall all men know that you are my disciples; if you have love one to another." 
APPENDIX A

CLASS ACT CONFLICT RESOLUTION SEMINAR SERIES 


\section{New Life SDA Church}

October 15, 2011

\section{The Dangers of a Judgmental Spirit}

\section{Introduction}

A. Scripture reading: Matthew 7:1-6

B. In his little book Illustrations of Bible Truth, H.A. Ironside pointed out the folly of judging others. He related an incident in the life of a man called Bishop Potter. "He was sailing for Europe on one of the great transatlantic ocean liners. When he went on board, he found that another passenger was to share the cabin with him. After going to see the accommodations, he came up to the purser's desk and inquired if he could leave his gold watch and other valuables in the ship's safe.

He explained that ordinarily he never availed himself of that privilege, but he had been to his cabin and had met the man who was to occupy the other berth.

Judging from his appearance, he was afraid that he might not be a very trustworthy person. The purser accepted the responsibility for the valuables and remarked, 'It's all right, bishop, I'll be very glad to take care of them for you. The other man has been up here and left his for the same reason!"'

C. Topic: "The Dangers of a Judgmental Spirit"

\section{Proclamation}

I. The first thing we must do is define our terms.

A. Definitions

1. Judge - What does it mean to judge, as used in Matthew 7:1? Greek krinete - to pronounce judgment; to subject to criticism. Used of those who act the part of judges or arbiters in the matters of the common life, or pass judgment on the deeds and words of others: Also used of those who judge severely (unfairly), finding fault with this or that in others, Matt. 7:1; Luke 6:37; Rom. 2:1. (For God's judgment of men's hearts and minds, COMPARE: Jeremiah 11:20)

2. Mote - Greek karphos, a mere chip or splinter of dried wood, chaff, etc. In other words, a small splinter of something that a light wind can carry away. 
3. Beam - Greek dokos, a log or plank, a piece of timber used in the construction of a house.

4. Hypocrite-Greek, hupokrites, a feigner, an actor under an assumed character (stage player).

5. That which is holy - A reference to truth, as we shall see later.

6. Dogs - SDABC says that in the time of Jesus, as well as today in the Orient, dogs were "the scavengers of town and city, and are for the most part, halfwild creatures. For the Jews the dog was also a ceremonially unclean animal, and since it had but little domestic value, was looked upon as utterly despicable (see Job 30:1). Elsewhere in Scripture, Paul uses the metaphor of a dog to appeal to church members in Philipi to reject the false teachings and divisive tactics of the Judaizing Christians. He called them dogs, telling the Philipians to beware of them. The SDABC says to call one a dog was strong expression of contempt. The term succinctly describes those in character who are shameless, impudent (impertinent, lacking courtesy), malignant, snarling, dissatisfied, and contentious.

7. Pearls - A reference to truth ... the word of God.

8. Swine - Used in a similar manner as dogs in the text. Another unclean animal is here used to depict the unscrupulous and disgusting nature or character of those the term describes.

B. Here's how the SDABC, 5:354, 355 puts it...

1. “Jesus here refers particularly to judging another person's motives, not to judging the right or wrong of his acts. God alone is competent to judge men's motives, because of the fact that He alone is able to read men's innermost thoughts (see Heb. 4:12; DA 314) ... Able to discern only the 'outward appearance' (1 Sam. 16:7) and not the heart, men inevitably make mistakes. Jesus does not here refer to that fine sense of discrimination by which the Christian is to distinguish between right and wrong (Rev. 3:18; cf. 5T 233), but rather to the habit of censorious (highly critical, fault-finding), sharp, and usually unjust criticism."

2. The word "judge" as used in Matthew 7:1 speaks to the attitude and practice of being critical and fault-finding, especially unfair criticism. This is especially true, in the sense of talking about and pointing out others, not for their acts, but the questioning of their motives. This is quite frightening. Frightening indeed.

3. Jesus expresses concern about the practice of spending our time in unfair criticism of others; and engaging in character assassination of one another, even though we don't have the facts to back up our accusations. He commands us today to turn away from the practice of assuming we know what's in the other person's mind. When we deal with the other person's weaknesses and faults, be careful how we deal with that, because often, their issues may be mere chips or splinters of dried wood or chaff, while our own stuff is more like a beam or log or plank - a piece of timber could be used in the construction of a house. The truth of the matter is that every individual 
has both chips and timber in their eyes, yet we find it so easy, so convenient to offer to remove the other person's perceived problems!

II. How judging (unfair criticism) affects the church, the criticizer, the criticized and others

A. The effect of unfair criticism upon the church

1. Criticizers create division in the church. They sow discord with their constant complaining and fault-finding. They manipulate people to "take their side" in matters, by pretending (remember, that's what hypocrites do) that whatever they are doing and saying is in the best interest of the church. Notice that they do not participate in what's happening in the church, and the main contribution they make is unsolicited criticism after everybody else has done all the hard work.

2. The spirit of unfair criticism often causes those who labor for the Lord to grow weary in well doing.

3. Unrelenting criticism of church leadership has consequences too.

4. Ellen White says: "The Hebrews were not willing to submit to the directions and restrictions of the Lord. They were restless under restraint, and unwilling to receive reproof. This was the secret of their murmuring against Moses. Had they been left free to do as they pleased, there would have been fewer complaints against their leader. All through the history of the church God's servants have had the same spirit to meet." \{PP 404.1\}

5. "It is by sinful indulgence that men give Satan access to their minds, and they go from one stage of wickedness to another. The rejection of light darkens the mind and hardens the heart, so that it is easier for them to take the next step in sin and to reject still clearer light, until at last their habits of wrongdoing become fixed. Sin ceases to appear sinful to them. He who faithfully preaches God's word, thereby condemning their sins, too often incurs their hatred. Unwilling to endure the pain and sacrifice necessary to reform, they turn upon the Lord's servant and denounce his reproofs as uncalled for and severe. Like Korah, they declare that the people are not at fault; it is the reprover [the spokesperson for God] that causes all the trouble. And soothing their consciences with this deception, the jealous and disaffected combine to sow discord in the church and weaken the hands of those who would build it up." \{PP 404.2\}

B. Criticism's effect upon the criticizer

1. Matthew 7:2 - The same thing that the unfair critic says about the criticized will be returned back upon him! (See Romans 2:1-3). Ellen White said this: "Satan will be judged by his own idea of justice. It was his plea that every sin should meet its punishment. If God remitted the punishment, he said, $\mathrm{He}$ was not a God of truth or justice. Satan will meet the judgment which he said God should exercise." (Manuscript 111, 1897). In other words, judgmental criticizers reveal their own coming judgment which will be put on them by God! 
2. Criticizers reveal the fact that they are self-righteous.

C. Effect upon the person being criticized

1. Galatians - The Judaisers criticized Paul, his authority and his gospel. They found fault with how the Gentile believers practiced the faith. They rejected Paul's gospel of righteousness by faith in Jesus alone. They demanded that the Gentiles be circumcised like they were. This criticism of Paul caused believers to become disoriented and confused ... some drifted back into adherence to the ceremonial law of rituals and sacrifices. Some of the Gentiles gave in to the criticisms and were circumcised. They lost sight of Jesus. A judgmental spirit destroys harmony ... it accuses people who're in the right ... of being in the wrong.

2. The apostle Paul was relentlessly criticized by the enemies of the faith, men who were too sure of themselves to listen and too arrogant to learn, even though they had been repeatedly counseled with. They sought to undermine Paul's authority, calling into question his apostleship. His ministry was based upon his claim that He had been personally selected by Jesus and taught of the Holt Spirit. Now, his very workmanship, the believers in the region of Galatia, was being destroyed by these conniving Jews who had convinced themselves that God approved of what they were doing to unsettle and undermine the faith of the Gentiles.

3. The criticized must hold on to the promise that God is with them if they are doing God's will. They cannot afford to become discouraged. They cannot give up. Pleasing God must be the sole desire of those who are called to be sons and daughters of God, because if there is any other motive for doing what we do, we will be overcome by discouragement.

4. Constant, unfair criticism can erode the victim's self-worth. This is true in all human beings, but more so in children and youth.

5. English evangelist George Whitefield (1714-1770) learned that it was more important to please God than to please men. Knowing that he was doing what was honoring to the Lord kept him from discouragement when he was falsely accused by his enemies. At one point in his ministry, Whitefield received a vicious letter accusing him of wrongdoing. His reply was brief and courteous: "I thank you heartily for your letter. As for what you and my other enemies are saying against me, I know worse things about myself than you will ever say about me. With love in Christ, George Whitefield." He didn't try to defend himself. He was much more concerned about pleasing the Lord.

6. I read somewhere a long time ago that "too much constructive criticism is destructive."

D. Criticism's effect upon third parties - warnings and admonitions

1. Some are turned off from Christ and the Church - Those who are exposed to the critical nature of church members often don't want to be part of the church. Co-workers of church members often observe the offensive attitudes 
of Christian co-workers and are turned off by what they see and hear in some who claim to be sons and daughters of God!

2. Some observers get caught up in the cycle of criticism - Sometimes third parties, who have no personal knowledge of the person or matters that are being criticized, are drawn into slanderous and evil surmising. Before you know it, you could be right there with the criticizers doing what they're doing and saying what they're saying against someone else's mote, while your timber is sticking out of your eye, preventing you from seeing yourself.

3. Sometimes the third-parties are children and youth who are destroyed in their own homes, or in the car driving home from church! This occurs where church members repeatedly and unfairly judge and criticize other people in front of their kids. Invariably, the children and youth come out of the home with a negative attitude and lack of respect for those who are discussed in the home! Then, to make matters worse, some of them spread the poison from their home among other children and youth, and before you know it, you're dealing with a major case of attitude poisoning.

\section{Counsel we shouldn't miss - Matthew 7:6}

A. Jesus taught what we should do concerning those who will not change ...

1. Give not: SDABC - Says here that Jesus transitions from the minor or imaginary faults in the life and character of others (you know those "cherished perceptions" we have of others) to the Christian's attitude toward those who are clearly and completely in the wrong and have no desire to amend their ways.

2. See now the transition Jesus makes ... from nit picking, to substantive issues. By the way, we're really getting into some serious matters here, because experience shows that it's the people who have no desire to change who tend to be the most critical and fault-finding in the church. They are the ones who sow discord with their constant criticism and judgmental attitudes. They are the ones who break up the church by discouraging others through merciless criticism and evil surmising. The folks in vs. 6 are the ones with the largest logs in their eyes, yet they spend most of their time pointing at the speck of dust in the preachers' eyes, the elder's eyes and everybody's eyes that doesn't conform to their personal standard of righteousness.

B. Counsel from Ellen White

1. In Thoughts from the Mount of Blessing, Ellen White had this to say about our text: "The effort to earn salvation by one's own works inevitably leads men to pile up human exactions as a barrier against sin. For, seeing that they fail to keep the law, they will devise rules and regulations of their own to force themselves to obey. All this turns the mind away from God to self. His love dies out of the heart, and with it perishes love for his fellow men. A system of human invention, with its multitudinous exactions, will lead its advocates to judge all who come short of the prescribed human standard. The atmosphere of selfish and narrow criticism stifles the noble and 
generous emotions, and causes men to become self-centered judges and petty spies." \{MB 123.1\}

2. Also, "The Pharisees were of this class. They came forth from their religious services, not humbled with a sense of their own weakness, not grateful for the great privileges that God had given them. They came forth filled with spiritual pride, and their theme was, 'Myself, my feelings, my knowledge, my ways.' Their own attainments became the standard by which they judged others. Putting on the robes of self-dignity, they mounted the judgment seat to criticize and condemn." \{MB 123.2\}.

3. Continuing, she says "The people partook largely of the same spirit, intruding upon the province of conscience and judging one another in matters that lay between the soul and God. It was in reference to this spirit and practice that Jesus said, 'Judge not, that ye be not judged.' That is, do not set yourself up as a standard. Do not make your opinions, your views of duty, your interpretations of Scripture, a criterion for others and in your heart condemn them if they do not come up to your ideal. Do not criticize others, conjecturing as to their motives and passing judgment upon them." $\{$ MB 123.3\}

4. Often, we lose precious time trying to convince naysayers. Don't give what is holy to the dogs. God's word, His truth is precious, holy, and transformational, but everybody will not yield to what God has said.

5. MB, p. 129 says - "Jesus here refers to a class who have no desire to escape from the slavery of sin. By indulgence in the corrupt and vile their natures have become so degraded that they cling to the evil and will not be separated from it. The servants of Christ should not allow themselves to be hindered by those who would make the gospel only a matter of contention and ridicule. But the Saviour never passed by one soul, however sunken in sin, who was willing to receive the precious truths of heaven. To publicans and harlots His words were the beginning of a new life. Mary Magdalene, out of whom He cast seven devils, was the last at the Saviour's tomb and the first whom He greeted in the morning of His resurrection. It was Saul of Tarsus, one of the most determined enemies of the gospel, who became Paul the devoted minister of Christ. Beneath an appearance of hatred and contempt, even beneath crime and degradation, may be hidden a soul that the grace of Christ will rescue to shine as a jewel in the Redeemer's crown."

\section{Conclusion and Commitment}

I. What did we learn from God's word to us today? What will we do with what we heard?

A. Summary and Conclusion

1. Fault-finding and criticism are not spiritual gifts!

2. If and when we have something to say, we should be fair about it. First, say it to the person concerned, not others. 
3. We all have a beam in our eye! Find something good and uplifting to say about others, because if all you can do is find fault, then you're showing that you're really the one with a problem.

B. Appeal

1. Jesus is saying to all of us today, "Stop the unfair criticism. Stop judging motives. Stop questioning other people's intentions when we don't have grounds to say that they're doing something wrong. Stop labeling different as wrong, simply because that's not what we're used to. Quit assigning evil motives to others' actions that we haven't tried to understand."

2. Jesus is saying to us today, "Let me take that log, the timber out of your eye ... then you'll be able to see like I see. Not only that, but you'll be able to see yourself and judge yourself, instead of wasting your precious time judging someone else. Brother Criticizer, Sister fault-finder, give me your heart. I will make your mind pure and true and fortified against Satan's delusions that you are holier than, smarter than, know all, better than, more right, know more, most important."

3. Invitation to come to Jesus. 


\section{Seminar One}

Topic: Resolving Family Conflict: Overcoming Conflict in the Christian Home.

The purpose of this seminar is to:

1. Explore and better understand the causes and remedies of family conflict.

2. Better acquaint participants with techniques for preventing and quickly resolving conflict in the home.

3. Encourage hopefulness in times of family relationship crisis.

The objectives of this seminar are:

1. God's will for family unity will be seen.

2. Participants will better understand the causes and remedies of family conflict.

3. Participants will learn techniques for preventing and resolving conflict in the home.

4. Participants will be inspired with determination to overcome conflict and with hope to endure times of family relationship crisis.

Definition of terms:

1. Definition of Christian: Follower of Christ Jesus.

2. Definitions of Conflict:

a. Not the typical minor disagreement, but a major disagreement or argument.

b. A prolonged fight.

c. A state or action of antagonism.

d. Friction or opposition resulting from actual or perceived differences or incompatibilities.

Being Christians doesn't exempt families from experiencing conflict.

1. Christians are still human beings, faced with the daily struggle against the selfish, fallen nature.

2. How conflict occurs - Differences of opinion is normal, healthy and necessary in productive human relations, but when disagreements are mishandled by either party (normally through unfair or careless words, actions and attitudes; emotional reactions; anger; or accusations and counteraccusations) feelings can get hurt ... and physical and emotional alienation often results.

Differences of opinion is healthy, but three elements cause conflict.

1. Attitudes (negative emotions, disrespectful).

2. Anger (revealed in careless or unfair words).

3. Accusations (and counter-accusations).

Some conflict areas in Adventist homes:

1. Marital problems (communication, sex, etc:).

2. Parents and children (setting limits, rules, etc.). 
3. Sibling rivalry.

4. Conflict over Adventist Christian values:

a. Worship and music tastes

b. Dating/marrying outside the faith

c. Entertainment

d. Dress

5. Conflict over finances (Tithe or pay the bills?)

Relationships at home set the tone for congregational relationships.

1. The religion of the home is manifested in corporate worship and relationships.

2. Home is where we mostly interact with people whom we offend, and vice versa.

3. The family circle is the training ground for learning how to interact and relate to the wider world.

4. It shows at church when correct conflict resolution techniques are practiced at home.

Common courtesies we should practice at home:

1. Please.

2. Thank you.

3. I'm sorry.

4. Excuse me.

5. You're welcome.

6. Not assuming things about family members, but asking questions for clarification.

7. Not questioning motives.

8. Treating family members as very important people, because they are.

What families can do to head off serious conflict.

1. Be proactive ... do diligence to avoid offense.

2. Establish mutually agreed protocols for the home in matters that can trigger conflict.

3. Remember the Golden Rule in all things.

4. The "soft answer" advisory.

5. Make love the central feature in the family.

6. Work on communication skills.

7. Don't assume anything, talk about everything.

8. Accept the "give and take" of practical living.

Paul's guide to conflict resolution.

1. Let's read Ephesians 4:25-32.

2. Lying (Gk, pseudos) - Falsehood, untruth, lie.

3. Members one of another - preserve the unity.

4. Be angry (righteous indignation), but don't sin (justifiable anger is directed against wrong doing, without animosity toward the wrongdoer... personal resentment, vindictive-ness and loss of control must be avoided) 
5. What does it mean to not let sun go down...?

6. Wrath - Personal resentment which can result from even justified anger turning sour.

7. Give no place to the Devil (diabolos - accuser) the opportunity to set us against one another.

8. Corrupt speech - (sapros - rotten, putrid, bad). Used in Matt. 13:48 of inedible fish that were thrown away. Foul speech ruins unity.

9. Which is good - Don't just avoid bad speech, speak words that accomplish a good purpose.

10. Grieve - (Gk, lupeo - to cause pain, to distress, to grieve) The Greek phrase may be translated "stop grieving." The Holy Spirit is grieved when we hurt one another.

11. Sealed - Remember, it is the Holy Spirit who seals us for heaven (Eph. $1: 12,13 ; 2$ Cor. $1: 22$ ).

12. Bitterness - Bitterness of temper ... leads to antagonism and lack of unity.

13. Wrath and anger - (Gk, thumos kai orge').

14. Thumos (wrath) denotes a momentary furious and excited state of mind.

15. Orge (anger) denotes a permanent condition of resentment and enmity.

16. Clamour (Gk. Krauge) - an outcry, loud quarreling.

17. Evil speaking (Gk. Blasphemia) - blasphemy, slander, railing. Clamour often becomes slander in an attempt to ruin the other person.

18. Malice (Gk. Kakia) - malignity, malice, ill-will, desire to injure.

19. Be kind (Gk. Chrestoi) - gentle, gracious.

20. Tenderhearted (Gk. Eusplagchnos) - compassionate, tenderhearted, pitiful (translated as 'bowels of mercies' in Col. 3:12).

21. "Forgiving one another even as God in Christ forgave you."

Helpful techniques to use.

1. Watch your words!

2. Watch your attitudes!

3. Don't misrepresent what the other person said or did (this exasperates the situation).

4. Don't accuse, stick to known facts.

5. Don't assume, ask for clarification.

6. Stick to the issue, don't start a new argument.

7. Deal with issues quickly (within time context).

8. Completely resolve the issue with apologies and forgiveness.

How families can resolve conflict quickly and completely.

1. Seek first to prevent unnecessary conflict.

2. Recognize that conflict is inevitable, and make a conscious Bible based decision on how you will handle issues when they occur. Personally commit to Ephesians 4:25-32.

3. Remember that family is the foundation of society and the church, and that Satan is seeking to destroy the family relationship. 
4. Ask God to work in you, both to will and to do of His good pleasure (Philippians 2:13).

When personal efforts fail.

1. Seek outside help (professional if necessary).

2. Sometimes an independent third party is able to put fresh eyes and listen with fresh ears to the causes and pain of difficult family conflict.

3. The family's pastor may be able to help, but it should be recognized that he may not be adequately or professionally trained and equipped to handle some types of conflict.

4. It is worth the effort to save the family. 


\section{Seminar Two}

Topic: Navigating the Obstacle Course of Workplace Conflict: Exploring Principles That Also Work for Transforming Congregational Conflict.

The purpose of this seminar is to:

1. Clarify and re-think the meaning of conflict.

2. Explore and better understand the causes and remedies of workplace conflict, and make relevant application to congregational life.

3. Equip participants with techniques for preventing and effectively resolving workplace conflict.

The objectives of this seminar are:

1. To transform participants' understanding and perception of what conflict is and is not.

2. To motivate participants to become more aware of their own conflict resolution approaches, and to make necessary attitudinal and behavioral changes to more effectively handle conflict.

3. To acquaint participants with some of the more common, yet often-times confused causes of conflict.

Typical definitions of conflict.

1. Not the typical minor disagreement, but "a major disagreement or argument"

2. "A prolonged fight"

3. "A state or action of antagonism"

4. "Friction or opposition resulting from actual or perceived differences or incompatibilities"

5. Dudley Weeks shows that certain words are often mentally associated with conflict: "Fight, anger, pain, war, impasse, destruction, fear, mistake, avoid, lose, control, hate, loss, bad, wrongdoing."

Re-thinking our views of conflict.

1. What conflict is usually viewed as.

a. Disruption in order, a negative experience, an error or mistake in a relationship.

b. A battle between incompatible self-interests or desires.

c. An isolated event we allow to define the entire relationship.

d. A struggle between right and wrong, good and evil.

2. What conflict could possibly be.

a. An outgrowth of diversity that might hold possibilities for mutual growth and for improving the relationship.

'Dudley Weeks, The Eight Essential Steps to Conflict Resolution: Preserving Relationships at Work, at Home and in the Community (New York: Penguin Putnam, 1992), 4. 
b. One part of a relationship that involves needs, values, perceptions, power, goals, feelings; not just interests or desires.

c. Events that punctuate a long-term relationship and can help clarify the relationship.

d. A confrontation between differences in certain aspects of a relationship, but not to the exclusion of other aspects that are still there to build on. ${ }^{2}$

Five common responses to conflict, as proposed by Dudley Weeks. ${ }^{3}$
1. Conquest
2. Avoidance
3. Bargaining
4. Band-aid
5. Role Player

Conquest response to conflict.

1. Scoring a victory; defeating the opponent is the goal.

2. The conflict becomes a battle to win:

3. Winning is the goal: "I'm right and you're wrong!"

4. The goal is to weaken the opponent, feeling that doing so somehow makes one's own strength greater.

5. Bullying, dominance and manipulation are used in an attempt to weaken the opponent.

6. Relationship is destroyed.

Avoidance response to conflict.

1. This is used because of the view that conflict is to be avoided; view that conflict is negative and bad!

2. We avoid conflict to pretend there's no conflict, because we don't feel adequately skilled to deal with the conflict.

3. For some, conflict is internally acknowledged, but confrontation with the other party is side-stepped.

4. Avoidance by diversion: changing the subject.

5. Avoidance doesn't work, because the conflict only gets worse.

6. Needs and feelings are not clarified.

7. Avoidance merely postpones dealing with the inevitable, because until it's resolved, conflict won't go away.

Bargaining response to conflict.

1. This is used when the parties see the conflict as a game to get one over on the other side!

${ }^{2}$ Weeks, The Eight Essential Steps to Conflict Resolution, 8.

${ }^{3}$ Ibid., 16-31. 
2. "If you do this the I will give up that!" Usually no one's needs are met as a result.

3. The focus is on demands both sides make, which from jump street, is the cause of the conflict!

4. Unrealistic demands create even more spin-off conflicts.

Band-aid response to conflict.

1. Quick fixes ignore the root of the conflict and focus on the appearance of a solution (e.g., moving one employee from a shared office to a different one, but never finding out the cause of their shouting matches when they worked together, only to have them scream at one another at the water cooler!)

2. This approach creates the illusion that the problem has been addressed, or that things will be fine now.

3. This approach robs the opportunity to create an effective process for ending or handling the conflict.

Role player response to conflict.

1. Positions are used to define the relationship: e.g., "I'm the parent, you're the child!" "I'm the teacher and you're the student who needs this grade ... you do as I say!" "I'm the man and the head of this house!" "I'm the eldest ... you need to obey me!"

2. This approach ignores the human needs of the other party and focuses on the roles each plays, and may unfairly shut out the contribution which every person could make.

Sources and types of conflict, according to Weeks. ${ }^{4}$

1. Diversity and differences

2. Needs based conflicts

3. Perceptions based conflicts

4. Power based conflicts

5. Conflict of values and principles

6. Feelings and emotions

7. A person's own internal conflicts

Conflict due to diversity and differences

1. Diversity is healthy! Damaging conflict is not!

2. "Within our diversity as humans there are differences in perceptions, needs, values, power, desires, goals, opinions and many other components of human interaction. These differences could lead to conflict. Depending on the way we deal with these differences and disagreements, conflicts can either be positive or negative"

${ }^{4}$ Weeks, The Eight Essential Steps, 33-61. 
3. "People often choose to feel threatened by the mere existence of a differing point of view ... or they let the differences they have with someone define their entire relationship."

Conflict due to needs.

1. When needs are ignored.

2. When the satisfaction of needs is obstructed.

3. When needs and desires are confused.

4. When needs are incompatible.

Conflict due to perceptions.

1. People interpret reality differently.

2. Many perceptions are factually incorrect, and are in reality, misperceptions.

3. Conflict resolution is unlikely if both parties fail to clarify their perceptions.

4. Poor self-perception causes conflicts with others.

5. Conflicts involving perceptions of the other party (sometimes perceptions are intentionally distorted by gossip, slander, etc., contrary to known evidence!).

6. Conflicts involving perceptions of the situation or threat.

Other sources and types of conflict.

1. Power (those who feel powerless often resent those who are perceived to have the power; sometimes power is misused and mishandled, causing conflict).

2. Values and principles (conflicts are often caused when personal preferences are confused with values and principles or ideas of right and wrong!).

3. Feelings and emotions (feelings and emotions have to be taken into account, as these are often the trigger for conflict when they are ignored).

4. Internal conflicts (such as personality disorders).

Christians and workplace conflict.

1. Matthew $18: 15,16 ; 20: 1-16$ - Avoid creating or contributing to destructive conflict.

2. Christians should not contribute to the problem through gossip.

3. Should be wary of taking sides, especially when the facts are not known.

4. Christians should be part of the solution, not the problem.

5. The Christian should develop a reputation for being a cooperative and committed employee, who has a fair view of others. 
Eight conflict strategies for everyone on the job - taken from Kenneth Cloke and Joan Goldsmith. ${ }^{5}$

1. Change the culture and context of conflict.

2. Listen actively, emphatically and responsively.

3. Acknowledge and integrate emotions to solve problems.

4. Search beneath the surface for hidden meaning.

5. Separate what matters from what gets in the way.

6. Stop rewarding, and learn from difficult behaviors.

7. Solve problems creatively, plan strategically, and negotiate collaboratively.

8. Explore resistance, mediate and design systems for prevention and resolution.

Other strategies for conflict resolution.

1. Be proactive ... actively plan to avoid giving offense.

2. Remember the Golden Rule in all relationships.

3. A "soft answer" is always a great idea in conflict.

4. Make kindness a priority in your life and speech.

5. Work on your own communication skills.

6. Be honest and truthful! You're entitled to your own opinions, but you're not entitled to your own facts.

7. Don't assume anything, ask for clarity.

8. Don't participate in gossip about people ... it hurts when it's done to you, doesn't it?

${ }^{5}$ Kenneth Cloke and Joan Goldsmith, Resolving Conflicts at Work: Eight Strategies for Everyone on the Job, 2nd ed. (San Francisco: Jossey-Bass, 2005), 1-313. 


\section{Seminar Three}

Topic: Welcome the Sabbath: An examination of how shifting from an occupational mindset before corporate Sabbath worship can promote healthy congregational relationships.

The purpose of this seminar is to:

1. To explore the concept of dealing with the importance and benefits of welcoming the Sabbath.

2. To examine any connection between worshippers' welcoming of the Sabbath and attitudes that promote harmonious congregational relationships.

The objectives of this seminar are:

1. To affirm the facts and benefits of the Bible Sabbath.

2. To help participants understand how to better keep the Sabbath in harmony with God's law.

3. To demonstrate the meaning of Sabbath "rest".

4. To highlight the need for an attitude adjustment, in down-shifting from secular speed to sacred power when the Sabbath begins.

5. To clarify the meaning of doing secular "work" Vs. lawful "good" in the context of Sabbath observance.

6. To show that true Sabbath worship and positive congregational relationships are intricately linked.

The Sabbath - Gen. 2:1-3; Exod. 20:8-11

1. Derives from the Hebrew Shabbat, from the root word Shin-Beit-Tav, meaning: to cease, to end, or to rest.

2. We are commanded to remember (zakhor) Shabbat. This means two things:

a. Don't forget the Shabbat

b. Don't forget the significance or what it means

3. The significance of Shabbat

a. Memorial of creation - Exod. 20:11

b. Memorial of deliverance, freedom - Deut. 5:15

4. Observe/keep (shamor) the Shabbat - Deut. 5:12

The Benefits of Sabbath Keeping:

1. Communion with God and reflection on freedom, deliverance, and redemption - joyful worship.

2. Physical rest

3. Family time

4. Sense of 'God-will': The satisfaction of obedience

5. Service: doing good for others

The idea that God rested from His works ascribes to God a human need in order to demonstrate to humans how He planned to supply it for them. The anthropomorphic 
language clearly points to God's concern for humans who do not only need to work but also to separate a particular time to enjoy deep personal communion with the Creator. The divine action - God's rest - reveals His willingness to join humans in fellowship during the seventh day. ${ }^{105}$

God's rest then means His ceasing the work of creation in order to be free for the fellowship with man, the object of his love, for the rejoicing and celebration of His completed work together with his son on earth, the imago Dei, his festive partner. ${ }^{106}$

Sabbath and the Attitude of Worship

1. The Sabbath represents and affords the privilege for humans to transition attitudinally from secular concerns to sacred contemplation and celebration.

2. Worship (celebrating the worth of God) becomes our priority and our preoccupation.

3. Sabbath observance is mankind surrendering, submitting and "entering" emotionally, mentally, physically, spiritually into God's "rest" (His fellowship).

4. Sabbath puts our total dependence upon God into perspective: We are His creation; He is our deliverer.

5. Sabbath commemorates the creation, and exalts the Creator (creation is not exalted, including humankind).

Humility and reverence should characterize the deportment of all who come into the presence of God. In the name of Jesus we may come before Him with confidence, but we must not approach Him with the boldness of presumption, as though He were on a level with ourselves. There are those who address the great and all-powerful and holy God, who dwelleth in light unapproachable, as they would address an equal, or even an inferior. There are those who conduct themselves in His house as they would not presume to do in the audience chamber of an earthly ruler. These should remember that they are in His sight whom seraphim adore, before whom angels veil their faces God is greatly to be reverenced; all who truly realize His presence will bow in humility before Him, and, like Jacob beholding the vision of God, they will cry out, "How dreadful is this place! This is none other but the house of God, and this is the gate of heaven." 107

${ }^{105}$ Roy Gane, "Sabbath and the New Covenant," Journal of the Adventist Theological Society 10, nos. 1, 2 (1999): 312-313. (Quoted from General Conference of SDA Biblical Research Institute website the article on "The Biblical Sabbath: The Adventist Perspective" by Dr. Angel Manuel Rodriquez).

${ }^{106}$ Hans K. LaRondelle, Perfection and Perfectionism (Berrien Springs, MI: Andrews University Press, 1971), p. 72. (Quoted from General Conference of SDA Biblical Research Institute website - the article on "The Biblical Sabbath: The Adventist Perspective" by Dr. Angel Manuel Rodriquez).

${ }^{107}$ White, Patriarchs and Prophets, 252. 
The house of God is desecrated and the Sabbath violated by Sabbath believers' children. They run about the house, play, talk, and manifest their evil tempers in the very meetings where the saints have met together to glorify God and to worship Him in the beauty of holiness. The place that should be holy, where a holy stillness should reign, and where there should be perfect order, neatness, and humility, is made to be a perfect Babylon and a place where confusion, disorder, and untidiness reign. This is enough to shut out God from our assemblies and cause His wrath to be kindled, that He will not be pleased to go out with the armies of Israel to battle against our enemies. ${ }^{108}$

When the worshipers enter the place of meeting, they should do so with decorum, passing quietly to their seats.... Common talking, whispering, and laughing should not be permitted in the house of worship, either before or after the service. Ardent, active piety should characterize the worshipers. ${ }^{109}$

The Sabbath is God's answer for the weariness of the saints.

Sabbath: A Pause for Peace

1. TGIF! - This is a very common expression among Sabbath keepers

2. We look forward to Sabbath!

3. Jesus went to the house of God on the Sabbath - Luke 4:16.

4. After six days of weary labor, we surely need "rest".

5. Appropriate "work" is lawful on the Sabbath.

Ellen white's counsel on managers of Adventist institutions giving employees ample time to prepare for the Sabbath:

Whenever it is possible, employers should give their workers the hours from Friday noon until the beginning of the Sabbath. Give them time for preparation, that they may welcome the Lord's Day with quietness of mind. By such a course you will suffer no loss even in temporal things. ${ }^{110}$

Counsels on how to prepare for the Sabbath at home:

On Friday let the preparation for the Sabbath be completed. See that all the clothing is in readiness, and that all the cooking is done. Let the boots be blacked, and the baths be taken. It is possible to do this. If you make it a rule, you can do it. The Sabbath is not to be given to the repairing of garments, to the cooking of food, to pleasure seeking, or to any other worldly employment.... Parents, explain your work and its

$3: 257$.

${ }^{108}$ Ellen G. White, Selected Messages (1958; repr., Washington, DC: review and Herald, 1980),

${ }^{109}$ White, Testimonies for the Church, 5:492.

${ }^{110}$ Ibid., $6: 356$. 
purpose to your children and let them share in your preparation to keep the Sabbath according to the commandment. ${ }^{111}$

"We should jealously guard the edges of the Sabbath. Remember that every moment is consecrated, holy time."

Changing Gears: Down-shifting from Secular Speed to Sacred Power

A Biblical Warning Against Sabbath Desecration.

If thou turn away thy foot from the sabbath, from doing thy pleasure on my holy day; and call the sabbath a delight, the holy of the LORD, honourable; and shalt honour him, not doing thine own ways, nor finding thine own pleasure, nor speaking thine own words: Then shalt thou delight thyself in the LORD; and I will cause thee to ride upon the high places of the earth, and feed thee with the heritage of Jacob thy father: for the mouth of the LORD hath spoken it. Isaiah 58:13, 14

Sabbath and Appropriate Work

1. "Not lawful for you to carry your bed!" - John 5:10

2. Jesus challenged for allowing His disciples to pluck the ears of corn Matthew 12:1-8

3. They attempt to trap Jesus with the question about lawfulness to heal on the Sabbath - Matthew 12:10

4. Notice in these texts how the question of Sabbath observance was made to become a source of conflict, contrary to God's plan for His people!

5. What constitutes appropriate "work" on the Sabbath?

The Sabbath is not intended to be a period of useless inactivity. The law forbids secular labor on the rest day of the Lord; the toil that gains a livelihood must cease; no labor for worldly pleasure or profit is lawful upon that day; but as God ceased His labor of creating, and rested upon the Sabbath and blessed it, so man is to leave the occupations of his daily life, and devote those sacred hours to healthful rest, to worship, and to holy deeds. ${ }^{113}$

God has given men six days wherein to labor, and He requires that their own work be done in the six working days. Acts of necessity and mercy are permitted on the

\footnotetext{
${ }^{11}$ Ellen G. White, Child Guidance (Washington, DC: Review and Herald, 1954), 528.

${ }^{112}$ White, Testimonies for the Church, 6:356.

${ }^{113}$ Ellen G. White, The Desire of Ages (1898; repr., Mountain View, CA: Pacific Press, 1940), 207.
} 
Sabbath, the sick and suffering are at all times to be cared for; but unnecessary labor is to be strictly avoided. ${ }^{114}$

God requires not only that we refrain from physical labor upon the Sabbath, but that the mind be disciplined to dwell upon sacred themes. By conversing upon worldly things, or by engaging in light and trifling conversation, we virtually transgress the fourth commandment. Talking upon anything or everything which may come into the mind, is speaking our own words. Every deviation from right brings us into bondage and condemnation. ${ }^{115}$

There are cases in which Christ has given permission to labor even on the Sabbath in saving the life of men or of animals. But if we violate the letter of the fourth commandment for our own advantage from a pecuniary point of view we become Sabbath breakers and are guilty of transgressing all the commandments, for if we offend in one point we are guilty of all. ${ }^{116}$

Sabbath Worship and Congregational Relationships - the Connection.

Four Sources of Congregational Conflict

1. Attitudinal - different feelings or perspectives about persons and issues. "Prejudices, stereotypes, or particular beliefs are all attitudes which people carry with them." 117

2. Substantive - when there are different opinions about facts, goals, ends, or means.

3. Emotional - when personal value is attached either to attitudinal or substantive forms of conflict.

4. Communicative - when there is a breakdown in healthy, open communication about the sources of conflict.

How Differences Become Conflicts - Difference is a given. Conflict is a choice.

1. Attitude - the choice to express or harbor a negative attitude over a difference (bias, prejudice, dislike).

2. Anger - the choice to surrender reason to negative and combative emotions because of a difference.

3. Accusation - the choice to accuse, blame, judge, or label another negatively over a difference, often by misstatement of facts, assumptions, or by confusing personal preference with right and wrong.

4. Actions - the choice to take malicious steps to 'get back' at the one disagreed with (slander, gossip, sharp words, manipulation of facts, lying).

${ }^{114}$ White, Patriarchs and Prophets, 307.

${ }^{115}$ White, Gospel Workers, 207- 208.

${ }^{116}$ White, Testimonies for the Church, 1:531.

${ }^{117} \mathrm{McSw}$ ain and Treadwell, Conflict Ministry in the Church, 17-18. 
Specific counsel regarding Sabbath keeping and resolving conflict:

Before the setting of the sun let the members of the family assemble to read God's word, to sing and pray. There is need of reform here, for many have been remiss. We need to confess to God and to one another. We should begin anew to make special arrangements that every member of the family may be prepared to honor the day which God has blessed and sanctified. ${ }^{118}$

There is another work that should receive attention on the preparation day. On this day all differences between brethren, whether in the family or in the church, should be put away. Let all bitterness and wrath and malice be expelled from the soul. In a humble spirit, "confess your faults one to another, and pray one for another." 19

Five Common (and ineffective) Ways of Handling Conflict ${ }^{120}$

1. Conquest: Win, destroy the opponent, score points.

2. Avoidance: Non-confrontation of the person or issue.

3. Bargaining: A game to gain the upper hand.

4. Band-aid: Quick fix which pretends issue is solved.

5. Role Player: Defining relationship by assertion of position or roles.

Strategies for Conflict Resolution

1. Be proactive ... actively plan to avoid giving offense.

2. Remember the Golden Rule in all relationships.

3. A "soft answer" is always a great idea in conflict.

4. Make kindness a priority in your life and speech.

5. Work on your own communication and listening skills.

6. Be honest and truthful! You're entitled to your own opinions, but you're not entitled to your own facts.

7. Don't assume anything, ask for clarity.

8. Don't participate in gossip about other people ... it hurts when it's done to you, doesn't it? Correct those who approach you with gossip, especially slander.

${ }^{118}$ White, Testimonies for the Church, 6:356, 357.

${ }^{119}$ Ellen G. White, The Faith I Live By (1958; repr., Washington, DC: Review and Herald, 1973), 34.

${ }^{120}$ Weeks, The Eight Essential Steps, 4. 


\section{Seminar Four}

Topic - By This Shall All Men Know: The Power of Loving Relationships as a Factor in Discipleship and Church Growth.

The purpose of this seminar is to:

1. Examine the role of loving relationships as a factor in discipleship and church growth

2. Raise members' awareness of the detrimental effects of a love deficient congregation

The objectives of this seminar are:

1. To discover the power of loving relationships as a factor in discipleship and church growth as demonstrated in Acts 2:42-47.

2. To define loving relationships in the context of congregational life, based on John 13:34-35.

3. To understand the connection between Spirit baptism and Christian fellowship.

What is Love?

1. Agape-(Gk) A selfless, sacrificial, unconditional love, the highest of the four types of love expressed (or indicated) in the Bible. (John 14:21).

2. Eros - (Gk, but does not appear in Scripture) It's meaning is portrayed in the OT book Song of Solomon. This is the physical, sensual love between a husband and wife.

3. Philia - (Gk) Close friendship or affection. ("Love one another with brotherly affection..." Rom. 12:10).

4. Storge - (Gk, but does not appear in Scripture) Family love, the bond among mothers, fathers, sisters and brothers.

5. Love is not merely a nice word or concept, but an action word, a state of being and doing.

Post-Pentecostal demonstration of love among the disciples.

After the descent of the Holy Spirit, when the disciples went forth to proclaim a living Saviour, their one desire was the salvation of souls. They rejoiced in the sweetness of communion with saints. They were tender, thoughtful, self-denying, willing to make any sacrifice for the truth's sake. In their daily association with one another, they revealed the love that Christ had enjoined upon them. By unselfish words and deeds they strove to kindle this love in other hearts. ${ }^{121}$

A survey of Acts 2:42-47 - See the Love!

1. Verse 42: Continuing steadfastly in the apostles' teaching.

2. Verse 42: Fellowship (brotherhood and sharing).

3. Verse 42: Breaking of bread (common eating/communion).

${ }^{121}$ White, The Acts of the Apostles, 547. 
4. Verse 42: Prayers (private and corporate).

5. Verse 43: Reverential awe because of two months of Holy Spirit's manifestation in preaching and miracles.

6. Verse 44: Unity (physical togetherness and unity of spirit).

7. Verses 44-45: This selflessness is only the result of agape.

8. Verses 46-47: God honors the loyalty and love of the members of the Church by adding to their numbers.

A Look at John 13:34-35 - Show the Love!

1. Verse 34: Is it really a new commandment? No, it was first stated in Leviticus 19:18.

2. Love (Gk. agapao) - In this passage literally reads - "keep on loving"

The command was new in that a new demonstration had been given of love, which the disciples were bidden to emulate.... The new command enjoined men to preserve the same relationship with one another that Jesus had cultivated with them and mankind generally. Where the old commandment enjoined men to love their neighbors as themselves, the new was, in fact, more difficult than the old, but grace for its accomplishment was freely provided. ${ }^{122}$

A Look at John 13:34-35 - Show the Love!

1. Verse 35: "By this..."

2. Evidence of true discipleship, walking with Jesus, is the love spoken of by Him in vs. 34.

3. "have love..." - Literally means to 'keep on having love' - this shows the emphasis on consistency in positive manifestations of loving relationships as the evidence of discipleship.

4. The word translated 'love' in this text is the same word translated 'charity' in 1 Corinthians 13.

5. The word love is a verb, an action word. Love is demonstrated, not merely a concept to talk about.

Spirit baptism and Christian fellowship.

The relationship between the baptism of the Holy Spirit and genuine Christian fellowship is also essential for the Christian to understand and experience. Even though we may receive the baptism of the Holy Spirit, we will not grow spiritually as God intends without a meaningful, mutually dependent fellowship with other Spiritfilled believers. To become Spirit filled, and remain somewhat isolated and independent of other Spirit-filled Christians, will not only hinder our spiritual growth but may lead to the loss of the fullness of the Spirit's presence in our life. ${ }^{123}$

122“A New Commandment," SDA Bible Commentary, 5:1032.

${ }^{123}$ Dennis Smith, 40 Days of Prayers and Devotions to Prepare for the Second Coming (Hagerstown, MD: Review and Herald, 2009), 103. 
The baptism of the Holy Spirit and fellowship groups go hand in hand. Both are necessary for the Christian to grow into the fullness of Christ. The baptism of the Holy Spirit is essential for the core members of a fellowship group in order for the group to function as God intends.... In order for the Spirit-baptized believer to keep the 'fire' from going out in his life, he needs not only to continually ask God for the Spirit's infilling (Eph. 5:18), but he must also continually keep in fellowship with other Spirit-filled believers. ${ }^{124}$

Counsel on dealing with erring members.

If thy brother shall trespass against thee," Christ declared, "go and tell him his fault between thee and him alone." Matthew 18:15. Do not tell others of the wrong. One person is told, then another, and still another; and continually the report grows, and the evil increases, till the whole church is made to suffer. Settle the matter "between thee and him alone." This is God's plan. "Go not forth hastily to strive, lest thou know not what to do in the end thereof, when thy neighbor hath put thee to shame. Debate thy cause with thy neighbor himself; and discover not a secret to another." Proverbs 25:8, 9. Do not suffer sin upon your brother; but do not expose him, and thus increase the difficulty, making the reproof seem like a revenge. Correct him in the way outlined in the word of God. ${ }^{125}$

Do not suffer [allow] resentment to ripen into malice. Do not allow the wound to fester and break out in poisoned words, which taint the minds of those who hear. Do not allow bitter thoughts to continue to fill your mind and his. Go to your brother, and in humility and sincerity talk with him about the matter. ${ }^{126}$

Whatever the character of the offense, this does not change the plan that God has made for the settlement of misunderstandings and personal injuries. Speaking alone and in the spirit of Christ to the one who is in fault will often remove the difficulty. Go to the erring one, with a heart filled with Christ's love and sympathy, and seek to adjust the matter. Reason with him calmly and quietly. Let no angry words escape your lips. Speak in a way that will appeal to his better judgment. Remember the words: "He which converteth the sinner from the error of his way shall save a soul from death, and shall hide a multitude of sins." James 5:20. ${ }^{127}$

Take to your brother the remedy that will cure the disease of disaffection. Do your

\footnotetext{
${ }^{124}$ Smith, 40 Days of Prayers and Devotions, 108-109.

${ }^{125}$ White, Testimonie s for the Church, 7:260.

${ }^{126}$ Ibid., 261.

${ }^{127}$ Ibid.
} 
part to help him. For the sake of the peace and unity of the church, feel it a privilege as well as a duty to do this. If he will hear you, you have gained him as a friend. ${ }^{128}$

All heaven is interested in the interview between the one who has been injured and the one who is in error. As the erring one accepts the reproof offered in the love of Christ, and acknowledges his wrong, asking forgiveness from God and from his brother, the sunshine of heaven fills his heart. The controversy is ended; friendship and confidence are restored. The oil of love removes the soreness caused by the wrong. The Spirit of God binds heart to heart, and there is music in heaven over the union brought about. ${ }^{129}$

"My brethren, prevail by love rather than by severity. When one at fault becomes conscious of his error, be careful not to destroy his self-respect. Do not seek to bruise and wound, but rather to bind up and heal." $" 130$

A Look at What Gossip Does to the Church. Definition: What is Gossip?

1. "Casual or unconstrained conversation or reports about other people, typically involving details that are not confirmed as being true." - Webster

2. "Rumor or talk of a personal, sensational, or intimate [private] nature; A person who habitually spreads intimate or private rumors or facts; Trivial, chatty talk or writing.." - thefreedictionary.com

3. "Idle talk or rumor, esp. about the personal or private affairs of others" - 1 Timothy 5:13

4. "Trivial writing or talk of an intimate nature about someone else, in either rumors or facts."

5. Synonyms: Scandal, slander, rumor, hearsay. Scandal is malicious gossip that is damaging to reputation.

Ellen White's Counsels on dealing with gossip (supplemental reading).

"Gossipers and news carriers are a terrible curse to neighborhoods and churches. Two thirds of all the church trials [problems] arise from this source."131

It pains me to say that there are unruly tongues among church members. There are false tongues that feed on mischief. There are sly, whispering tongues. There is tattling, impertinent meddling, adroit [clever or skillful] quizzing. Among the lovers of gossip some are actuated by curiosity, others by jealousy, many by hatred against those through whom God has spoken [spiritual leaders] to reprove them. All these

\footnotetext{
${ }^{128}$ White, Testimonie s for the Church, 7:261.

${ }^{129}$ Ibid.

${ }^{130}$ Ibid., 265.

${ }^{131}$ Ibid., 2:465
} 
discordant elements are at work. Some conceal their real sentiments, while others are eager to publish all they know, or even suspect, of evil against another. ${ }^{132}$

I saw that the very spirit of perjury, that would turn truth into falsehood, good into evil, and innocence into crime, is now active. Satan exults over the condition of God's professed people. While many are neglecting their own souls, they eagerly watch for an opportunity to criticize and condemn others. All have defects of character, and it is not hard to find something that jealousy can interpret to their injury. "Now," say these self-constituted judges, "we have facts. We will fasten upon them an accusation from which they cannot clear themselves." They wait for a fitting opportunity and then produce their bundle of gossip and bring forth their tidbits. ${ }^{133}$

Is there no law of kindness to be observed? Have Christians been authorized of God to criticize and condemn one another? Is it honorable, or even honest, to win from the lips of another, under the guise of friendship, secrets which have been entrusted to him, and then turn the knowledge thus gained to his injury? Is it Christian charity to gather up every floating report, to unearth everything that will cast suspicion on the character of another, and then take delight in using it to injure him? Satan exults when he can defame or wound a follower of Christ. He is "the accuser of our brethren." Shall Christians aid him in his work ${ }^{134}$

An earnest effort should be made in every church to put away evil speaking and a censorious spirit as among the sins productive of the greatest evils in the church. Severity and faultfinding must be rebuked as the workings of Satan. Mutual love and confidence must be encouraged and strengthened in the members of the church. Let all, in the fear of God and with love to their brethren, close their ears to gossip and censure. Direct the talebearer to the teachings of God's word. Bid him obey the Scriptures and carry his complaints directly to those whom he thinks in error. This united action would bring a flood of light into the church and close the door to a flood of evil. Thus God would be glorified, and many souls would be saved. ${ }^{135}$

The names of God's chosen servants have been handled with disrespect, and in some cases with absolute contempt, by certain persons whose duty it is to uphold them. The children have not failed to hear the disrespectful remarks of their parents in reference to the solemn reproofs and warnings of God's servants. They have understood the scornful jests and depreciatory speeches that from time to time have met their ears, and the tendency has been to bring sacred and eternal interests, in their minds, on a level with the common affairs of the world. What a work are these parents doing in making infidels of their children even in their childhood! This is the way that children

\footnotetext{
${ }^{132}$ White, Testimonies for the Church, 5:94.

${ }^{133}$ Ibid.

${ }^{134}$ Ibid., 95 .

${ }^{135}$ Ibid., 5:609.
} 
are taught to be irreverent and to rebel against Heaven's reproof of sin. Spiritual declension can but prevail where such evils exist. These very fathers and mothers, blinded by the enemy, marvel why their children are so inclined to unbelief and to doubt the truth of the Bible. They wonder that it is so difficult to reach them by moral and religious influences. Had they spiritual eyesight, they would at once discover that this deplorable condition of things is the result of their own home influence, the offspring of their jealousy and distrust. Thus many infidels are educated in the family circles of professed Christians. ${ }^{136}$

There are many who find special enjoyment in discoursing and dwelling upon the defects, whether real or imaginary, of those [spiritual leaders] who bear heavy responsibilities in connection with the institutions of God's cause. They overlook the good that has been accomplished, the benefits that have resulted from arduous labor and unflinching devotion to the cause, and fasten their attention upon some apparent mistake, some matter that, after it has been done and the consequences have followed, they fancy could have been done in a better manner with fairer results, when the truth is, had they been left to do the work, they would either have refused to move at all under the attending discouragements of the case, or would have managed more indiscreetly than those who did do the work, following the opening of God's providence.

But these unruly talkers will fasten upon the more disagreeable features of the work, even as the lichen [a simple plant consisting of a fungus] clings to the roughness of the rock. These persons are spiritually dwarfed by continually dwelling upon the failings and faults of others. They are morally incapable of discerning good and noble actions, unselfish endeavors, true heroism, and self-sacrifice. They are not becoming nobler and loftier in their lives and hopes, more generous and broad in their ideas and plans. They are not cultivating that charity that should characterize the Christian's life. They are degenerating every day and are becoming narrower in their prejudices and views. Littleness is their element, and the atmosphere that surrounds them is poisonous to peace and happiness. ${ }^{137}$

Evil speaking is a twofold curse, falling more heavily upon the speaker than upon the hearer. He who scatters the seeds of dissension and strife reaps in his own soul the deadly fruits. How miserable is the talebearer, the surmiser of evil! He is a stranger to true happiness. ${ }^{138}$

Satan has many helpers. Many who profess to be Christians are aiding the tempter to catch away the seeds of truth from other hearts. Many who listen to the preaching of the word of God make it the subject of criticism at home. They sit in judgment on the sermon as they would on the words of a lecturer or a political speaker. The message

\footnotetext{
${ }^{136}$ White, Testimonies for the Church, 4:195.

${ }^{137}$ Ibid., 4:196.

${ }^{138}$ Ibid., 5:176.
} 
that should be regarded as the word of the Lord to them is dwelt upon with trifling or sarcastic comment. The minister's character, motives, and actions, and the conduct of fellow members of the church, are freely discussed. Severe judgment is pronounced, gossip or slander repeated, and this in the hearing of the unconverted. Often these things are spoken by parents in the hearing of their own children. Thus are destroyed respect for God's messengers, and reverence for their message. And many are taught to regard lightly God's word itself. ${ }^{139}$

Thus in the homes of professed Christians many youth are educated to be infidels. And the parents question why their children are so little interested in the gospel, and so ready to doubt the truth of the Bible. They wonder that it is so difficult to reach them with moral and religious influences. They do not see that their own example has hardened the hearts of their children. The good seed finds no place to take root, and Satan catches it away. ${ }^{140}$ 1941), 45 .

${ }^{139}$ Ellen G. White, Christ's Object Lessons (1900; repr., Washington, DC: Review and Herald,

${ }^{140}$ Ibid., 46. 


\section{Seminar Five}

Topic - Healing the Wounds: The Role and Responsibility of the Offended, Offenders and Observers in Conflict Resolution.

The purpose of this seminar is to:

1. To examine the roles and responsibilities of all parties (offended, offenders and observers) in congregational conflict resolution.

2. To discover God's healing power in conflict resolution.

Overview of the seminar:

1. The Duty of the Offended in Conflict Resolution

2. The Offender's Duty to the Offended and to God

3. The Duty of Observers in Congregational Conflict

4. The Role of the Holy Spirit in Healing the Wounds

Read Matthew 18:15-20

Definition of terms

1. Offended - One harmed by the injurious attitudes, actions or words of another.

2. Offender - One who causes harm to another through attitudes, actions or words; an abuser or attacker.

3. Observer - Third party who has first-hand knowledge of wrongdoing, or one who is made aware of alleged wrongdoing through the testimony of other witnesses (which may include the testimony of the offended and offender); One who is called upon to adjudicate a dispute or conflict.

Note: All human beings play the role of the offended, the offender and the observer from time to time.

What is the duty of the offended?

Typical (and ineffective) responses of the offended

1. Passive Withdrawal - Silence, sulking, coldness, etc.

2. Triangulation - Telling third parties about the matter without first seeking to resolve it with the offender.

3. Desire for Revenge - Harboring the hurt, which then ripens into malice (evil intent or desire to do harm).

4. Aggressive Counter-Attack - Offended in fight mode; the use of malicious spoken or written words and taking action to get even with (hurt) the offender.

5. Unforgiveness - Even after the offender has repented.

What God requires of the offended 
1. Acknowledge the issue and the hurt that's in your own heart. Do not secretly hold a matter against another that he does not know you're hurting over - Leviticus 19:17(a).

2. Address the problem to the offender (there are very important reasons for this, including clarifying the issue, preventing the spreading of misperceptions, and promoting a positive outcome) - Matt. 18:15.

3. Forgive the repentant offender (unforgiveness hinders reconciliation) Luke 17:1-4; Matt. 18:21-35.

Ellen White's counsel:

If thy brother shall trespass against thee," Christ declared, "go and tell him his fault between thee and him alone." Matthew 18:15. Do not tell others of the wrong. One person is told, then another, and still another; and continually the report grows, and the evil increases, till the whole church is made to suffer. Settle the matter "between thee and him alone." This is God's plan. "Go not forth hastily to strive, lest thou know not what to do in the end thereof, when thy neighbor hath put thee to shame. Debate thy cause with thy neighbor himself; and discover not a secret to another." Proverbs 25:8, 9. Do not suffer [allow] sin upon your brother; but do not expose him, and thus increase the difficulty, making the reproof seem like a revenge. Correct him in the way outlined in the word of God. ${ }^{141}$

Whatever the character of the offense, this does not change the plan that God has made for the settlement of misunderstandings and personal injuries. Speaking alone and in the spirit of Christ to the one who is in fault will often remove the difficulty. Go to the erring one, with a heart filled with Christ's love and sympathy, and seek to adjust the matter. Reason with him calmly and quietly. Let no angry words escape your lips. Speak in a way that will appeal to his better judgment. Remember the words: "He which converteth the sinner from the error of his way shall save a soul from death, and shall hide a multitude of sins. James $5: 20{ }^{142}$

What is the duty of the offender?

Typical (and ineffective) responses of the offender

1. Denial or justification of wrongdoing, hence, no repentance or apology for wrong done.

2. Demanding forgiveness, acceptance or reconciliation without any acknowledgement of, remorse for, or cessation of wrongdoing (usually done by talking about the perceived unforgiveness of the offended).

3. Blaming the victim for the offense (common in cases of domestic abuse, but not limited to that setting).

4. Insincere "apology' - "If I offended you, I am sorry."

${ }^{141}$ White, Christ's Object Lessons, 260.

${ }^{142}$ Ibid., 261. 
5. Continuation or escalation of the offensive behavior.

What God requires of the offender

1. Acknowledge (confess) the wrong done and the hurt caused - James 5:16.

2. Repentance (discontinue the offence) - Luke 17:1-4.

3. Restore whatever was stolen from the offended.

4. Apology - private or public (depending on the forum of the offence in question) - Steps to Christ, p. 38.

What about the unrepentant offender?

1. Unfortunately, ego and pride often prevent offenders from acknowledging that they have wronged others, even when there's no question about it (most of the times when know when we are wrong)

2. For unrepentant offenders, see Matt. 18:16, 17

3. The offended can (and often must choose) to forgive the offender, even in the absence of an apology

4. Unrepentant offenders hinder reconciliation

5. What does Luke 23:34 mean?

Father, forgive them; for they know not what they do." His mind passed from His own suffering to the sin of His persecutors, and the terrible retribution that would be theirs. No curses were called down upon the soldiers who were handling Him so roughly. No vengeance was invoked upon the priests and rulers, who were gloating over the accomplishment of their purpose. Christ pitied them in their ignorance and guilt. He breathed only a plea for their forgiveness,-- "for they know not what they do."

Had they known that they were putting to torture One who had come to save the sinful race from eternal ruin, they would have been seized with remorse and horror. But their ignorance did not remove their guilt for it was their privilege to know and accept Jesus as their Saviour. Some of them would yet see their sin, and repent, and be converted. Some by their impenitence would make it an impossibility for the prayer of Christ to be answered for them. Yet, just the same, God's purpose was reaching its fulfillment. Jesus was earning the right to become the advocate of men in the Father's presence. ${ }^{143}$

The apostle says, Confess your faults one to another, and pray one for another, that ye may be healed." James 5:16. Confess your sins to God, who only can forgive them, and your faults to one another. If you have given offense to your friend or neighbor, you are to acknowledge your wrong, and it is his duty freely to forgive you. Then you are to seek the forgiveness of God, because the brother you have wounded is the property of God, and in injuring him you sinned against his Creator and Redeemer. The case is brought before the only true Mediator, our great High Priest, who "was in all points

\footnotetext{
${ }^{143}$ White, The Desire of Ages, 744.
} 
tempted like as we are, yet without sin," and who is "touched with the feeling of our infirmities," and is able to cleanse from every stain of iniquity. Hebrews 4:15. ${ }^{144}$

True confession is always of a specific character, and acknowledges particular sins. They may be of such a nature as to be brought before God only; they may be wrongs that should be confessed to individuals who have suffered injury through them; or they may be of a public character, and should then be as publicly confessed. But all confession should be definite and to the point, acknowledging the very sins of which you are guilty. ${ }^{145}$

The spirit of self-justification originated in the father of lies and has been exhibited by all the sons and daughters of Adam. Confessions of this order are not inspired by the divine Spirit and will not be acceptable to God. True repentance will lead a man to bear his guilt himself and acknowledge it without deception or hypocrisy. Like the poor publican, not lifting up so much as his eyes unto heaven, he will cry, "God be merciful to me a sinner," and those who do acknowledge their guilt will be justified, for Jesus will plead His blood in behalf of the repentant soul. ${ }^{146}$

What is the duty of the observer?

Typical (and ineffective) responses of observers

1. Bystander Apathy - Avoidance, disengagement, indifference, disregard for the suffering of the abused.

2. Fear - Public silence; private 'support' for the abused.

3. Partiality - Unfair judgment: taking sides with the offender, often due to a personal friendship, family relationship or bribery (material or otherwise).

4. Mob Enchantment - Caught in the emotional frenzy against the innocent (Num. 16:1-50; Matt. 27:15-26).

5. Constructive observer intervention in congregational conflict is rare, compared to the responses above.

What God requires of the observer of conflict

1. Scripture addresses the role of observers of conflict more than it addresses the role of the parties who are directly involved! Observers may be: Family members, friends, eye-witnesses, judges, co-workers, church members, neighbors, members of a jury, leaders, supervisors, passersby, etc.

2. In matters that are formally or informally adjudicated, it is the observer who judges (decides innocence or guild, right or wrong)

3. Righteous judgment is required by God - John 7:24

\footnotetext{
${ }^{144}$ Ellen G. White, Steps to Christ (1892; repr., Mountain View, CA: Pacific Press, 1956), 37.

${ }^{145}$ Ibid., 38 .

${ }^{146}$ Ibid., 38, 40.
} 
God requires righteous judgment

1. John 7:24 - Don't judge based on their faces!

2. Prov. 24:23-25 - It's not good to show partiality.

3. Lev. 19:15 - Judge your neighbor fairly, impartially.

4. Deut. 1:9-17 - "Don't be partial. Don't be afraid. Judgment is of God"

5. Deut. 16:18-20 - "do not pervert [twist] others' words ... in judgment"

6. Prov. 17:15 - The partial [unfair] observer and the offender are both an abomination to God!

7. Exodus 23:1-9 - Don't circulate a false report ... bribe.

The role of the Holy Spirit in healing the wounds

1. He will guide our words, attitudes and actions when we submit.

2. When we err or are hurt, He will tell us what to do.

3. The Holy Spirit is the Comforter, the Healer of all. 
APPENDIX B

SURVEY APPROVAL AND PROMOTIONAL DOCUMENTS 


\section{New Life Seventh-day Adventist Church
Celebrating a Brand New Life in Christ}

April 27, 2011

Institutional Review Board

Andrews University

Berrien Springs, MI 49104-0355

To Whom It May Concern:

New Life Seventh-day Adventist Church is pleased to support the Doctor of Ministry Project of our pastor, Everton A. Ennis, being undertaken by him at Andrews University.

On Wednesday April 27, our Church Board voted institutional consent to support his research project entitled: "A Conflict Resolution Program for the New Life Wamer Robins, Georgia, Seventh-day Adventist Church". He has consent to present seminars, sermons and workshops on the theme of the project in various forums at the church, and to gather relevant research information via focus groups comprised of the church membership and Sabbath School membership.

\section{Respectfully,}

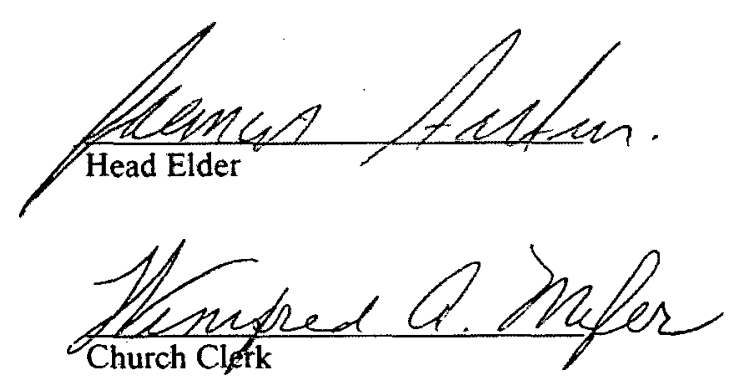

Pastor: EA Ennis | Telephone: 478-922-6286 | Internet: www.aBrandNewLife.org

1601 Green Street, Warner Robins, GA 31093 


\section{INTERVIEW PROTOCOL}

Pastor Everton A. Ennis

Doctor of Ministry Degree Student

Andrews University

Phone: (478) 334-1484

Email: eaennis@hotmail.com

November 30,2011

"A Conflict Resolution Program for the New Life, Warner Robins, Georgia, Seventh-day Adventist Church: Seminar on Resolving Family Conflict"

\section{Interview Protocol for Focus Groups}

\section{NOTE to Group Members}

This evaluation is formative and qualitative. This means that my primary point is to gather information that helps me improve my ongoing efforts at ministering in conflict resolution situations; and that the information I am collecting is by design descriptive rather than numeric. We have don't need to be concerned with counting things... I just want your words and your impressions of the subject material.

All information I collect is confidential as to who provided it. For example, I will not disclose who actually participated in this focus group nor will my final report make any attributions for quotes. I hope this encourages you (i.e., if you need encouragement :-) to speak freely.

\section{Lead-off Questions:}

- How would you characterize the seminar, in terms of the stated purpose and objectives?

- l'd like each of you to share with the group, in your own way, what you learned from today's presentation.

- What part of the presentation do you strongly agree or disagree with, and why?

- How do you see this presentation benefitting our members at home, at church?

- From a biblical perspective, how has your understanding of God's will for the family in matters of conflict been impacted?

- What part of the presentation challenged you the most and caused you to have a stronger desire to resolve conflict biblically?

- Is there anything that I didn't present in the seminar that you believe would add to it's completeness for the home, and what would that be?

\section{Follow-up Questions:}

I certify that any further questions arising from the initial questions will remain within the framework of the research approval that I seek. 


\section{DMIN COMMITTEE—PROJECT APPROVAL LETTER}

\section{Andrews QUniversity}

April 22, 2011

Pastor Everton Ennis

$207 \mathrm{Haywood} \mathrm{Dr}$

Kathleen, GA 31047

Dear Pastor Ennis:

Your project proposal, titled A Conflict Resolution Program for the New Life, Warner Robins, Georgia, Seventh-day Adventist Church, has been formally approved by the Doctor of Ministry Committee, subject to approval by the Institutional Review Board (IRB).

According to your proposal submission, you have requested Dr. James North to serve as your project advisor. This arrangement is also approved. We congratulate you on your progress, and wish you every success as you work to complete your degree.

Blessings,

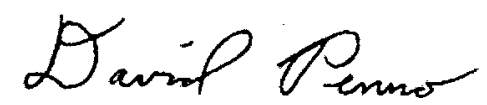

David Penno, PhD

Doctor of Ministry Project Coach

Seventh-day Adventist Theological Seminary

Andrews University

Cc: James North 
October 11, 2011

\title{
Andrews University
}

Pastor Everton Ennis

Tel: (478) 334-1484

Email: eaennis@hotmail.com

\begin{abstract}
RE: Application for Approval of Research Involving Human Subjects IRB Protocol \#:11-080 Application Type: Original Advisor: James North, Jr. Dept.: Doctor of Ministry

Title: A Conflict Resolution Program for the New Life Warner Robins, Georgia Seveth-day Adventist Church
\end{abstract}

Thank you for submitting your IRB application for approval of research involving human subjects entitled: "A Conflict Resolution Program for the New Life Warner Robins, Georgia Seveth-day Adventist Church" IRB protocol \# 11-o8o. We would like to inform you that your study has been evaluated and determined to be Exempt from IRB review according to Andrews University guidelines for the Doctor of Ministry Exempt status. You may now proceed with your research.

We ask that you reference the protocol number in any future correspondence regarding this study for easy retrieval of information.

Please note that any future changes made to the study design and/or consent form require prior approval from the IRB before such changes can be implemented.

While there appears to be no more than minimum risk with your study, should an incidence occur that results in a research-related adverse reaction and/or physical injury, this must be reported immediately in writing to the IRB. Any research-related physical injury must also be reported immediately to the University Physician, Dr. Hamel, by calling (269) 473-2222.

Please feel free to contact our office if you have any questions.

Best wishes in your studies,

$$
\text { Heninalar }
$$

Sarah Kimakwa

IRB, Research \& Creative Scholarship 


\section{Pastor Ennis Needs Your Help!}

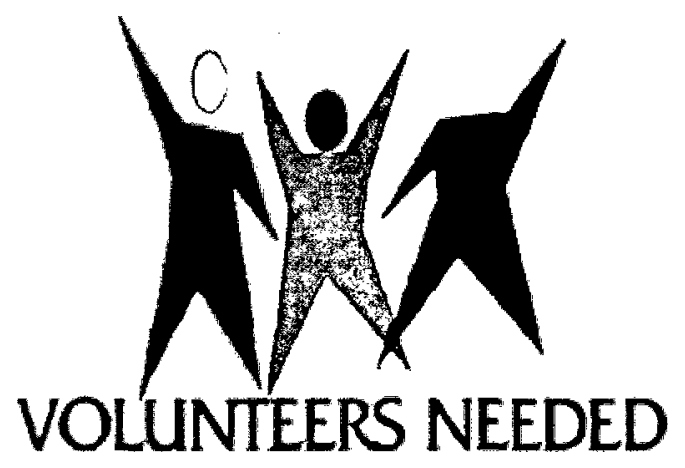

Greetings, New Life Family! As many of you know, I'm doing a project for my doctoral degree with Andrews University. pertaining to the development of a conflict resolution program for the church.

I will be presenting various seminars, semons and workshops on this subject, starting on the $30^{\mathrm{t}}$ of this month, and contimuing mitil April next year.

I need your help!

I'm soliciting unpaid volunteers, 18 years old and above, who are willing and able to be part of focus groups (you don't have to be part of every group after eviery presemtation) which are aimed at belping me gather vital feectback via the group interview process.

If rou're interested in helping out: Call me on my cell phone 334-1484 Or email me at eaennis $a$ hotmail.com

Thanks in advance,

Pastor EA Enmis

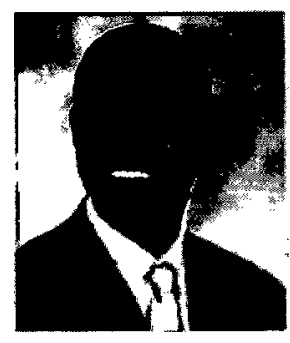




\section{Volunteers Needed!}

\section{Are You...}

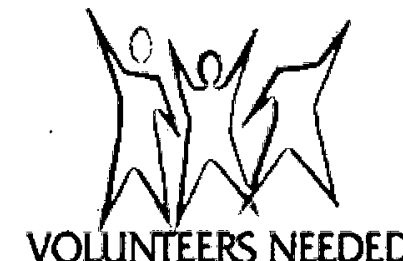

18 years old and above?

Willing to donate $45-60$ minutes?

Open to help me earn my doctoral degree?

\section{Well... I need your helpIII} (please read below) 8:15 PM

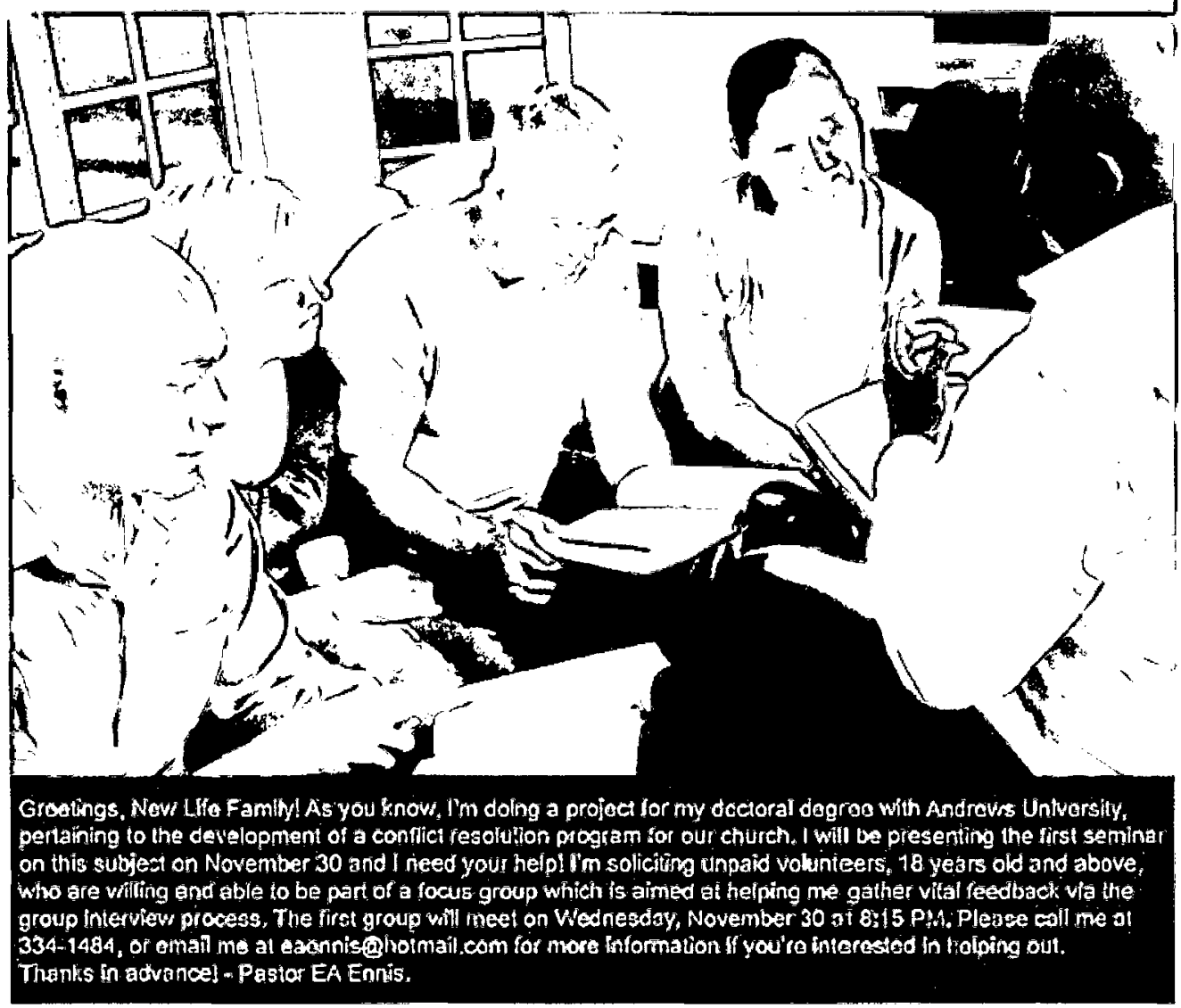




\title{
Andrews $\$$ University
}

\author{
Seventh-day Adventist Theological Seminary
} Informed Consent Form

A Conflict Resolution Program for the New Life, Warner Robins, Georgia, Seventh-day

Adventist Church

Pastor Everton A. Ennis

Doctor of Ministry Degree Student

Andrews University

Phone: (478) 334-1484

Email: eaennis@hotmail.com

\section{PURPOSE}

Like many churches, the Warner Robins New Life Seventh-day Adventist Church has experienced episodes of disruptive conflict in the past. Sometimes, these episodes can have longlasting effects that undermine a church's ability to rise to their full ministry potential. A structured and intentional focus on conflict resolution-based discipleship training will foster church unity, and promote a passion for soul winning and church growth.

\section{INCLUSION CRITERIA}

I understand that participants in the focus groups will be unpaid volunteers, age 18 and above, who are willing and able to meet at the times scheduled, for up to two hours, and who are desirous of assisting the research process. I further understand that participants will be recruited from within the church membership and Sabbath School membership (Adventists and nonAdventists who regularly attend the church, but do not yet have membership here), and that group members must have been physically present during the presentation they will provide feedback on.

\section{PROCEDURE}

I understand that I will be asked to give my open and bonest opinion, understanding and views concerning presentations that are made, and that my responses will be recorded electronically as well as in hard written or typed notes for later transcription and organization.

\section{RISKS AND DISCOMFORTS}

I understand that there are no risks of any kind for participating in this study.

\section{BENEFITS/RESULTS}

I understand that I may not receive any direct benefits from participating in this study. I understand that the results may help pastors and other conflict resolution trainers to better teach conflict resolution in churches and the wider society. I understand that the information collected during this study will be included in a Doctoral Dissertation, and may be presented or published in professional meetings or journals.

\section{VOLUNTARY PARTICIPATION}

I understand that my participation in this study is voluntary. I understand that I may discontinue my participation in this study at any time without any penalty or prejudice. I also understand that there is no compensation in return for my participation. 


\section{CONFIDENTIALITY}

I understand that all information and test results will be kept confidential. No personal identifiers, if any is required, will be sold or revealed, and records of the research will be kept secure by the investigators. Only the investigators will have access to any individual data. At no time will I be identified individually in any type of publication or presentation.

\section{REQUEST FOR MORE INFORMATION}

The study has been explained to me, and I have had an opportunity to ask questions. If any other questions should arise during this study I understand that I can contact either: Pastor Everton A. Ennis at 478-334-1484 or their research supervisor, Dr. James North at 269-471-3244. A contact address for Dr. North is: SDA Theological Seminary, Andrews University, Berrien Springs, MI 49104

I have explained the purpose of this research, all procedures, and possible risks and benefits to the best of my ability to

Investigator Signature

Date

I confirm that has explained to me, the purpose of the research. I have read and understand this consent form and have had all my questions answered to my satisfaction. Therefore, I agree to give my consent to participate as a subject in this research project.

Participant Signature

Date

Witness to Signature

Date 


\section{CLASS Act Conflict Resolution Seminar Schedule}

\begin{tabular}{|c|c|c|c|}
\hline Seminar & Date & Title & $\begin{array}{l}\text { Focus } \\
\text { Group }\end{array}$ \\
\hline 1 & Wed. Nov. 30,2011 & $\begin{array}{l}\text { Resolving Family Conflict: Overcoming Conflict in } \\
\text { the Christian Home }\end{array}$ & $11-30-11$ \\
\hline 2 & Sat., Dec. 31. 2011 & $\begin{array}{l}\text { Navigating the Obstacle Course of Worlyplace } \\
\text { Conflict }\end{array}$ & $12-31-11$ \\
\hline 3 & Sat., Jan. 14,2012 & $\begin{array}{l}\text { Welcome the Sabbath: How Shifting from an } \\
\text { Occupational Mindset Can Promote Healthy } \\
\text { Congregational Relationships }\end{array}$ & $1-14-12$ \\
\hline 4 & Sat, Jan. 28,2012 & $\begin{array}{l}\text { By This Shall All Men Know: The Power of Loving } \\
\text { Relationships as a Factor in Discipleship and Church } \\
\text { Growth }\end{array}$ & $1-28-12$ \\
\hline 5 & Sat. Feb. 25,2012 & $\begin{array}{l}\text { Healing the Wounds: The Role and Responsibility of } \\
\text { the Offended. Offenders and Observers in Conflict } \\
\text { Resolution }\end{array}$ & $2-25-12$ \\
\hline
\end{tabular}




\section{BIBLIOGRAPHY}

Barth, Dianne F. "Off the Couch: Thoughts about the Therapeutic Process, and the Dynamics of Client-Therapist Interactions. http://www.psychologytoday .com/blog/the-couch/201210/managing-anxiety-in-the-face-real-danger (accessed June 3, 2013).

Barthel, Tara Klena, and David V. Edling. Redeeming Church Conflicts: Turning Crisis into Compassion and Care. Grand Rapids, MI: Baker Books, 2012.

"Be angry and sin not." Seventh-day Adventist Bible Commentary. Edited by Francis D. Nichol. 1953-57. Reprint, Washington, DC: Review and Herald, 1980. 6:1027.

Bixby, Douglas, J. Challenging the Church Monster: From Conflict to Community. Eugene, OR: Wipf and Stock, 2002.

Bolton, Robert. People Skills: How to Assert Yourself, Listen to Others, and Resolve Conflicts. 2nd ed. New York: Simon \& Schuster, 1986.

Bramson, Robert. Coping with Difficult People. New York: Bantam Doubleday Dell Publishing Group, 1981.

Brauns, Chris. Unpacking Forgiveness: Biblical Answers for Complex Questions and Deep Wounds. Wheaton, IL: Crossway, 2008.

Brinkman, Rick, and Rick Kirschner. Dealing with People You Can't Stand: How to Bring Out the Best in People at Their Worst. New York: McGraw-Hill, 1994.

Brooks, Ricki Lee. Let's Stop fighting: A Biblical Approach for Working Out Our Differences. Silverdale, WA: Sound Communication, 2012.

Brown, F, S. Driver, and C. Briggs. The Brown-Driver-Briggs Hebrew and English Lexicon. 1906. Reprint, Peabody, MA: Hendrickson Publishers, 1999.

Bullard, Jr., George W. Every Congregation Needs a Little Conflict. St. Louis, MO: Chalice Press, 2008.

Cavaiola, Alan A., and Neil J. Lavender. Toxic Coworkers: How to Deal with Dysfunctional People on the Job; Working With Narcissists, Borderlines, Sociopaths, Schizoids, and Others. Oakland, CA: New Harbinger Publications, 2000 . 
Chapman, Gary. Everybody Wins: The Chapman Guide to Solving Conflicts Without Arguing. Carol Stream, IL: Tyndale House Publishers, 2006.

Chapman, Gary, and Jennifer Thomas. The Five Languages of Apology: How to Experience Healing in All Your Relationships. Chicago, IL: Northfield Publishing, 2006.

. When Sorry Isn't Enough: Making Things Right with Those You Love. Chicago, IL: Northfield Publishing, 2013.

"Christ's Kingdom." Seventh-day Adventist Bible Commentary. Edited by Francis D. Nichol. 1953-57. Reprint, Washington, DC: Review and Herald, 1980. 6:122.

Cloke, Kenneth, and Joan Goldsmith. Resolving Conflicts at Work: Eight Strategies for Everyone on the Job. 2nd ed. San Francisco: Jossey-Bass, 2005.

Cooper, Donald R. and Pamela S. Schindler. Business Research Methods. 11th ed. New York: McGraw-Hill Irwin, 2011.

De Ville, Jard. The Pastor's Handbook on Interpersonal Relationships: Keys to Successful Leadership. Silver Spring, MD: The Ministerial Association, General Conference of Seventh-day Adventists, 1995.

"Everlasting Gospel." Seventh-day Adventist Bible Commentary. Edited by Francis D. Nichol. 1953-57. Reprint, Washington, DC: Review and Herald, 1980. 7:827.

Gane, Roy. "Sabbath and the New Covenant." Journal of the Adventist Theological Society 10, nos. 1, 2 (1999): 312-313. Quoted in Angel M. Rodriquez, "The Biblical Sabbath: The Adventist Perspective. General Conference of SDA Biblical Research Institute website.

Geortzen, Leroy W. Understanding, Managing and Redeeming Church Conflict. [Tacoma, WA?]: 2012.

Greenfield, Guy. The Wounded Minister: Healing From and Preventing Personal Attacks. Grand Rapids, MI: Baker Book House, 2001.

Halverstadt, Hugh F. Managing Church Conflict. Louisville, KY: Westminster/John Knox Press, 1991.

Harper, Gary. The Joy of Conflict Resolution: Transforming Victims, Villains and Heroes in the Workplace and at Home. Gabriola Island, BC, Canada: New Society Publishers, 2004.

Haugk, Kenneth C. Antagonists in the Church: How to Identify and Deal with Destructive Conflict. Minneapolis, MN: Augsburg Publishing House, 1988. 
Hohnberger, Jim, with Tim and Julie Canuteson. It's About People: How to Treat Others, Especially Those We Disagree With, the Way Jesus Treats Us. Oshawa, Ontario, Canada: Pacific Press, 2003.

LaRondelle, Hans K. Perfection and Perfectionism. Berrien Springs, MI: Andrews University Press, 1971. Quoted in Angel M. Rodriquez, "The Biblical Sabbath: The Adventist Perspective. General Conference of SDA Biblical Research Institute website.

Leas, Speed B. Introduction to Conflict Management in Congregations. Edited by David B. Lott. Herndon, VA: The Alban Institute, 2001.

Lederach, John Paul. The Little Book of Conflict Transformation: Clear Articulation of the Guiding Principles by a Pioneer in the Field. Intercourse, PA: Good Books, 2003.

Maravelas, Anna. How to Reduce Workplace Conflict and Stress: How Leaders and Their Employees Can Protect Their Sanity and Productivity from Tension and Turf Wars. Franklin Lakes, NJ: Career Press, 2005.

Mayer, Bernard. The Dynamics of Conflict: A Guide to Engagement and Intervention. 2nd ed. San Francisco: Jossey-Bass, 2012.

McSwain, Larry L., and William C. Treadwell Jr. Conflict Ministry in the Church. Silver Spring, MD: The Ministerial Association, General Conference of Seventh-day Adventists, 1997.

Menjares, Pete C. "Is There a Biblical Basis for Encouraging Diversity?" 26 April 2010. $\mathrm{http}$ ://unityinchristmagazine.com/theology/is-there-a-biblical-basis-forencouraging-diversity (accessed May 8, 2012).

Nelson, Alan, and Gene Appel. How to Change Your Church Without Killing It. Nashville, TN: Word Publishing, 2000.

"A New Commandment." Seventh-day Adventist Bible Commentary. Edited by Francis D. Nichol. 1953-57. Reprint. Washington, DC: Review and Herald, 1980. 5:1032.

Newberger, Kenneth C. Hope in the Face of Conflict: Making Peace with Others the Way God Makes Peace with Us; Introducing the Judeo-Christian Model of Peacemaking. [N.p.]: Three Sons Publishing, 2011.

North, James J., Jr. "The Minister as a Counselor." In The Adventist Minister, edited by C. Raymond Holmes and Douglas Kilcher, 92. Berrien Springs, MI: Andrews University Press, 1991. 
Oosterwal, Gottfried. "Leaders and Cross-Cultural Communication: Communicating Across Cultural Boundaries." In Embracing Diversity: How to Understand and Reach People of all Cultures, edited by Leslie N. Pollard, 22-31. Hagerstown, MD: Review and Herald, 2000.

Pachter, Barbara, and Susan Magee. The Power of Positive Confrontation: The Skills You Need to Know to Handle Conflicts at Work, at Home and in Life. New York: Marlowe and Company, 2000.

Perschbacher, Wesley J., ed. The New Analytical Greek Lexicon. 1990. Reprint, Peabody, MA: Hendrickson Publishers, 1999.

Pneuman, Roy W. "Nine Common Sources of Conflict in Congregations." In Conflict Management in Congregations, edited by David B. Lott, 45-53. Herndon, VA: The Alban Institute, 2001.

Poirier, Alfred. The Peacemaking Pastor: A Biblical Guide to Resolving Church Conflict. Grand Rapids, MI: Baker Books, 2006.

Porter, Thomas. The Spirit and Art of Conflict Transformation: Creating a Culture of Just Peace. Nashville, TN: Upper Room Books, 2010.

Ramsbotham, Oliver, Tom Woodhouse, and Hugh Miall. Contemporary Conflict Resolution. 3rd ed. Malden, MA: Polity Press, 2011.

Rediger, G. Lloyd. Clergy Killers: Guidance for Pastors and Congregations Under Attack. Louisville, KY: Westminster John Knox Press, 1997.

Runde, Craig E., and Tim A. Flanagan. Becoming a Conflict Competent Leader: How You and Your Organization Can Manage Conflict Effectively. San Francisco: Jossey-Bass, 2007.

Sande, Ken. The Peacemaker: A Biblical Guide to Resolving Personal Conflict. 3rd ed. Grand Rapids, MI: Baker Books, 2004.

Sande, Ken, and Kevin Johnson. Resolving Everyday Conflict. Grand Rapids, MI: Baker Books, 2011.

Seamands, David A. Healing for Damaged Emotions: Recovering from the Memories That Cause Our Pain. Wheaton, IL: Victor Books, 1981.

Segler, Franklin M. Understanding, Preparing for, and Practicing Christian Worship. 2nd ed. Revised by Randall Bradley. Nashville, TN: Broadman \& Holman Publishers, 1996. 
Shawchuck, Norman. How to Manage Conflict in the Church. Vol. 1 of Understanding and Managing Conflict. 8th ed. Fargo, ND: Spiritual Growth Resources, 2003.

. How to Manage Conflict in the Church. Vol. 2 of Conflict Interventions \& Resources. 5th ed. Fargo, ND: Spiritual Growth Resources, 2003.

. How to Manage Conflict in the Church. Vol. 3 of Dysfunctional

Congregations. 2nd ed. Fargo, ND: Spiritual Growth Resources, 2002.

Shelley, Marshall. Well-Intentioned Dragons: Ministering to Problem People in the Church. 2nd ed. Minneapolis, MN: Bethany House Publishers, 1994.

Smedes, Lewis B. Forgive and Forget: Healing the Hurts We Don't Deserve. New York: HarperCollins, 1984.

. The Art of Forgiving: When You Need to Forgive and Don't Know How. New York: Ballantine Books, 1996.

Smith, Dennis. 40 Days of Prayers and Devotions to Prepare for the Second Coming. Hagerstown, MD: Review and Herald, 2009.

Southerland, Dan. Transitioning: Leading Your Church Through Change. Grand Rapids, MI: Zondervan, 1999.

Stagner, Ross, comp. "The Dimensions of Human Conflict." Detroit, MI: Wayne State University Press, 1967. Quoted in Larry L. McSwain and William C. Treadwell Jr. Conflict Ministry in the Church. Silver Spring, MD: The Ministerial Association, General Conference of Seventh-day Adventists, 1997.

Staples, Russell, L. "The Minister as a Member of the Community." In The Adventist Minister, edited by C. Raymond Holmes and Douglas R. Kilcher, 45-52. Berrien Springs, MI: Andrews University Press, 1991.

"Statistics in the Ministry." Pastoral Care Inc. http://www.pastoralcareinc.com/statistics (accessed June 3, 2013).

Strauch, Alexander. If You Bite and Devour One Another: Biblical Principles for Handling Conflict. Reprint. Littleton, CO: Lewis and Roth Publishers, 2011.

Susek, Ron. Firestorm: Preventing and Overcoming Church Conflicts. Grand Rapids, MI: Baker Books, 1999.

Tyree, Gregory. The Master's Peace: Understanding and Resolving Conflict in the Church. [N.p.], 2013. 
Ursiny, Timothy. The Coward's Guide to Conflict: Empowering Solutions for Those Who Would Rather Run Than Fight. Naperville, IL: Sourcebooks, 2003.

Van Yperen, Jim. Making Peace: A Guide to Overcoming Church Conflict. Chicago, IL: Moody Press, 2002.

"Walter Bradford Cannon." Wikipedia Encyclopedia. http://en.wikipedia.org/wiki/ Walter_Bradford_Cannon (accessed June 3, 2013).

Weeks, Dudley. The Eight Essential Steps to Conflict Resolution: Preserving Relationships at Work, at Home and in the Community. Los Angeles: J.P. Tarcher, 1992.

White, Ellen G. The Acts of the Apostles. Nampa, ID: Pacific Press, 1911. . Child Guidance. Washington, DC: Review and Herald, 1954. 1941.

. Christ's Object Lessons. 1900. Reprint, Washington, DC: Review and Herald, . The Desire of Ages. 1898. Reprint, Mountain View, CA: Pacific Press, 1940. . Evangelism. 1946. Reprint, Hagerstown, MD: Review and Herald, 2002. . The Faith I Live By. 1958. Reprint, Washington, DC: Review and Herald, 1973.

. Gospel Workers. Washington, DC: Review and Herald, 1948.

. Mind, Character and Personality. 2 vols. Nashville, TN: Southern Publishing Association, 1977.

. Patriarchs and Prophets. 1890. Reprint, Nampa, ID: Pacific Press, 1958.

. Selected Messages. 3 vols. 1958. Reprint, Washington, DC: Review and Herald, 1980.

. Steps to Christ. 1892. Reprint, Mountain View, CA: Pacific Press, 1956.

. Testimonies for the Church. 9 vols. Boise, ID: Pacific Press, 1948.

. Testimonies to Ministers and Gospel Workers. 1923. Reprint, Mountain View, CA: Pacific Press, 1962. 


\section{VITA}

\section{Everton A. Ennis}

Address: 207 Haywood Dr., Kathleen, GA

Contact: $\quad$ Cell: (478) 334-1484 / Email: eaennis@hotmail.com

\section{EDUCATION}

Bachelor of Theology Degree - Oakwood University, Huntsville, AL, 1999

Master of Divinity Degree - SDA Theological Seminary, Berrien Springs, MI, 2001

Doctor of Ministry Degree - SDA Theological Seminary, Berrien Springs, MI, 2014

\section{PROFESSIONAL CERTIFICATIONS \& ENDORSEMENTS}

2011 Individual Crisis Intervention \& Peer Support - Houston Healthcare, Warner Robins, GA

2012 Critical Incident Stress Management: Basic - Houston Healthcare,

\section{PASTORAL EXPERIENCE}

2010-Present Chaplain (volunteer) at Houston Medical Center, Warner Robins, GA

2008-Present South Atlantic Conference - Georgia: Eastview SDA in Americus, and New Life SDA in Warner Robins

2002-2008 South Atlantic Conference - North Carolina: Philadelphia SDA in Council; Praise Tabernacle of SDA in Whiteville, and Macedonia New Life Center in Lumberton.

\section{ORDINATION}

2005 Ordained to the Gospel Ministry on June 18

\section{ACCOMPLISHMENTS IN PASTORAL MINISTRY}

$2002 \quad$ Founded Praise Tabernacle of SDA, Whiteville, NC.

2003 Founded Macedonia New Life Center, Lumberton, NC.

2005 Renovated the church edifice at Philadelphia SDA Church, Council, NC.

2006 Constructed the education and worship center in Whiteville, NC.

2008-Present Successfully transitioned the New Life Church in Warner Robins, GA.

\section{SEMINARS AND WORKSHOPS CONDUCTED}

2006-Present Conducted CLASS Act Seminars in numerous churches: elders and church leadership, church board orientation, congregational conflict resolution training, and evangelism. 